\title{
Performance of institutional investors
}

\author{
Citation for published version (APA):
}

Schweitzer, M. (2000). Performance of institutional investors. [Doctoral Thesis, Maastricht University]. Universiteit Maastricht. https://doi.org/10.26481/dis.20000322ms

Document status and date:

Published: 01/01/2000

DOI:

10.26481/dis.20000322ms

Document Version:

Publisher's PDF, also known as Version of record

\section{Please check the document version of this publication:}

- A submitted manuscript is the version of the article upon submission and before peer-review. There can be important differences between the submitted version and the official published version of record.

People interested in the research are advised to contact the author for the final version of the publication, or visit the DOI to the publisher's website.

- The final author version and the galley proof are versions of the publication after peer review.

- The final published version features the final layout of the paper including the volume, issue and page numbers.

Link to publication

\footnotetext{
General rights rights.

- You may freely distribute the URL identifying the publication in the public portal. please follow below link for the End User Agreement:

www.umlib.nl/taverne-license

Take down policy

If you believe that this document breaches copyright please contact us at:

repository@maastrichtuniversity.nl

providing details and we will investigate your claim.
}

Copyright and moral rights for the publications made accessible in the public portal are retained by the authors and/or other copyright owners and it is a condition of accessing publications that users recognise and abide by the legal requirements associated with these

- Users may download and print one copy of any publication from the public portal for the purpose of private study or research.

- You may not further distribute the material or use it for any profit-making activity or commercial gain

If the publication is distributed under the terms of Article $25 \mathrm{fa}$ of the Dutch Copyright Act, indicated by the "Taverne" license above, 


\title{
PERFORMANCE OF INSTITUTIONAL INVESTORS
}

\author{
PROEFSCHRIFT
}

ter verkrijging van de graad van doctor aan

de Universiteit Maastricht,

op gezag van de Rector Magnificus, Prof. Dr. A.C. Nieuwenhuijzen Kruseman, volgens het besluit van het College van Decanen,

in het openbaar te verdedigen

op woensdag 22 maart 2000 om 16.00 uur

door

Mark Schweitzer 


\section{Promotores:}

Prof. Dr. P.M.A. Eichholtz

Prof. Dr. C.G. Koedijk

Prof. Dr. P.C. Schotman

\section{Beoordelingscommissie:}

Prof. Dr. S.J. Maijoor (voorzitter)

Prof. Dr. J.M.G. Frijns (Vrije Universiteit Amsterdam)

Prof. Dr. C.J.M. Kool

Prof. Dr. J.P. Mei (NYU, Stern School of Business) 


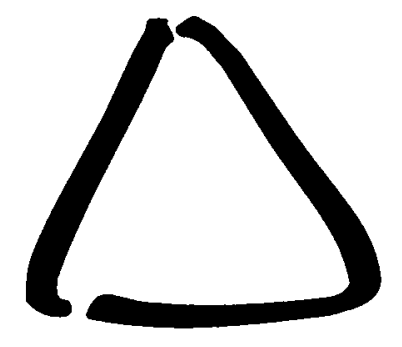

VOORWOORD

Sinds 1996 heb ik gewerkt aan het proefschrift dat nu voor u ligt. Ik heb dit met veel plezier gedaan en ben trots op het uiteindelijkc resultaat. De getekende drichoek geeft een kader aan de overige 150 pagina's en doet mij denken aan schoonheid, groei, stabiliteit, simpelheid, veelzijdigheid en het woord unick. Ik probeer u uit te leggen waarom deze figuur mijn tijd aan de Universiteit Maastricht het best beschrijft.

Voor mij is het een fantastische tijd geweest waarin ik de kans gekregen heb om me te specialiseren op het gebied van prestatiemeting in een omgeving die mij tegelijkertijd stimulecrde tot een steeds bredere ontwikkeling. Hoe raar dat misschien ook is maar ik voel me meer generalist dan een specialist. Hierbij denk ik aan college geven, scriptanten begeleiden, een congres organiseren, lezingen houden, een Robeco prijs winnen, een corporate bond database opzetten, en een internet beleggingsspel ontwikkelen. Heel veel verschillende activiteiten die niets direct met een proefschrift te maken hebben, maar wel een enorme verbreding geven.

Ondanks mijn interesse en plezier in deze verbredende activiteiten was mijn hoofdtaak natuurlijk toch om het proefschrift tot een goed einde te brengen. Ook hieraan heb ik met veel plezicr gewerkt. Ik ben blij dat $\mathrm{ik}$ de kans heb gekregen om verschillende soorten onderzoeken te doen, naar verschillende soorten institutionele beleggers te kijken, en me niet hoefde te storten op, hoc interssant ook, tot het voor de duizendste keer toetsen van een 'asset pricing model'.

De drie-eenheid dic dit alles mogelijk gemaakt hebben zijn in eerste instantie mijn drie promotoren: Peter, Piet en Kees. Door hun verscheidenheid en aanvullende kwaliteiten was het voor mij een fantastische combinatie. Nu kon zowel de verdieping als de verbreding plaatsvinden. Ik heb cen hoop geleerd over economische theorie, econometrie, financiering, en schrijfvaardigheid, maar zeer zeker ook over psychologie en marketing! 
Naast de drie promotoren ben ik ook heel blij dat ik werkzaam mocht zijn bij de sectie financiering. De samenstelling stond garant voor cen levendige en stimulerende sfeer, waarin het heerlijk werken was. Ik hoop dat de sectie de\%e energie zal behouden. In het bijzonder denk ik hicrbij aan Rogér, Ronald, de dames van het secretariaat en de docenten van blok 2.3 .

De driehoek is natuurlijk niet complect zonder het thuisfront. Papa en mama hebben altijd gezorgd voor de stimulans om grenzen te vericggen, maar hebben mij impliciet altijd de garantie gegeven dat ze achter me staan. Ik vind dat een bijzonder gevocl. Femke ben ik voor van alles dankbaar, maar misschicn nog wel het meest dat ze toch een paar jaar langer in het mooie Maastricht is willen blijven wonen.

Het is mooi geweest.

Mark Schweitzer

Amsterdam, December 1999 


\section{Table of Contents}

CHAPTER 1

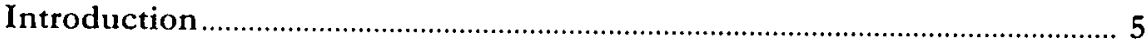

1.1 Outline 8

CHAPTER 2

Performance: a Theoretical Perspective ........................................................ 11

$\begin{array}{ll}2.1 \text { Performance Mcasurement } & 11\end{array}$

2.2 Performance of the Institutional Investor 12

2.3 Measuring Investment Returns 13

- Discrete versus Continuous Calculated Returns 14

- Time-Weighted versus Money-Weighted Returns 16

$\begin{array}{ll}2.4 & \text { How to Measure Performance } \\ & 16\end{array}$

- Comparing Returns Directly 17

- Correcting for Total Risk: Sharpe Ratio 17

- Correcting for Market Risk: Jensen $\alpha \quad 18$

- Correcting for Operational Risk: Tracking Error 19

- Choosing between the Techniques 19

2.5 Performance Attribution 20

- Index Choice and Asset Pricing Models $\quad 20$

- Survivorship $\quad 21$

- Persistence $\quad 21$

- Horizon $\quad 22$

- Selection Ability $\quad 22$

- Timing Ability 23

- Structure of the Fund $\quad 24$

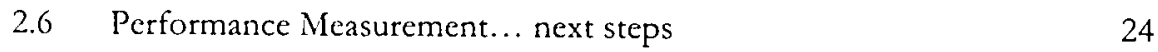


CHAPTYR 3

The Threat to Performance: Inflation ......................................................... 27

3.1 The Multi-Period Inflation Hedge Potential of Stocks 29

3.3 Parameter Values $\quad 34$

3.3 The Risk-liree Asset in the Model 36

3.4 Conclusion 36

Appendix 3A: Derivation of the Model 37

CIIAPTER 4

The Performance of the Dutch Pension Fund System ................................. 41

4.1 Data Description 42

4.2 The Performance of the Pension Funds 44

- Equitics $\quad 45$

- Bonds $\quad 50$

- Real Fstate $\quad 51$

- Cross-Sectional Analysis: Size Effect? 52

4.3 Conclusion $\quad 52$

C.HAPTER 5

Performance of European \& US Mutual Funds Compared.......................... 55

5.1 The Structure of the Industry in Europe and the United States 56

5.2 Conduct in the Industry 62

5.3 Performance of the Mutual Fund Industry 63

- Data $\quad 64$

- Summary Statistics $\quad 67$

- Development through time $\quad 67$

- Are Funds Doing What They Are Supposed To? 71

- The Influence of Fees on Performance 75

- The Underperformance of European Index Funds 75

- The Outperformance of Small Cap Mutual Funds 76

5.4 Conclusion 76

CHAPTER 6

Performance \& Information Costs of Real Estate Investments .................. 79

6.1 The International Real Estate Securities Market 81

6.2 International and Domestic Property Companies 83

6.3 More formal tests of the price for information 87

6.4 Results 89

6.5 Explanation of the test results 93

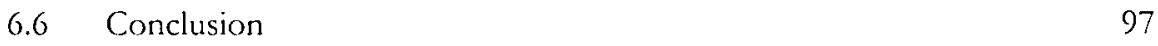

Appendix 6.A Database Internationals 98 
CHAPTIER 7

REIT Performance: Does Managerial Specialization Pay? 99

7.1 Data Description

7.2 Measuring Specialization

104

7.3 Measuring Outperformance

106

7.4 Results

108

7.5 Other Factors Generating Performance

111

7.6 Conclusion

Appendix 7.A: REITs in Sample

CHAPTER 8

Summary

CHAPTER 9

References

CHAPTER 10

Nederlandse Samenvatting

CHAPTER 11

Curriculum Vitae 
CHAPTER 1

\section{Introduction}

In the last decades the western society has developed an increasing tendency towards the critical assessment of the quality and effectiveness of products and services provided in all possible areas. Governments question whether they can improve the efficiency of certain operations by exposing them to market forces. Consumer organizations raise their voices to test and examine the value for money of specific products. Private investors fight for more rights in shareholders meetings supported by the increased attention for corporate governance. Obviously, as enormous amounts of money are at stake, institutional investors are no exception to this critical assessment and find their performance under increased scrutiny.

One of the most striking and unique examples of the increased scrutiny is the recent lawsuit of the British Unilever pension fund against Mercury Asset Management, the largest UK fund manager ${ }^{1}$. The pension fund gave the manager a mandate of more than 1 billion pounds and in the contract it stated: 'the return would be expected to be no more than 3 percent below the benchmark for any four successive calendar quarters'. The money manager, however, underperformed the benchmark by 8 percent in the first four quarters. In the past such a performance justified the discharge of the money managers. This has also happened in this case, but this time the fund also launched a High Court suit alleging negligence and seeking damages. This has not happened before, and the case is therefore attracting the attention of many parties as stakes are very high and the outcome will define the new level playing field in the money management industry. This also justifies the attention the lawsuit is receiving in the international financial press. Several important questions need answering. Is MAM to blame? Should a correction for risk take place? Is the horizon used relevant and correct? Can we explain the underperformance? Should Unilever have taken earlier action on the underperformance? Currently, many discussions are taking place to examine the implications in case Unilever

\footnotetext{
I See the newspaper article on the next page for details.
} 


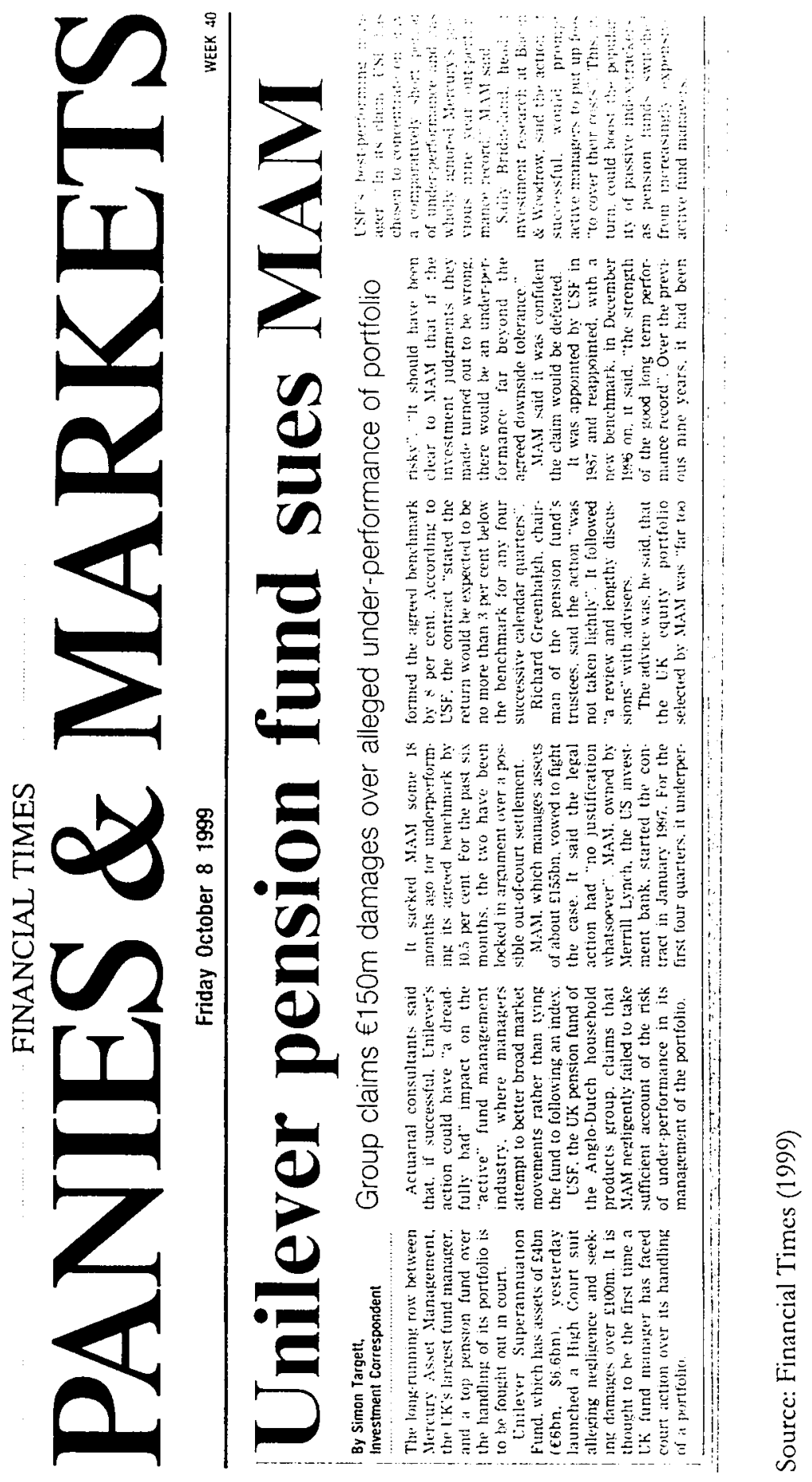


wins the lawsuit. To insure themselves against such compensation claims money managers might have to increase fees from 50 basispoints to more than 1 per cent. This might in turn also imply an enormous boost to passive investment strategies.

This case and the impact and size of the institutional investors demands and justifies enormous efforts to measure performance in general and to improve the performance measurement systems. This is exactly what this thesis tries to do. It describes and analyzes the performance of institutional investors and contributes to some of the unsolved puzzles in the literature.

The literature has already devoted much attention to the subject. A recent survey by Eichholtz et al. [1999] among Dutch pension fund managers indicates that almost $90 \%$ of the money managers currently use performance measurement techniques to manage their portfolio. The authors also show that the outcome of the performance measurement has consequences in terms of bonuses, promotions, and changes in mandates. Does the use and attention for performance measurement within the money management industry imply that our money is safe? One of the earliest papers that tried to answer this question is Jensen [1968], who examined the performance of 115 mutual funds. He showed that only $34 \%$ of the existing mutual funds are able to outperform the market on a riskadjusted basis. The remaining $66 \%$ underperformed the market. On average the riskadjusted return of the funds was minus $1.1 \%$. More recent studies confirm these results. Gruber [1996], for example, shows that the average risk-adjusted performance is minus $1.5 \%$.

The data on mutual funds are relatively easily available; hence, academia focuses on their performance. A few studies, however, have evaluated the performance of other institutional investors like pension funds. They too confirm the underperformance of institutional investors. See for example Lakonishok et al. [1992] who concludes: "pension fund equity managers seem to subtract rather than to add value". In other words, even though we know that institutional investors measure their own performance, they still underperform benchmarks and therefore should be able to increase their performance. Ultimately this would enhance the value of our investments as well. Does this mean that individuals would be better off if they invested their wealth themselves, which would make institutional investors and money managers redundant?

Two issues need further clarification. First, institutional investors do more than just try to track or outperform a particular benchmark. They also provide services in terms of riskcontrol, education, easy-diversification and one-stop-shopping. These characteristics are also part of the performance of an institutional investor. In this thesis, however, we focus on the financial performance. Second, the literature justifies further research to improve the measurement techniques, upgrade data collection procedures and above all to find explanations for the performance. The more detailed questions read like: how should performance be measured? Can anything be said about the relative performance? Is an 
institutional investor better than the competition? How can performance be explained and influenced? After these questions one is ready to ask more detailed questions like which benchmark should to use? How to correct for risk? How can an investor outperform the benchmark? What should the horizon and frequency be?

This thesis investigates these questions by using and exploring new data-sets of real estate companies, European mutual funds and pension funds. Some of these sets give a possibility for detailed analysis of how we could explain the performance. The next section gives an outline of all individual chapters and the questions answered in each of them.

\subsection{Outline}

This thesis consists of 6 chapters, which focus on different aspects of the performance of the institutional investor. This section briefly describes the content of each of the chapters.

Chapter 2 presents an overview of the theoretical aspects of performance measurement and gives a survey of the existing literature. This chapter sets the stage for the remainder of the thesis. In chapter 3 we test the horizon sensitivity of stock returns, which also applies to performance measurement techniques. In chapter 4 we analyze a unique dataset of Dutch pension fund performance. Chapter 5 explores the mutual fund industry in Europe and compares it with its counterparts in the United States. Chapters 6 and 7 focus on institutional real estate investors. Chapter 8 concludes the thesis. Below we present short abstracts of chapters 3 through 7 .

In chapter 3 we extend the analysis of chapter 2 and apply it to the analysis to the horizon sensitivity of stock prices. For performance measurement it is important to see what impact the investment horizon has. We show that the often empirically found negative hedge ratio between stock returns and inflation can be consistent with the Fisher hypothesis. This hypothesis says that stock returns should move one-to-one with expected inflation. We show that the hedge ratio can be either positive or negative depending on the investment horizon. The model is driven by the persistence in inflation. This result has an important impact for investors, as choosing the investment horizon becomes more important than previously thought.

In chapter 4 we take a look at the performance of pension funds in the Netherlands using a unique data set provided by WM-company. These data present a disappointing picture of the stock portfolio of all pension funds. Over the whole sample period the funds lose up to $2 \%$ on an annualized basis relative to global market developments. The most important explanation we could find is the lack of competition between the funds and possibly the limited governance of the pension funds. One possible solution to the 
underperformance for the funds is to reduce the part of the portfolio that is managed externally, as this is an explanation given by practitioners for the underperformance. Due to the limited data availability it is impossible to obtain clear conclusions for the fixed income and real estate portfolio. To improve the performance measurement and the quality of the results derived from it, it is important that all pension funds communicate their benchmarks clearly.

Chapter 5 moves to the mutual fund industry. We analyze the development and performance of the European mutual fund industry and compare it with the industry in the United States, using the traditional Structure-Conduct-Performance (SCP) paradigm. We find that Europe is still lagging behind the American mutual fund industry when it comes to total asset size, average fund size, and market importance. Furthermore, it appears that a few large domestic fund groups dominate the mutual fund markets in the individual European countries. The performance of domestic equity funds is tested using a data set containing the main European countries and the United States. The most striking results of these performance tests are the outperformance of small cap mutual funds and the increasing performance of all German mutual funds.

Chapter 6 uses the well-known fact that international diversification improves investment performance. We exploit a unique worldwide data-set of listed property companies that provides us with the opportunity to investigate the performance of international property investment strategies through public and private markets. Especially the former route has become more feasible given increased securitization of property markets. Our results indicate that international property investment through public securities systematically outperforms private international investment strategies.

Chapter 7 extends the issue of chapter 6 using a larger U.S. based data-set. We investigate whether managerial specialization explains the performance of investment trusts. One of the unsolved puzzles in the literature regarding the performance of mutual funds concerns the persistence of this performance. We argue that specialization is one of the factors determining this persistence. We use data regarding US Real Estate Investment Trusts since managerial specialization of these companies can be measured in a straightforward way. We look at the effects of specialization by property type and by geographic region and find that property specialization does indeed lead to outperformance of the market by property companies, whereas geographical specialization leads to underperformance.

Chapter 8 concludes the thesis and provides a summary. 
CHAPTER 2

\section{Performance: a Theoretical Perspective}

Performance measurement has attracted the interest of several branches of academic study. Finance focuses on mutual funds and tries to explain the performance of funds and test different asset pricing models. Management control focuses on issues within a single firm, while industrial organization examines performance at an industry-wide level. As explained in chapter 1, this thesis studies the performance of institutional investors and mainly uses the financial literature as reference. The purpose of this chapter is to put this focus in perspective. We will start in section 2.1 and 2.2 to show how the basic ideas of financial performance measurement relate to the other branches. In section 2.1 we discuss the basic framework and purpose of performance measurement in general and explore methods used to measure performance. In section 2.2 we link these ideas with the operations of an institutional investor. We will focus this discussion on the performance of a single firm instead of the performance of a whole industry ${ }^{2}$. In sections 2.3 through 2.6 we explore theoretical issues in the literature in more detail.

\subsection{Performance Measurement}

The basis and purpose for any performance measurement system is to evaluate the added value of management to a business using a given number of inputs. Figure 2.1 gives a schematic overview of the operations of a regular business. Management uses the inputs, labor, capital, and natural resources, and tries to add value to these inputs. The problem is that this process of adding value happens within a black box, which we usually call 'management'. This makes it difficult to measure the effectiveness of management. To get a picture of the added value of management, we have to examine the outputs produced in relation to the inputs. Outputs can be differentiated between benefits or turnover and costs. Exploring and benchmarking these figures gives an idea about the performance.

\footnotetext{
2 We focus the discussion in this chapter on the performance on firm level, as this is the focus of most chapters in the thesis. In contrast to the analysis on firm level, an analysis on matket and internal level are also interesting. In chapters 4 and 5 we will analyze the performance on market level.
} 
Ratios to measure performance, among others, include profitability, Economic Value Added, and stock performance. 3 . To use these measures to assess the added value of the managers they have to be compared with some benchmark or target. For example, a company might aim for a profitability figure of $10 \%$ on invested capital or on a figure larger than the industry average. However, other ratios might focus solely on a cost or turnover figure. The literature abounds with articles on both the theoretical and empirical aspects of the performance measurement within regular businesses. In this thesis, however, we focus on the performance measurement of an institutional investor. In the next section we link the performance of a regular business with the performance of a financial institution.

\subsection{Performance of the Institutional Investor}

The principles of performance measurement of an institutional investor can be explained by figure 2.2, which is an extension of figure 2.1. That is, an institutional investor can also be evaluated in terms of the labor and capital used to run the business. However, there is one important difference with a regular business in terms of the capital used. The institutional investor has two types of capital. On the one hand, the institutional investor uses capital like buildings and computer systems. On the other it invests its customers' capital into the assets of other companies. A good example is a mutual fund: it acts mainly as an entity to invest the savings of customers, but to do this it uses capital and labor to

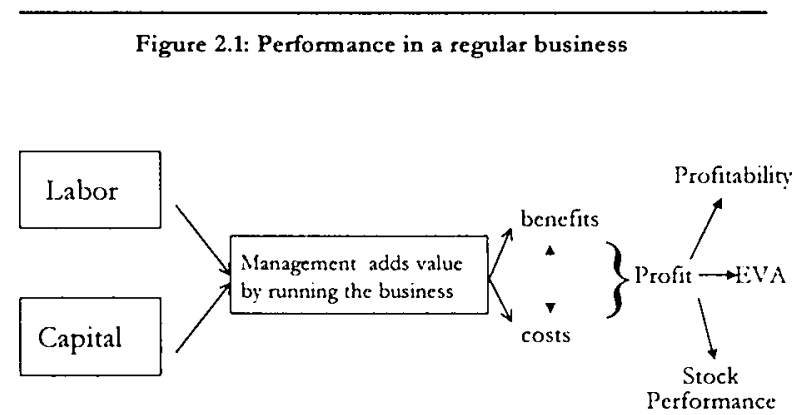

This figure presents the basic framework of the performance of the management in a regular business

operate. Obviously, the customers will pay the costs involved in running the business. For performance measurement this has important consequences. In contrast to a regular business, the benefits of management are hard to measure in terms of profit as returns

${ }^{3}$ The Economic Value Added is a technique recently developed by Stewart (1991) and will be cxplained further in section 2.4 . 
and costs will be directly related to the return made on the investments. This makes the stock performance of the mutual fund an appropriate measure for the performance. Where the capital of a fund is legally separated, the performance measurement should also be done twice: once for the clients' capital and once for the owners' capital. As the size of the latter is usually relatively small, it makes sense to focus studies on the former. It is important to note that performance can also be measured by characteristics like the degree of service, the knowledge of the employees, the information provided, and the security level the investor offers. It is this thesis, however, we focus on the performance in monetary terms. Also in the financial literature stock performance is widely used to evaluate the added value of a mutual fund or the money management industry in general. However, even in the financial literature other performance indicators are used as well. For example, Gruber [1996] indicates that the service of an investor to the customers extends the security selection itself, but also includes customer service, the level of transaction costs and the level of the diversification within the portfolio. In chapter 5 we will see that this could be an explanation for the increased popularity of mutual funds and other institutional investors, despite their relatively low performance when measured solely by stock returns. As the literature mostly uses returns as the measure of performance, the next sections examine the techniques used to calculate returns.

Figure 2.2: Special case of institutional investors

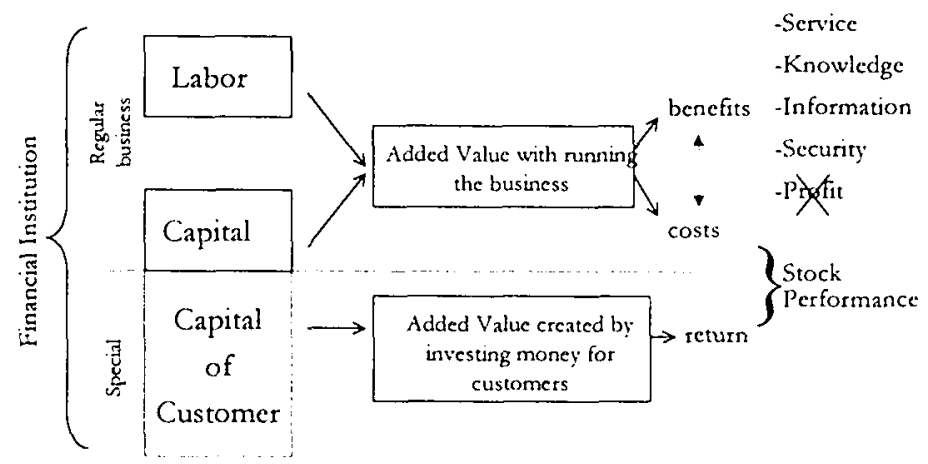

This figure presents the framework based on figurc 2.1. The bottom part is added to represent the capital of the customer.

\subsection{Measuring Investment Returns}

In principle the return on an investment project is easily calculated as the returns minus the costs divided by the invested capital. In this section we will show some of the complications involved. In the first sub-section we explore the difference between 
discrete and continuous calculated returns and how this impacts the compounding over time. In the second sub-section we will explain the difference between time- and moneyweighted returns.

\subsubsection{Discrete versus Continuous Calculated Returns}

This sub-section treats briefly the difference between discrete or arithmetic returns and continuous or geometric returns. Equation (2.1) presents the discrete return and (2.2) the continuous return.

$$
\begin{aligned}
& R_{d, t+1}=\frac{P_{t+1}+D i v_{t+1}-P_{t}}{P_{t}} \\
& R_{c, t+1}=\log \left(\frac{P_{t+1}+D i v_{t+1}}{P_{t}}\right)
\end{aligned}
$$

In which $R_{d}$ is the discrete return, $R_{r}$ is the continuous return, $P$ is the price of the asset or dollar value of the portfolio at a certain time $t$ and the $D i v$ is the received dividend during the time period. Figure 2.3 gives an overview of the timings of the different symbols. We assume that dividends are not re-invested at the time that they are paid. Throughout this thesis we use discrete returns when a cross-sectional analysis is carried out and continuously calculated returns when a time series is analyzed. Two examples will show the reason behind this practice.

Figure 2.3 Timing Convention

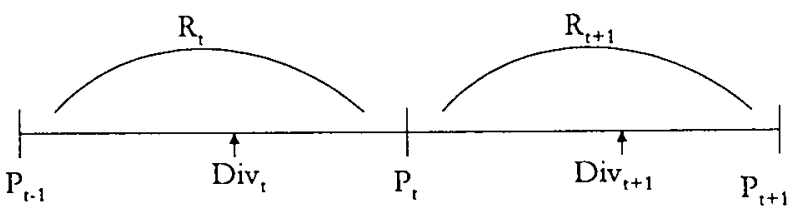

This figure presents the timings of the different definitions.

First of all, we will tum to methodologies to compound returns over time. A standard procedure is the calculation of an average return over time. If we take a simple average of 
discrete returns, we introduce a bias positively depending on the size of the discrete returns. For example, consider an asset worth $\$ 100$ at $t-1$; it drops to 50 at time $t$, and increases again to 100 at $t+1$. The overall return is $0 \%$, but the mean of the discrete returns gives a value of $25 \%$. This is calculated as the average of minus $50 \%$ and plus $100 \%$. To calculate the return correctly over time one has to use $(2.3)^{4}$.

$$
R_{d, t}^{(k)}=\left[\prod_{j=0}^{k-1}\left(1+R_{d,(t-\jmath)}\right)\right]^{1 / k}-1
$$

If we use continuously calculated returns the averaging over time is easy as we can take simple averages directly.

$$
R_{c, l}^{(k)}=\frac{1}{k} \sum_{j=0}^{k-1} R_{c, r-j}
$$

The validity can easily be shown using a two-period example. For clarity we leave dividends out.

$$
\begin{aligned}
\bar{R}_{c, l+1}^{(2)}=\frac{R_{c, t}+R_{c, t+1}}{2} & =\frac{\log \left(P_{t}\right)-\log \left(P_{t-1}\right)-\log \left(P_{t+1}\right)-\log \left(P_{t}\right)}{2} \\
& =\frac{\log \left(P_{t+1}\right)-\log \left(P_{t-1}\right)}{2}
\end{aligned}
$$

If we fill in the data of the earlier example, we find that the average return is indeed $0 \%$. This result also applies to the calculations of annualized volatilities. As discrete returns can not be added up over time, one cannot calculate an annualized standatd deviation without introducing a bias. Again this bias will be bigger if the returns are higher. To circumvent any extra biases we will use continuously calculated returns consistently throughout this thesis when we analyze the time series behavior of asset returns.

The second example we explore is the construction of an index or portfolio consisting of different assets. To calculate the return of the portfolio at a particular time we cannot use continuously calculated returns, as we want to know what the dollar value of an investment is at a particular time. If, for example, we invest $\$ 40$ in asset $A$ and $\$ 60$ in asset $B$, we want to know the dollar value of the portfolio at the end of the period. To calculate the dollar value we can either use the price at that time and multiply it by the number of shares or have the weight multiplied with the discrete return. The continuously calculated return will not give us the dollar value unless we transfer these returns using exponential multiplication. If we do not have the dollar value of the portfolio, we are not able to calculate returns at all as neither (2.3) nor (2.4) can be filled in. Therefore, in this

\footnotetext{
4Campbell, Lo, and MacKinlay [1997] is used as inspiration for this explanation.
} 
thesis we use discrete returns when we calculate indices and perform cross-sectional analyses.

\subsubsection{Time-Weighted versus Money-Weighted Returns ${ }^{5}$}

The difference berween time-weighted and money-weighted returns is important if cash is added or withdrawn from the portfolio throughout the period. In line with the previous discussion, we have to be careful with the calculation of the dollar value at the end of the period, as it can be higher or lower due to existing cash flows. This problem is highly relevant for pension funds and mutual funds as they have money flows in and out of the fund due to the nature of their operation. We will show that the more details we have on these cash flows the better the estimation of a fund's performance will be.

The money-weighted return is based on (2.1) and incorporates net cash flows during the period. It is generated as follows:

$$
R_{m \psi, t+1}=\frac{P_{t+1}+D i v_{t+1}-N C_{t+1}-P_{t}}{P_{t}+\lambda N C_{t+1}}
$$

Where $N C$ represents the net cash flow during the period and $\lambda$ a value between 0 and 1 depending on the timing of the cash flow. In (2.5) $P$ represents the total dollar value of a portfolio. If the cash flow appears at the end of the period, $\lambda$ is small, as the investment cannot be used to make money. If we knew the exact timing of the cash flow, we would prefer the time-weighted calculation. All it does is to split the period at the specific times that the cash flow takes place. This enables returns to be calculated for the individual periods using (2.1). Afterwards, the time-weighted return can be calculated using (2.3). In the money management industry, the time-weighted returns are usually preferred as this technique, though, corrects for the timings of the cash flow. A drawback of the technique is that cash flows have to be known at all times, which implies that the management information system should be very sophisticated. To circumvent this burden it is a common practice, for example among Dutch pension funds, to calculate a monthly money-weighted return and use those to estimate the time-weighted return over the year.

\subsection{How to Measure Performance}

As soon as we know the return characteristics, a question arises: "To what extent did the institutional investor add value to the business?" This brings us to the different method we can use to evaluate the performance of the institutional investor.

\footnotetext{
5 This paragraph uses Bodie, Kane and Marcus [1999] as reference, which can de used to study derivations in more detail
} 
First, a distinction should be made between absolute performance and relative performance. In the case of the absolute performance we could compare the return with a pre-specified level of performance. For example, we could compare it with $0.0 \%$ indicating that performance is good as long as the money manager does not lose any money. Taking the Dutch pension funds as the example, we could also choose the 'rekenrente' (is the interest that funds use to estimate and discount back the liabilities) as such a benchmark ensures that funds are able to pay the promised pensions.

Relative performance is measured against the performance of a specific benchmark. This method is preferred as it corrects for market developments, which the money manager cannot influence. The choice of the benchmark is very important as this determines the applicability of the overall performance indicator. Several branch organizations have published criteria for a proper benchmark, such as the AIMR (Association for Investment Management and Research) in the United States and the VBA (Vereniging voor Beleggingsanalisten) in the Netherlands. The important ones are: Relevance, Availability, Stability, and Easy \& Objective Selection Criteria. (See VBA [1998]) The choice of the benchmark is also important in terms of the management of the money manager. In section 2.7 we elaborate on this issue, and in the remainder of this section we present and discuss different methods.

\subsubsection{Comparing Returns Directly}

The easiest technique one can use is to compare the average return with the return on a specific benchmark. It is a technique widely used by practitioners, but is also found in academia. For example, see Lakonishok et al. [1992], who try to compare the structure and performance of the pension fund industry with the mutual fund industry. Their research is used in this thesis as a basis for chapters 4 and 5. Comparing returns directly means that they do not correct for risk. In the next sub-sections we will discuss techniques that do.

\subsubsection{Correcting for Total Risk: Sharpe Ratio}

One of the basic ideas in the finance theory is that there is no free lunch and that a higher investment return is directly associated with extra risk. That is, returns are positively related to risk. The first risk measure that comes to mind is the Sharpe ratio, named after its developer William Sharpe. (See Sharpe [1966]). It uses total risk, which is measured by the standard deviation of the portfolio returns. This measure is also called volatility. A higher volatility means that individual returns are greatly dispersed around the mean of the distribution. This measure is also used in the theory of Markowitz, which every economics student learns and which is presented in all standard finance handbooks (See for example Ross, Westerfield \& Jaffe [1996]). The theory yields the mean-variance efficient frontier and when combined with the risk free rate gives the so-called 'capital market line'. The Sharpe ratio is directly derived from this line and is presented as (2.6) 


$$
S_{i}=\frac{\bar{R}_{i}-\bar{R}_{f}}{\sigma_{i}}
$$

Where $\overline{\mathrm{R}}$ is average return over the period for portfolio $i$, and for the risk free rate $f$, and $\sigma$ is the standard deviation of portfolio $i$, over the same horizon. The ratio is calculated both for the portfolio and the benchmark. The fund outperforms the benchmark if the ratio is higher than the corresponding ratio of the benchmark.

In practice many measures have been derived from the Sharpe ratio. The most important is the M2-measure developed by Modigliani and Modigliani [1997]. It also adjusts the return on the portfolio for differences in total risk measured by the standard deviation. The difference with the Sharpe ratio is that it is not a ratio but a return figure, which might be easier to intepret. That is, the M2-measure can directly be compared with the return on the benchmark. Thus the M2-measure enables the manager to compare returns easily.

\subsubsection{Correcting for Market Risk: Jensen $\alpha$}

In the previous sub-section we showed that the Sharpe ratio is based on total risk. From asset pricing theories like the Capital Asset Pricing Model (CAPM), we know that total risk can be separated into specific risk and market risk as only the latter is priced in the market. The famous measure that enables us to correct for market risk is the Jensen $\alpha$, which is derived from the CAPM (See Jensen [1968]). The measure is also used to test the asset pricing models itself, but in the context of performance measurement we apply it to test for selection and timing abilities of the institutional investor. The Jensen $\alpha$ is presented in (2.7) as $\alpha_{i}$.

$$
R_{t t}-R_{f t}=\alpha_{i}+\beta_{i}\left[R_{m t}-R_{f t}\right]+\varepsilon_{i t}
$$

Where $\mathrm{R}$ represents the return in a specific period for fund $i$, market index $m$, and risk free rate $f, \beta$ is the measure for the exposure to the market and $\varepsilon$ relates to the specific risk the fund has.

The measure for outperformance and underperformance is the $\alpha$. If $\alpha$ is positive, the fund performs better than expected given its level of systematic risk, and if $\alpha$ is negative, it performs worse on a risk-adjusted basis than the market index. In section 2.5 we will see that this framework can easily be extended to test for other indicators as well.

In section 2.1 we briefly introduced Economic Value Added. Currently, this measure is widely used by consultants in practice and evaluated in the corporate finance literature. An often unobserved characteristic is that this family of techniques is actually the same as the Jensen $\alpha$. Economic Value Added starts from the premise of the weighted average 
cost of capital, which uses the CAPM- $\beta$ as a reference point of the riskiness of the business. A realized return higher than the expected return implies added value by management and is indicated by a positive EVA measure. This is exactly the same for Jensen $\alpha$.

\subsubsection{Correcting for Operational Risk: Tracking Error}

For investors the impact of market risk and total risk is important and should be corrected for. An important question, however, concerns the organizational level at which this should be done. For example, a pension fund might already manage the market and total risk by the allocation over stocks, bonds and real estate. Funds do this when they carry out an Asset Liability Management study. As inputs into the study the funds uses the liability structure of the fund and its risk behavior. The end result is an asset allocation over different assets and indices. This means that the exposure to different risk categories is determined by the asset allocation or benchmark choices. After the determination of the asset allocation and corresponding benchmarks, the internal and external money managers have the task to track or even outperform these benchmarks. They should not do this by increasing the risk profile of their investments as this would limit the applicability of the Asset Liability Management study. The same argument holds for active trading strategies. Notwithstanding quescions whether active strategies pay out in the end, there exists the risk that the investment performance has different characteristics than the index. Again this might change the risk profile of the investments. We call this the operational risk. To correct and control these risks portfolio managers are usually instructed to follow an index allowing for a certain tracking error. The tracking error is calculated as:

$$
T E_{i}=\sigma\left(R_{t 1}-R_{m t}\right)
$$

Where $T E$ is the tracking error of the portfolio or fund $i$, calculated as the standard deviation $\sigma$ of the difference between the return of the fund and the benchmark.

A value for $T E$ of $3 \%$ means that there is a $95 \%$ chance that the actual return of the fund lies between minus $6 \%$ and plus $6 \%$ with respect to the benchmark. A bigger tracking error leads to a bigger dispersion of actual returns and an increased probability that the fund has a much lower or higher return than the benchmark. A bad outcome is the operational downside risk for a pension fund, which is important as it is not corrected for by any of the existing risk measures and ALM studies.

\subsubsection{Choosing between the Techniques}

How should we choose between these techniques? Usually, to answer this question we use arguments related to the underlying assumptions, adjustments to new theories and personal preferences. For performance measurement systems these arguments are still 
relevant, but the identification of the purpose and goal of the performance measurement system is more important. The arguments refer back to the introduction of this chapter, where we discussed the added value of management. To choose between the techniques mentioned in the previous sub-section we first have to formulate the purpose of the system itself. For example, we think that the Sharpe ratio is suitable to measure the performance of an overall portfolio, as total risk is ultimately highly relevant for the investor. The Jensen $\alpha$ is better if an individual portfolio is evaluated and we only want to correct for specific risk, as total risk is taken care of at a different level. This is for example the case when we evaluate the performance of mutual funds. An individual investor usually invests in several mutual funds as the funds often have a specific geographical or sector focus. The tracking error is most suited for performance measurement of money managers or individual portfolio managers working for an institutional investor like a pension fund or a mutual fund. The management wants to control the risk that the portfolio manager does not do what he is hired to do: to follow a specific benchmark.

For these reasons it is logical that the literature mainly uses Jensen $\alpha$ as the basis for the studies on performance measurement. In the next section we present an overview of some of the other issues discussed in this extensive literature.

\subsection{Performance Attribution}

As soon as the performance is determined, three important issues arise. First, we have to determine whether we trust the technique we use. Second, we should ensure that the data reflects reality, and thirdly, we have to take account of the economic arguments used today, which can explain performance. In this section we describe some of the items analyzed in different studies.

\subsubsection{Index Choice and Asset Pricing Models}

The choice of the benchmark is crucial for all performance tests and determines the validity of the performance figure itself. There are actually two sides to the index choice: one is directly related to the application of the performance test and the second influences the validity of the asset-pricing model used.

In the first case, the choice of the index is relevant in practice where one can use it as the definition of the task and the outcome in order to assign consequences for the money manager. For example, the relative performance could be a reason for an extra bonus or promotion, but might also lead to a reduction of a mandate or even discharge. As discussed with reference to the tracking error, these consequences limit the freedom of the money manager. This means that the choice of the benchmark is crucial and demands much thought. If all money managers followed the same leading index, it might influence 
the performance of the market negatively. The choice and use of customized benchmarks gives the true added value of the money manager ${ }^{6}$.

The index choice receives a lot of attention in the literature and is directly related to the debate regarding the pricing models. Roll [1977] is the earliest paper to show that the choice of index influences the applicability of the CAPM. He also showed that general stock indices usually lay within the efficient frontier and definitely do not always correspond to the market portfolio derived in theory. These arguments are also known as Roll's critique. As a response, he was one of the founders of the Arbitrage Pricing Theory (Ross[1978]), which considers other factors besides the market index as priced risk factors. It is straightforward that neglecting these existing risk factors will introduce a bias in performance measures using the CAPM as the main model. On the other hand, this might also give investors the opportunity to outperform the market by increasing their exposure to the neglected risk factors. (See Ferson and Harvey [1996]).

Another issue related to the asset pricing models is that the models assume that the factor loadings are constant through time. Lehmann and Modest [1987], for example, show that funds are able to change their portfolio from high beta securities to low beta securities if the outlook of the market worsens. The response would be to build a conditional model on a pre-specified information set.

Besides Ross [1978] and Lehmann and Modest [1987], the literature on the validity and usage of the asset pricing model is very large and an extensive overview is beyond the scope of the thesis. A good overview on asset pricing can be found in Campbell et al. [1997].

\subsubsection{Survivorship}

Another reason to explain the performance found is survivorship bias. In general it refers to the fact that funds with a bad performance will disappear and might not be included in empirical studies. This might result in an upward bias to the performance measured. Many studies have tried to assess its impact. See for example Brown et al. [1992], Elton et al. [1995], Malkiel [1995], who all conclude that it is important to reduce the survivorship bias as it influences the performance statistics. They all conclude, moreover, that the money management industry on average underperforms the benchmarks. In chapters 4 and 5 we confirm this conclusion for both the mutual fund industry and the pension fund industry.

\subsubsection{Persistence}

An issue related to those reviewed in the last two sub-sections is the persistence of the performance of the institutional investor. Persistence means that the top-performers in

\footnotetext{
${ }^{6}$ Sec also Goetzmann and Massa [1999] for the influence of index tracking on the market performance.
} 
one period remain the top in the next period. The same holds for the bad performers. If we can show that an individual money manager is able to outperform the market consistently, it would be very beneficial to increase the amount of money that he is investing. And if we find a group of these outperformers, we might even detect some trends and determine the factors that might explain the performance.

However, it is still an issue as to which persistence patterns are found in the data. Hendricks et al. [1993] find significant persistence for poor performers. For the topperformers they also found some persistence, but the result was not significant. They call this the hot hand phenomenon. In a 1997 paper the same authors introduce the so-called $\mathrm{J}$-curve effect as especially the good performers show persistence in their results. An explanation for this result might be found in the fact that the bad performers disappear, as investors tend to withdraw their money. This idea is also a cornerstone for the debate on the survivorship bias in performance measurement techniques. See for example, Malkiel [1995], Brown et al. [1997], Carhart [1997], and Hendricks et al. [1997].

\subsubsection{Horizon}

Related to persistence is the investment horizon. The performance measured may be due to the time period chosen or due to the frequency of the data. Most academic studies use monthly data of at least three years to test the performance of mutual funds or asset pricing models. In practice money managers have an incentive to window dress their result at the end of the year. These activities are telated to the incentive schemes that the money managers face. An important reference in this line of research is Jensen \& Murphy [1990], who discuss the relation between the performance and incentives to the management.

In this thesis we explore this issue of the horizon chosen with respect to the relation between inflation and stock returns in chapter 3 . We show that the relation becomes positive if we extend the horizon, whereas it is negative in the short run.

\subsubsection{Selection Ability}

An investor has to make several choices, all of which could explain part of the performance. To examine the choices we carry out an attribution analysis. Traditionally, the important choices that had to be made after the asset allocation are first of all in which country to invest and secondly the choice of the individual security. Obviously, changing the composition over different countries and assets will influence the performance measured against a particular benchmark. A relative new selection criterion is the choice of a particular style. For example, the investor has to choose between large companies and small companies. It is known from studies like Fama and French [1992] that small companies outperform large companies. This result does not hold in all subperiods, which means that the investor is sometimes better off investing in larger companies. The institutional investor can have an added value if he is able to forecast which style will do better. Obviously, many other styles can be distinguished and are used 
in practice. The important ones are value versus growth strategies and size effects. Value companies are defined as the ones with high book-to-market of low price-earnings ratios. For growth companies it is vice-versa. With a momentum strategy the money manager tries to forecast the outperforming stocks by looking at past performance. See Sharpe [1992], Grinblatt et al [1995], Brown and Goetzmann [1997], Carhart [1997], and Daniel et al. [1997] as examples of recent studies testing some of these variables. In general their results suggest that these are important and indeed explain performance.

Throughout this thesis we use (2.9) to test for attribution. It gives an insight into the activities of the fund and what the fund actually has done to add value. This model is widely used and is based on Sharpe [1992]. The $\alpha$-measure is measure for performance and the $\beta$-coefficients estimate the asset allocation to the different benchmarks. This is the reason why we apply the restriction that the $\beta$ 's add to one. If a manager gets a higher return than the summation over these benchmarks $\alpha$ will be greater than zero, which indicates outperformance. The $\alpha$ estimated in (2.9) can be compared with the $\alpha$ in general asset pricing models. The only difference is that our model controls for investment allocation decisions, whereas a general asset pricing model adjusts for risk-exposures.

$$
R_{t}=\alpha+\sum_{j=1}^{J} \beta_{j} R_{j}+\varepsilon_{t}, \quad \text { where } \sum_{j=1}^{J} \beta_{j}=1
$$

The choice of benchmarks is crucial in this set-up. If, for example, we want to know in which countries the funds invest, we take several country indices as the benchmark. The estimated $\beta$ 's will indicate which part of the portfolio is invested in each of the countries and thus explain where the performance comes from. Sharpe [1992] argues that it is desirable, but not strictly necessary, that the different benchmarks are 1) mutually exclusive, 2) exhaustive, and 3) have returns that "differ". The remaining outperformance, measured by $\alpha$, can then be explained by stock selection or timing. In case that the funds use different strategies than those captured within the benchmark a misspecification might occur. For example, in the case that we would not use a Dutch stock index as benchmark, whereas the fund invests in the Netherlands the estimation might be biased. Therefore, there is a clear need for early publication of investment strategies and benchmarks. To circumvent this problem we use a broad range of indices throughout this thesis.

\subsubsection{Timing Ability}

In section 2.4 we already touched shortly on the issue as to whether fund managers are able to buy and sell securities at the right time. Money managers usually claim that they are able to do this, but several studies have shown the opposite. Gruber [1996] gives a thorough analysis of the timing inability of the money manager. The inability might be related to the efficiency of the market. This could, for example, explain that Koedijk et al. 
[1998] find an added value of Dutch mutual funds investing in smaller companies. It is possible that these markets are less efficient than the market for large companies. As not all information is reflected in the price, fund managers with the private information can indeed have an added value and beat the market. This result can be due to selection and timing abilities or both. We confirm these results in chapter 5 for European mutual funds.

As a consequence of timing and stock picking inabilities we see an increasing trend towards indexation. That is, a fund chooses a benchmark index, buys assets to track the index, and rebalances when needed. The trading costs drop (but will not become zero) and the tracking error will be small. Goetzmann and Massa [1999] examine the effects on the financial market of this trend of increased indexation. They clearly find that the indexation trend explains the unusual recent performance of the S\&P500 relative to the small-cap indices, since the S\&P 500 is often used as the benchmark. One could argue that this reduces the efficiency of the market as an investor buys a security even though the price might be too high. This might again give more possibilities for money managers to add value by active strategies. Nevertheless, we believe that there is room for more index tracking funds. However, to limit the effects on the market efficiency, it is important to put more emphasis on the choice and development of the benchmark.

\subsubsection{Structure of the Fund}

The effects on performance of organizational structures of funds are attracting increasing attention. One of the first paper in this area was that by Lakonishok et al. [1992] who compare the performance of the mutual fund industry with the pension funds in the United States. They clearly find that the pension funds underperform their benchmarks and try to contribute this to the agency structure. Other more recent examples are papers by Tufano and Sevick [1997] and Sirri and Tufano [1998]. In the first paper the authors link the structure and composition of a board to the fees the funds charge and in the second examines flows in and out of funds and finds a relation with the size of the fund's complex and the current media attention.

In this thesis we explore these issues especially in chapters 5,6 and 7. In chapters 6 and 7 we test whether the composition of a property portfolio determines the performance. We find that information costs play an important role in the success of the funds. In chapter 5 we compare the development and structure of the mutual funds in the United States and Europe and test for effects on performance. It appears that the funds in Europe are all doing the same. That is, the herding behavior is much more severe, whereas in the United States funds have different characteristics.

\subsection{Performance Measurement... next steps}

In this final sub-section we take a look at the future for performance measurement. In this chapter we gave an overview of the literature written about the performance 
measurement in general and some individual issues. In this section we focus on a few areas, in which we think that progress can and should be made.

In terms of improving the measurement techniques, a closer should look should be taken at the horizon and frequency effects of the techniques. In chapter 3 we illustrate possible horizon effects using the relation between inflation and stock returns. Another area might be the incorporation of other risk measures, which is done to some extent in the corporate finance literature. One could think of risk measures based on Value at Risk techniques.

We are convinced that the choice of the benchmark is important, which we have discussed in sub-section 2.5. A subject not mentioned, however, which could increase the efficiency of the performance measurement techniques, is the consistent publication of these benchmarks before the fund starts the operation. All studies so far have tested the exposure to different benchmarks as in some cases the benchmark used is unknown and in others we are not sure whether the benchmark has been changed. If the money managet disclosed more information, we would then know what they wanted to do and to achieve, which would make it easy to tell whether they succeeded or not. A benchmark also has the advantage that it tells the manager what to do. That is, the benchmark gives the manager a well-defined task. A side benefit of well-communicated benchmarks is that we are better able to compare the performance of funds. It is important to note that this does not influence the further development of asset pricing tests. Throughout this thesis we test the performance against different benchmarks to deal with this problem.

Another means important to increase the efficiency of performance tests is to increase the availability of data. In the United States data is available on a very extensive basis. In Europe this is true to a lesser extent. In chapter 4 we present the first comprehensive study on Dutch pension funds, but the scope of the chapter is still limited due to data restrictions. In chapter 5 we come across the same problem, but to a lesser extent, for the European mutual funds. In contrast, we benefit in chapters 6 and 7 from the data set of Global Property Research.

A final, most important issue is the explanation and analysis of the performance. Sirri and Tufano [1997] is a recent example of this. They try to explain the performance using organizational characteristics like the board structure and fees. In contrast, the mainstream finance literature is still focused on the issues related to the choice of the asset-pricing model, the influence of the survivorship, and benchmark sensitivity. We are convinced that the introduction of the organizational characteristics in the finance literature is a fruitful and important avenue for further research. 
CHAPTER 3

\section{The Threat to Performance: Inflation ${ }^{7}$}

One of the biggest fears for investors is increasing inflation as it reduces the real return on investments. As with any other risk in the financial market, the investor might want to try to reduce the risk exposure by adjusting the composition of the portfolio.

In this chapter we focus on the risk associated with inflation and the extent to which stocks can be used as a hedge against inflation. The theoretical basis for this strand of the literature is the Fisher hypothesis, describing the link between real and nominal teturns. Applied to stocks, the Fisher hypothesis implies that there should be a one-to-one relation between expected nominal stock returns and expected inflation. However, in contrast to the Fisher hypothesis, several studies found a negative relation between inflation and stock returns. See for example, Fisher [1930], Bodie [1976], Fama [1975, 1981, and 1990], Fama and Schwert [1977], Geske and Roll [1983], James et al. [1985], and Lee [1992] who all reject the Fisher hypothesis and indicate that stocks are a poor hedge against inflation. It seems, however, that there is an important horizon effect. In contrast to the studies mentioned, Boudoukh and Richardson [1993] and Evans and Lewis [1995] show that there exists a positive relation if a longer horizon is taken. In this chapter we focus on the hedge potential and examine how it is influenced by the investment horizon.

What explains the short-term negative hedge potential of stocks? Fama [1981] argues that inflation simply acts as a proxy for real-activity variables in relations between inflation and stock returns. Higher expected economic activity would lead to a positive stock return, but due to the non-neutrality of money, increasing inflation leads to lower economic

\footnotetext{
7 This paper is based on: P.C. Schotman, and M. Schweitzer, "Horizon sensitivity of the Inflation Hedge of Stocks", Journal of Empirical Finance, forthcoming.
} 
activity and thus to lower stock returns. This is the reason why central bankers always warn governments for inflationary policies.

In contrast to this negative effect one would expect the Fisher hypothesis to hold in the long run. For example, Campbell and Shiller [1988] explain that inflation has two effects in a present value relation linking the stock price to the expected discounted future dividends. First, higher inflation increases the discount rates, which lowers returns. The second effect of increasing inflation is the rise of future dividends and therefore the rise of expected stock returns. Due to nominal price rigidities in the short run the price elasticity is not necessarily equal to one. This means that the net effect is ambiguous in the short run, but will be positive in the long run.

Surprisingly, to our knowledge there is only one study (Boudoukh and Richardson [1993]) that explores the horizon sensitivity of the hedge potential of stocks. They develop a model of the inflation/stock return relation over longer time horizons and find a positive correlation at a 5-year frequency. This indicates that there is indeed some horizon sensitivity and that stocks might be a good inflation hedge in the long run.

Time series characteristics are important when we explore the horizon sensitivity. First of all, the volatility of stock returns is usually much higher than the volatility of inflation, which makes it difficult to test for correlation between stock returns and inflation. Even more important is the widely recognized strong persistence of inflation. Several authors empirically show that inflation is persistent. See, among many others, Barsky [1997], Juselius [1995] and Haldrup [1997].

This horizon sensitivity is very important for investors to deal with inflation risk. An investor might not be interested in short-term performance at all. Therefore, as in traditional portfolio models correlation coefficients between assets and risk factors are assumed to be constant, it is interesting to study the effects of changing correlation coefficients. This will affect the hedge potential of stocks immediately. We wish to explain why it is consistent that the hedge ratio is negative in the short run but that in the long run stocks are a good hedge against inflation. According to the Fisher hypothesis the hedge ratio should be positive. For investors this result will affect them substantially. For example investors, like Dutch pension funds, that have liabilities stated in real terms with a long horizon underestimate the hedge potential of stocks if they only use the short run hedge potential of stocks.

In this chapter we examine the portfolio problem of the investor that faces inflation risk. We develop a model that accommodates the two following stylized facts: a short-term negative hedge ratio and long-term positive hedge ratio. 
The remainder of the chapter is organized as follows: in section 3.1 we set up the theoretical model. In section 3.2 we implement the model and in section 3.3 we present the conclusion.

\subsection{The Multi-Period Inflation Hedge Potential of Stocks}

In this section we set up a theoretical model explaining the development of the hedge ratio with a changing horizon. Our model should be able to accommodate a short-term negative relation as well as a positive one in the long run. Most computational details are presented in the appendix.

We assume that the one-period stock return is generated by:

$$
R_{t+1}=c+\beta E_{t}\left[\Pi_{t+1}\right]+\varphi\left(\Pi_{t+1}-E_{t}\left[\Pi_{t+1}\right]\right)+e_{t+1}
$$

This means that the stock return $R$ depends on a constant real return $c$, the expected inflation $E_{t}\left[\Pi_{t+1}\right]$, the unexpected inflation, and an independent noise term $\mathrm{e}_{t+1}$ with variance $\sigma_{e}^{2}$. The Fisher relation is represented by $\beta$ as it measures the relation between expected inflation and stock returns. If $\beta$ is equal to one, it means that the pure Fisher hypothesis holds. The coefficient $\varphi$ indicates the linear dependency of unexpected inflation shocks to stock returns.

Equation (3.2) is our model for inflation:

$$
\Pi_{t+1}=\mu+\alpha(\Pi,-\mu)+\eta_{t+1}
$$

That is, inflation depends on the long run inflation $\mu$, the deviation of inflation in the previous period from the long-term mean and an independent shock $\eta_{t}$ with variance $\sigma_{\eta}^{2}$. For transparency reasons we decided to use this $\operatorname{AR}(1)$ model ${ }^{8}$. The key parameter is inflation persistence $\alpha$.

To evaluate the hedge potential we derive a hedge ratio from a simple portfolio maximization problem. We define our portfolio as $r_{t}=\Delta R_{t}+(\mathrm{I}-\Delta) R_{f t}-\Pi_{t}$, where $R_{f t}$ is the risk-free rate. We choose $\Delta$, the percentage of the portfolio invested in stocks, such that we minimize the variance of $r_{b}$. This gives us the following hedge ratio for the oneperiod model:

\footnotetext{
$8 \mathrm{We}$ assume that there is no autocorrelation left in the error term. We can easily allow a possible violation by extending the model with more lagged variables.
} 


$$
\Delta^{(1)}=\frac{\operatorname{Cov}_{t}\left(R_{t}, \Pi_{t}\right)}{\operatorname{Var}_{t}\left(R_{t}\right)}=\frac{\varphi \sigma_{\eta}^{2}}{\varphi^{2} \sigma_{\eta}^{2}+\sigma_{c}^{2}}
$$

Equation (3.3) shows that the empirically found negative hedge ratio can be explained by a negative value of coefficient $\varphi$. This means that an unexpected increase in inflation reduces the stock return at the same time. To illustrate the model we use statistics found in the literature. Taking Fama and Schwert [1977] as the benchmark $\varphi=-4.0$. The variances of the unexpected changes of the stock returns and inflation are also important. It is well known that the variance of stock return is much higher than the variance of inflation. If we substitute standard estimates, $2.0 \%$ on an annual basis for $\sigma_{\eta}$ and $20.0 \%$ on an annual basis for $\sigma_{e}$, we get a hedge ratio of minus $3 \%$. This means that the investor should short $3 \%$ of the portfolio in stocks to have the optimal protection against inflation with an annual horizon.

From (3.3) and the example we learn that the Fisher coefficient $\beta$ or the inflation persistence $\alpha$ does not play a role at all, whereas theory predicts it should. In this chapter we show that this negative one-period hedge ratio is consistent with the Fisher hypothesis in the long run. We will show that the inflation persistence and the Fisher hypothesis do play a role if we expand the model to a multi-period model.

We start with a two-period model, in which we define the two-period return as the summation of the return in the first period plus the return in the second period. It can easily be shown that we get the following expression for the two-period return:

$$
R_{t+2}^{(2)}=2 c+\beta E_{t}\left[\Pi_{t+1}+\Pi_{t+2}\right]+\varphi\left(\eta_{t+1}+\eta_{t+2}\right)+\beta\left(E_{t+1}-E_{t}\right)\left[\Pi_{t+2}\right]+e_{t+1}+e_{t+2}
$$

Equation (3.4) shows that in contrast to the one-period model an unexpected rise in inflation has two effects in the multi-period setting. First, there is a direct effect, which is the same as in the one-period model. The effect is dependent on the value of $\varphi$, which is the same as in the one-period model. Second, there is also an indirect effect due to the adjustment of the inflation expectation. An unexpected shock in the period $t+1$ will lead to higher expected inflation in the next period depending on $\alpha$ the inflation persistence. The value of $\beta$, our Fisher coefficient, will determine what the effect will be of the adjustment of the expected inflation. We present the two-period hedge coefficient in (3.5), in which we find that the inflation persistence parameter and the Fisher coefficient do play a role. Despite a negative short-term effect caused by $\varphi$, the hedge coefficient might become positive depending on the magnitude of the inflation persistence $(\alpha)$ and the Fisher coefficient $(\beta)$ on the one hand and the variances on the other. 


$$
\Delta^{(2)}=\frac{\operatorname{Cov}_{t}\left(R_{t+2}^{(2)}, \Pi_{t+2}^{(2)}\right)}{\operatorname{Var}_{t}\left(R_{t+2}^{(2)}\right)}=\frac{((1+\alpha)(\alpha \beta+\varphi)+\varphi) \sigma_{\eta}^{2}}{\left((\alpha \beta+\varphi)^{2}+\varphi^{2}\right) \sigma_{\eta}^{2}+2 \sigma_{t}^{2}}
$$

It might be the case that the negative short-term effect is still not offset by the increase in expected inflation in the second period. If we extend our model to a multi-period model, the Fisher coefficient becomes more important at the expense of the short-term effect. As we assume that inflation is persistent, a shock this year has an effect on next year's expected inflation, as we saw in the two-period model. In the multi-period setting, however, it also has an effect on all other years. The higher the persistence, the more we revise our expectations of future inflation following a shock in inflation. As a consequence this process will increase stock returns according to (3.1) as they are determined by the expected inflation.

Table 3.1 presents the long-term hedge ratio for different values of the inflation persistence and the coefficient for the Fisher hypothesis. If there is no inflation persistence at all $(\alpha=0)$, there is no long-term hedge potential either. The magnitude of the hedge potential if we assume inflation persistence depends on the Fisher coefficient $(\beta)$. In the case that the Fisher hypothesis holds $(\beta=1)$, there is a perfect hedge and the investor should invest the whole portfolio in stocks. If Fisher does not hold at all $(\beta=0)$ we get hedge ratios that go to infinity, which is consistent with the model, but not very realistic. It can be shown that the sign of this hedge ratio depends on the sign of the short-term coefficient $\varphi$. As investors never have infinite horizons, we will we explore the sensitivities of the model in more detail for horizons up to 30 years.

Table 3.1: Long-term hedge ratios

\begin{tabular}{l|cc}
\hline & $\alpha=0.00$ & $\alpha=1.00$ \\
\hline$\beta=0.00$ & $\varphi \sigma_{n}^{2} /\left(\varphi^{2} \sigma_{n}^{2}+\sigma_{c}^{2}\right)$ & $\pm \infty$ \\
$\beta=1.00$ & $\varphi \sigma_{n}^{2} /\left(\varphi^{2} \sigma_{n}^{2}+\sigma_{\bullet}^{2}\right)$ & 1.00 \\
\hline \multicolumn{3}{l}{ The long-term hedge ratios for different values } \\
of $\alpha$ and $\beta$.
\end{tabular}

As investors never have infinite horizons we calculate the ratio for the hedge potential in the case that $\alpha=0.7$, that $\alpha=0.9$ and that $\alpha=1.0$ for different $k$. Figure 3.1.a presents the results for the case that the Fisher hypothesis holds $(\beta=1.0)$, figure 3.1.b for $\beta=0.5$ and figure 3.1.c for $\beta$ equal to zero.

Figure 3.1.a shows, in line with (3.3), that the one-year hedge ratio is negative and indeed independent of the inflation persistence $\alpha$ or the Fisher coefficient $\beta$. In the case that $\alpha=1.0$, the highest value for inflation persistence, we see that the hedge ratio becomes 
positive after eight years. As we have shown in table 3.1 , it moves towards one. In the case that $\alpha$ is only 0.9 it takes 10 years before the hedge ratio becomes positive and it will not increase as much. Finally, if the inflation persistence is very low, it hardly increases the hedge ratio, which will not become positive at all. This is mainly due to the fact that today's shocks in inflation are not reflected in next year's inflation at all. Furthermore, the immediate effect on the stock return is negative. In figure 3.1.b we present the case where the Fisher hypothesis only holds partly $(\beta=0.5)$. Here we see the same picture appearing. If inflation is persistent, the hedge ratio will become positive after 14 years, indicating that stocks are a good hedge against inflation at a very long horizon. If inflation is not persistent, the hedge ratio hardly changes as today's inflation shocks have only a direct effect on the stock return and not on tomorrow's inflation. In figure 3.1.c we show the results for the case that $\beta$ is equal to zero, assuming that the Fisher hypothesis does not hold. This means that the stock return is only dependent on a drift term, shocks in inflation and an independent noise term. As stock returns are not adjusted due to changes in expected inflation, the hedge ratio will remain negative. Even though inflation shocks do not influence stock returns, it still influences the inflation in the next period. Furthermore, in the multi-period framework shocks in inflation also influence the inflation expectation in the next period, which are formed in the previous period. This is called the prediction error and is formally presented in (3.3). This prediction error increases the shock of inflation, which increases the covariance with the stock return. As the short-term effect $\varphi$ is negative, the multi-period hedge will go to minus infinity depending on the value of the inflation persistence $\alpha$. 
Figure 3.1.a: Hedge Ratios for different $\alpha$

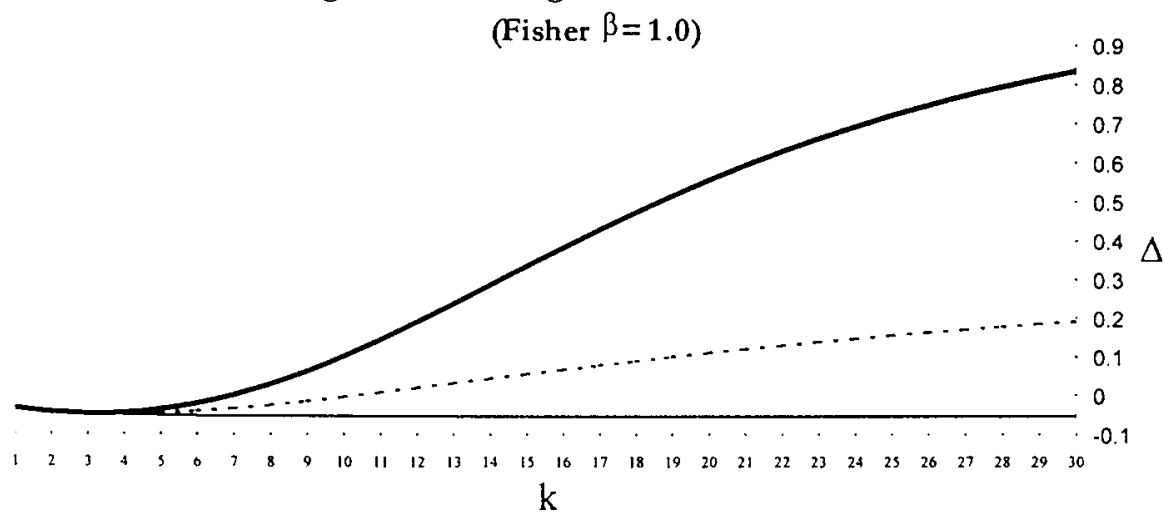

Figure 3.1.b: Hedge Ratios for different $\alpha$

(Fisher $\beta=0.5$ )

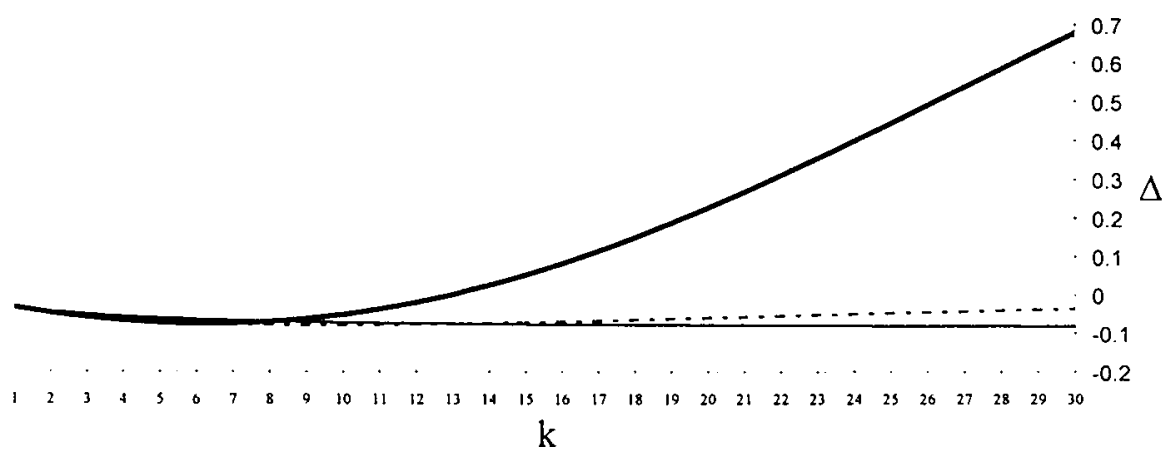

Figure 3.1.c: Hedge Ratios for different $\alpha$

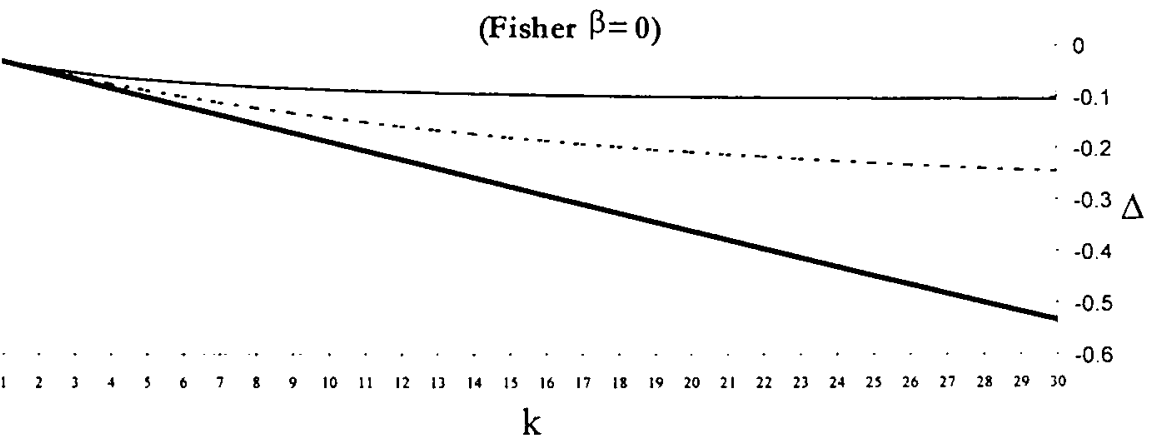

Values for $\alpha: \quad 0.7 \quad \cdots \cdots \cdot 0.9-1.0$

This figure shows the hedge ratio $\Delta$ for different $k$ horizons for different values of inflation persistence $\alpha$. 


\subsection{Parameter Values}

For parameter values of our theoretical model we use data for inflation and total stock return for the United States and for the Netherlands. For the U.S. we take the series from Ibbotson Associates (1998) for the period between 1926 and 1997. The inflation is the logarithmic return on the 'Consumer Price Index' and is denoted by $\Pi_{u s}$ in table 3.2. The stock return is represented by $R_{u s}$ and is the total annual logatithmic return on the price of the S\&P with re-investment of dividends. For the Netherlands we take data from a BZWstudy (1996) for a period between 1947 and 1996. The stock return is the total return of the all index for the Netherlands calculated by the CBS (Central Bureau of Statistics). In the table the stock return is indicated as $R_{n l}$. The inflation is the Consumer Price Index, denoted by $\Pi_{\mathrm{rl}}$. All time series are collected at an annual basis.

Table 3.2 presents the summary statistics for all four time-series. We calculate the statistics for the United States for the wholc sample as well as for sub-period that corresponds with the Dutch sample.

Table 3.2: Summary Statistics

\begin{tabular}{|c|c|c|c|c|c|c|}
\hline & \multicolumn{4}{|c|}{ United States } & \multirow{2}{*}{\multicolumn{2}{|c|}{$\begin{array}{c}\text { Netherlands } \\
1947-1996\end{array}$}} \\
\hline & \multicolumn{2}{|c|}{$1926-1997$} & \multicolumn{2}{|c|}{$1947-1996$} & & \\
\hline & $\Pi_{u s}$ & $\mathrm{R}_{\mathrm{us}}$ & $\Pi_{\mathrm{us}}$ & $R_{u s}$ & $\Pi_{\mathrm{nl}}$ & $R_{n l}$ \\
\hline Mean & 3.05 & 10.43 & 3.99 & 11.86 & 4.22 & 11.05 \\
\hline St.dev & 4.38 & 19.40 & 3.09 & 14.80 & 2.80 & 17.96 \\
\hline Max & 16.69 & 43.17 & 12.50 & 42.28 & 10.28 & 54.96 \\
\hline Min & -10.87 & -56.81 & -1.82 & -30.74 & -1.10 & -24.35 \\
\hline Cor with $\Pi$ & 1.00 & -0.04 & 1.00 & -0.30 & 1.00 & -0.30 \\
\hline
\end{tabular}

Some well-known facts are reconfirmed by this table. The average stock teturn is between $6 \%$ and $8 \%$ higher than the average inflation rate. The standard deviation or variance of stocks is much higher than the standard deviation of inflation. This is especially true for the Netherlands where the standard deviation is eight times bigger. Obviously, the higher volatility for stock returns results in higher maximum and lower minimum values. The most interesting summary statistic for our paper is the correlation of stock returns with inflation. For all periods we find a negative value, which is in line with the existing literature. 
We start to test our theoretical model directly by running the following OLS-regressions that are derived from the basic model represented by (3.1) and (3.2). Both are represented by:

$$
\begin{aligned}
& R_{t+1}=c+\beta \alpha \Pi_{t}+\varphi \eta_{t+1}+\varepsilon_{t+1} \\
& \Pi_{t+1}=\mu(1-\alpha)+\alpha \Pi_{t}+\eta_{t+1}
\end{aligned}
$$

\begin{tabular}{|c|c|c|c|c|c|}
\hline & $\sigma_{i}$ & $\sigma_{\eta}$ & $\varphi$ & $\alpha$ & $\beta$ \\
\hline \multicolumn{6}{|l|}{ United States } \\
\hline$-1926-1997$ & 19.67 & 3.32 & $\begin{array}{l}-0.30 \\
(0.71)\end{array}$ & $\begin{array}{c}0.65 \\
(0.09)\end{array}$ & $\begin{array}{c}0.77 \\
(0.82)\end{array}$ \\
\hline$-1947-1996$ & 14.17 & 2.31 & $\begin{array}{l}-2.21 \\
(0.88)\end{array}$ & $\begin{array}{c}0.58 \\
(0.09)\end{array}$ & $\begin{array}{c}-0.49 \\
(0.97)\end{array}$ \\
\hline \multicolumn{6}{|l|}{ Netherlands } \\
\hline$-1947-1996$ & 17.71 & 2.45 & $\begin{array}{l}-1.53 \\
(1.06)\end{array}$ & $\begin{array}{c}0.53 \\
(0.12)\end{array}$ & $\begin{array}{c}-2.58 \\
(1.71)\end{array}$ \\
\hline
\end{tabular}

Table 3.3: OLS Results

Table 3.3 presents the results of the regressions that are relevant for the calculation of the hedge ratio. We ran the regressions three times corresponding with the summary statistics in table 3.2. The first three columns represent the variances and covariance of the unexpected shocks. As expected we see that the shocks in the stock returns are much higher than the shocks of inflation. In line with the summary statistics we find negative covariances between the shocks for the after war period and a positive for the whole sample period. The measure for inflation-persistence $\alpha$ is in all cases lower than expected. By doing some further tests we learned that the results are very sensitive to specific events like the Korean war with extremely high shocks. We would also like to make several remarks on the econometrics of these tests. First of all parameter $\beta$ is estimated very imprecisely as is common in the literature. Although we cannot reject the hypothesis that $\beta=0$, neither can we reject the Fisher hypothesis $\beta=1$ for the full sample of 71 years. The problem with this type of regressions is that the dependent variable is very noisy. The $\mathrm{R}^{2}$ of the return regressions is very low. On the other hand, the explanatory variable inflation is slowly moving and also subject to measurement error. The effects of inflation can only be observed at longer horizons. But long-horizon regressions suffer from many econometric problems as well. Either the samples are very short, or overlapping samples cause inference relying too much on asymptotic results. For example, Boudoukh and Richardson [1993] show that it takes 200 years of data to find reliable positive covariance of stock returns and inflation at five-year horizons. Secondly, the expected inflation is 
likely to be measured with error for two reasons. First inflation numbers themselves have measurement error. Second, expected inflation depends on the specified time series model for inflation. Any error in this model or instability of its parameters leads to measurement error in expected inflation. A reason for the low value of $\alpha$ is the usual small bias for autoregressive parameters (see Kendall 1954).

\subsection{The Risk-Free Asset in the Model}

Finally, we discuss our results within a mean variance framework. As we have shown in appendix 3.A, we used the minimum variance framework to derive the hedge ratio $\Delta$. The derivation is based on the assumption that the remaining part of the portfolio $1-\Delta$ is invested in the risk-free asset. In practice this might not be very relevant as investors can chose between many different asset categories, but we feel our framework is suitable to discuss the hedge potential of assets. Most important is the relevance of the rish-free asset. In most empirical studies people use the one month $T$-bill as proxy. In the way we have set up the hedge ratio it means that the risk-free asset is risk-free in nominal terms. This means that, in the multi period model, the risk-free asset is a government bond with exactly, the same maturity as the hedge ratio. Consequently, this risk-free asset is not a hedge against inflation at all as nominal terms are fixed and real returns are dependent on the realized inflation.

\subsection{Conclusion}

This chapter shows that the negative inflation hedge of stocks can become positive if the investment horizon changes. First of all we develop a model in which the negative sign in the short run is perfectly consistent with the Fisher hypothesis in the long run. This process is driven by the persistence in inflation, which is the crucial parameter. We show that even if the Fisher coefficient is only slightly positive, the inflation persistence still causes a positive inflation hedge of stocks in the longer horizon. This horizon effect can be extremely important for investors that have a long run perspective. 
APPENDIX 3.A

\section{Derivation of the Model}

In this appendix we present the derivation of our model.

We assume that (3.A.1) and (3.A.2) hold:

$$
R_{t+1}=c+\beta E_{t}\left[\Pi_{t+1}\right]+\varphi\left(\Pi_{t+1}-E_{t}\left[\Pi_{t+1}\right]\right)+e_{t+1}
$$

where $R$ is the stock return, $c$ is a constant real return, $\beta$ the Fisher coefficient related to the expected inflation for $t+1$ at $t, \varphi$ the short-term coefficient related to the shock in inflation at $t+1$, and $e$ is the independent error term with variance $\sigma_{e}^{2}$. For inflation we assume:

$$
\Pi_{t+1}=\mu+\alpha\left(\Pi_{t}-\mu\right)+\eta_{t+1}
$$

where $\Pi$ is the inflation, $\mu$ is the long run inflation, $\alpha$ the persistence measure, $\eta$ is unexpected inflation with variance $\sigma_{\eta}^{2}$.

To evaluate the hedge potential we derive a ratio from the following multi period mean variance optimization setting:

$$
r_{i+k}=\Delta R_{t+k}+(1-\Delta) R_{r, t+k}-\Pi_{t+k}
$$

In which $r$ is the real return on the portfolio, that consists for $\Delta$ of the nominal return on the stock portfolio $\mathrm{R}$ and for $1-\Delta$ of the nominal return on the risk free asset $R_{r}$. Finally inflation $\Pi$ is deducted. The portfolio has the following variance:

$$
\operatorname{Var}_{i}\left(r_{t+k}\right)=\Delta^{2} \operatorname{Var}_{t}\left(R_{t+k}\right)+\operatorname{Var}_{i}\left(\Pi_{t+k}\right)-2 \Delta \operatorname{Cov}_{t}\left(R_{t+k}, \Pi_{t+k}\right)
$$

where we use the following definitions:

$$
\begin{aligned}
& \operatorname{Var}_{t}\left(R_{t+k}\right)=E\left[\left(R_{t+k}-E_{t}\left(R_{t+k}\right)\right)^{2}\right], \\
& \operatorname{Var}_{t}\left(\Pi_{t+k}\right)=E\left[\left(\Pi_{t+k}-E_{t}\left(\Pi_{t+k}\right)\right)^{2}\right], \text { and } \\
& \operatorname{Cov}_{t}\left(R_{t+k}, \Pi_{t+k}\right)=E\left[\left(R_{t+k}-E_{t}\left(R_{t+k}\right)\right)\left(\Pi_{t+k}-E_{t}\left(\Pi_{t+k}\right)\right)\right]
\end{aligned}
$$


From the first order conditions we find:

$$
\Delta^{(k)}=\frac{\operatorname{Cov}_{t}\left(R_{t+k}, \Pi_{t+k}\right)}{\operatorname{Var}_{t}\left(R_{t+k}\right)}
$$

To calculate the one-period hedge ratio we rewrite (3.A.1) with (3.A.2). We get:

$$
R_{t+1}=(c+\beta \mu)+\alpha \beta\left(\Pi_{t}-\mu\right)+\varphi \eta_{t+1}+e_{t+1}
$$

We use (3.A.6) and (3.A.2) to calculate the one-period hedge ratio:

$$
\Delta^{(1)}=\frac{\operatorname{Cov}_{1}\left(R_{t+1}, \Pi_{t+1}\right)}{\operatorname{Var}_{t}\left(R_{t+1}\right)}=\frac{\varphi \sigma_{\eta}^{2}}{\varphi^{2} \sigma_{\eta}^{2}+\sigma_{e}^{2}}
$$

If we extend the model to a two-period model we assume that $R_{t+2}^{(2)}=R_{t+1}+R_{t+2}$ and that $\Pi_{t+2}^{(2)}=\Pi_{t+1}+\Pi_{t+2}$.

We first derive the two period return $R_{t+2}^{(2)}$. The first period return is equal to (3.A.6). For the second period return we have:

$$
R_{t+2}=(c+\beta \mu)+\alpha^{2} \beta\left(\Pi_{t}-\mu\right)+\alpha \beta \eta_{t+1}+\varphi \eta_{t+2}+e_{t+2}
$$

We see that the inflation shock in period $t+1$ has an impact on the stock return one period later. If we combine (3.A.6) and (3.A.8) we get the two-period retum:

$$
R_{t * 2}^{(2)}=2(c+\beta \mu)+\alpha \beta(1+\alpha)\left(\Pi_{t}-\mu\right)+\alpha \beta \eta_{t+1}+\varphi\left(\eta_{t+1}+\eta_{t+2}\right)+e_{t+1}+e_{t+2}
$$

Along the same lines we get the expression for inflation:

$$
\Pi_{t+2}^{(2)}=2 \mu+\alpha(1+\alpha)\left(\Pi_{t}-\mu\right)+(1+\alpha) \eta_{t+1}+\eta_{t+2}
$$

Combining (3.A.9) and (3.A.10) we get the following two-period hedge ratio:

$$
\Delta^{(2)}=\frac{\operatorname{Cov}_{1}\left(R_{t+2}^{(2)}, \Pi_{t+2}^{(2)}\right)}{\operatorname{Var}_{1}\left(R_{t+2}^{(2)}\right)}=\frac{((1+\alpha)(\alpha \beta+\varphi)+\varphi) \sigma_{\eta}^{2}}{\left((\alpha \beta+\varphi)^{2}+\varphi^{2}\right) \sigma_{\eta}^{2}+2 \sigma_{e}^{2}}
$$

To evaluate the results for longer horizons we derive general expressions for the multiperiod return and inflation. We furst model the multi-period return $(k>1)$ :

$$
\begin{aligned}
R_{t+k}^{(k)} & =\sum_{j=1}^{k} R_{t+j} \\
& =R_{t+1}+R_{t+2}+\ldots+R_{t+k} \\
& =k(c+\beta \mu)+\alpha \beta \frac{1-\alpha^{k}}{(1-\alpha)}\left(\Pi_{t}-\mu\right)+\frac{\alpha \beta}{(1-\alpha)} \sum_{j=1}^{k-1}\left(1-\alpha^{k-j}\right) \eta_{t+j}+\varphi \sum_{j=1}^{k} \eta_{t+j}+\sum_{j=1}^{k} e_{t+j}
\end{aligned}
$$


The multi-period inflation itself is modeled as follows:

$$
\begin{aligned}
\Pi_{t+k}^{(k)} & =\sum_{j=1}^{k} \Pi_{t+j} \\
& =\Pi_{t+1}+\Pi_{t+2}+\ldots+\Pi_{t+k} \\
& =k \mu+\alpha \frac{1-\alpha^{k}}{1-\alpha}\left(\Pi_{t}-\mu\right)+\sum_{j=1}^{k} \frac{1-\alpha^{k-j+1}}{1-\alpha} \eta_{t+j}
\end{aligned}
$$

For the variance of the return and inflation and the covariance between the two series we have the following three expressions:

$$
\operatorname{Var}_{i}\left(R_{t+k}^{(k)}\right)=\frac{\alpha^{2} \beta^{2}}{(1-\alpha)^{2}}\left(k-1-2 \frac{\alpha-\alpha^{k}}{1-\alpha}+\frac{\alpha^{2}-\alpha^{2 k}}{1-\alpha^{2}}\right) \sigma_{\eta}^{2}+k \sigma_{e}^{2}+\frac{2 \alpha \beta}{1-\alpha}\left(k-1-\frac{\alpha-\alpha^{k}}{1-\alpha}\right) \varphi \sigma_{\eta}^{2}+\varphi^{2} k \sigma_{\eta}^{2}
$$$$
\operatorname{Var}_{i}\left(\Pi_{i+k}^{(k)}\right)=\left(k-2 \frac{\alpha-\alpha^{k+1}}{1-\alpha}+\frac{\alpha^{2}-\alpha^{2(k+1)}}{1-\alpha^{2}}\right) \frac{1}{(1-\alpha)^{2}} \sigma_{\eta}^{2}
$$$$
\operatorname{Cov}_{t}\left(\Pi_{t+k}^{(k)}, R_{t+k}^{(k)}\right)=\frac{\alpha \beta}{(1-\alpha)^{2}}\left(k-1-\frac{\alpha-\alpha^{k}}{1-\alpha}(1+\alpha)+\alpha \frac{\alpha^{2}-\alpha^{2 k}}{1-\alpha^{2}}\right) \sigma_{\eta}^{2}+\left(\frac{k}{1-\alpha}-\frac{\alpha-\alpha^{k+1}}{(1-\alpha)^{2}}\right) \varphi \sigma_{\eta}^{2}
$$

This gives the following expression for the multi-period hedge ratio:

$$
\Delta^{(k)}=\frac{\frac{\alpha \beta}{(1-\alpha)^{2}}\left(k-1-\frac{\alpha-\alpha^{k}}{1-\alpha}(1+\alpha)+\alpha \frac{\alpha^{2}-\alpha^{2 k}}{1-\alpha^{2}}\right) \sigma_{\eta}^{2}+\left(\frac{k}{1-\alpha}-\frac{\alpha-\alpha^{k+1}}{(1-\alpha)^{2}}\right) \varphi \sigma_{n}^{2}}{\frac{\alpha^{2} \beta^{2}}{(1-\alpha)^{2}}\left((k-1)-2 \frac{\alpha-\alpha^{k}}{1-\alpha}+\frac{\alpha^{2}-\alpha^{2 k}}{1-\alpha^{2}}\right) \sigma_{\eta}^{2}+k \sigma_{e}^{2}+2 \frac{\alpha \beta}{1-\alpha}\left(k-1-\frac{\alpha-\alpha^{k}}{1-\alpha}\right) \varphi \sigma_{\eta}^{2}+\varphi^{2} k \sigma_{\eta}^{2}}
$$

For the long-term hedge ratio this means that:

$$
\lim _{k \rightarrow \infty} \Delta^{(k)}=\frac{(\alpha \beta+(1-\alpha) \varphi) \sigma_{\eta}^{2}}{\alpha^{2} \beta^{2} \sigma_{\eta}^{2}+(1-\alpha)^{2}\left(\sigma_{e}^{2}+\varphi^{2} \sigma_{\eta}^{2}\right)+(2 \alpha \beta(1-\alpha) \varphi) \sigma_{\eta}^{2}}
$$


CHAPTER 4

\section{The Performance of the Dutch Pension Fund System ${ }^{9}$}

The Dutch pension fund system provides and guarantees pensions to almost 12 million individuals using a capital based system with 1100 funds and a combined market value of 600 billion guilders. Even within the European context it is an important industry as only the United Kingdom has a larger pension fund system. On a per capita basis the Dutch pension fund industry is the largest in the world. The important role the industry plays in the nation has stimulated this study of the performance of the pension funds.

Despite the importance of the pension funds, the academic literature regarding performance measurement of pension funds is limited. In general, the performance evaluation literature focuses on American mutual funds for one very good reason: data availability. In chapter 4 we already discussed the fact that in Europe even for mutual funds data are scarce, but the lack of data on Dutch pension funds is even more severe. In the past funds were able to keep all information to themselves, as they were not obliged to present their results publicly. The general public did not bother with the investment performance as the labor unions represented them on the board of the pension funds. What is most important, however, is that the funds guarantee the payment of a pension, and individuals can not change between funds due to bad performance. However, the last decade has seen an increased tendency towards performance measurement and publication. It resulted in new regulation on annual reports of pension funds, and in voluntary disclosure of performance statistics. It gave WM-company the possibility to collect data on the asset returns of an increasing number of pension funds ${ }^{10}$. In 1986 WM started with 25 funds with a combined value of 64 billion Guilders, which has increased to 375 billion Guilders in 1997. They present statistics of the whole

\footnotetext{
9 This chapter is based on: M. Schweitzer, "The Performance of the Dutch Pension Funds", LIFE-yorking paper, 1999.

10 WMcompany is a financial consultancy, with a subsidiary in the Netherlands, and specialized in pension funds. One of their main products is the collection and presentation of the performance of the Dutch pension funds.
} 
industry, but some of the funds also disclose information about their own fund. A thorough study using these data, however, has never been carried out until now.

Literature on the performance of pension funds in other countries is also very scarce. The most recent studies are Lakonishok et al. [1992] and Blake et al. [1997]. The former evaluates the performance of the money management industry in the United States and finds that pension fund managers underperform a general stock index. They claim that this underperformance can be explained by agency problems. That is, the pension fund manager has fewer incentives to do his utmost. The latter study examines the performance of the pension funds in the United Kingdom and finds very little crosssectional variation indicating that funds are all doing similar things. The industrial organization of the Dutch pension system gives us an opportunity to extend the existing literature. The main differences between the Dutch system and the UK and the US systems are that funds will never disappear for performance reasons, and that funds do not face the threat that individuals withdraw money due to bad investment performance. Funds only have to ensure that they can pay out the promised pensions. This will affect the asset allocation between stocks, bonds and real estate. Therefore any performance measurement system should correct for attribution due to the liability structure a fund has.

In this study we examine the performance of the Dutch pension funds using a technique that corrects for the asset allocation between different classes. This enables us to compare the performance of the Dutch pension funds with other institutional investors and stock and bond indices. The remainder of the chapter is organized as follows: in section 4.1 we describe the data, in section 4.2 we study the performance, and conclude the chapter in section 4.3 .

\subsection{Data Description}

The data we analyze is provided by WM-company and consists of two parts. The first part is monthly data of the whole WM-universe. This means that the information concerns all funds together and that no cross-sectional tests are possible. It covers the period from January 1988 through December 1997. The index does not have the same constituents at all times as the number of funds increases through time from 25 in 1988 till 235 in 1997. The two largest pension funds by far, ABP and PGGM, are left out of the universe calculations, as they would dominate the index. The increase reflects the increased attention to and focus on performance. This might induce a selection bias as only the well performing funds will disclose their information voluntarily. During the whole sample period we have data on the time-weighted returns, total asset sizes and the weights of 
different asset classes"1. We are able to distinguish total assets, equity, fixed income, real estate and cash.

The second part gives information on 45 individual funds without the disclosure of names, but ranked in three size bands. These 45 funds are chosen to provide us with a reasonable time series for each fund. The data have a quarterly frequency and cover the period between the first quarter of 1993 through the last quarter of 1997. Besides the same items available for the monthly series, we also have statistics on the activity of the fund within each category.

Figure 4.1: Coverage WMcompany Increases

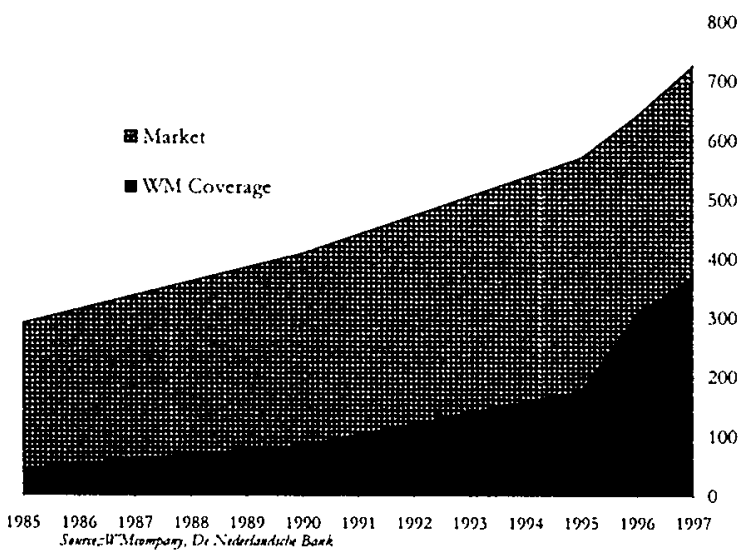

The data of WM-company are limited to the funds that supply data to them. Table 4.1 and figure 4.1 give an indication about the coverage of the data. Table 4.1 compares the cross-sectional sample with the whole universe. We see that the sample mainly consists of the bigger funds. In our sample the category over 1000 million is divided at a value of 3 billion guilders. Thus we have 16 funds with a value between 1 and 3 billion and 12 funds with a value higher than 3 billion. The table also indicates that the smaller funds in general do not disclose their data to WM-company. Figure 4.1 shows the development of the market capitalization of the fund covered by WM-company and compares it with the total assets of all pension funds. Coverage increases through time from 16\% in 1986 till more than $50 \%$ in 1997 . The results of both table 4.1 and figure 4.1 indicate that the data available to us provide a good proxy of the performance of the pension fund industry.

11 The time-weighted retums are the standard methodology to measure returns for an investor as it corrects for inflow and outflow of money during the period. See Bain [1996] and chapter 2 for an explanation. 
Table 4.1: The Number of Funds Compared

\begin{tabular}{|c|c|c|c|}
\hline & \multicolumn{3}{|c|}{ Sizc Bands } \\
\hline & $<250^{*}$ & $250-1000^{*}$ & $>1000 \%$ \\
\hline Existing & 544 & 63 & 46 \\
\hline Our sample & 0 & 17 & $16+12$ \\
\hline \multicolumn{4}{|c|}{$\begin{array}{l}\text { This table presents the number of funds that exist in } \\
\text { the different size categories. ") Numbers are } \\
\text { presented in million Guilders. *) Source is the } \\
\text { 'Verzekeringskamer' (1998) and numbers only } \\
\text { represent the funds with a liability risk. }\end{array}$} \\
\hline
\end{tabular}

\subsection{The Performance of the Pension Funds}

At present pension funds publish their performance in their annual reports and a comparison through an independent branch organization: "Vereniging van Bedrijfspensioenfondsen". Table 4.2 presents an example how this is done. If we just evaluate the 1-year return, we see that the performance ranges from $11.3 \%$ to $15.7 \%$. The range is reduces if we compare the average returns over the last 5 years, which might suggest that some funds obtained very low or very high returns just by chance. For individuals, comparing absolute returns might be a suitable way to evaluate the performance of their fund as the return is directly related to the premium they have to pay: a higher absolute return on the investment leads to a lower premium. However, these higher returns might have been caused by a different liability structure or at the cost of increasing liability risk, and not by the investment skill of a fund manager. For this reason we present the asset allocation in the last three columns of table 4.2. Roughly speaking, the funds with the highest returns also have the highest allocation to equities. For managers of a Dutch pension fund, the choice between the different asset categories is partly determined by the structure of the liabilities. It is very difficult to differentiate the data between the liability and timing component. Ambachtsheer and Erza [1998] developed a method that tries to circumvent this problem by comparing the total asset return with a liability return. It is based on the Economic Value Added technique developed by Stewart [1991]. The liability return is determined by an index bond with the same duration as the liabilities themselves. The difference between the asset return and the liability return is corrected for the risk taken to get a measure of the added value of a pension fund manager given the liability structure. This method has a lot of potential, but strong assumptions on the required rate on the capital at risk and the lack of index-linked bonds make the application to the Dutch pension system premature. 
Table 4.2: Pension Fund Performance

\begin{tabular}{lccccc}
\hline & $\begin{array}{c}1-y r \\
\text { return }\end{array}$ & $\begin{array}{c}5-y r \\
\text { return }\end{array}$ & $\begin{array}{c}\text { Fixed } \\
\text { Income }\end{array}$ & liquity & $\begin{array}{c}\text { Real } \\
\text { Estate }\end{array}$ \\
\hline ABNAMRO & 15.7 & 12.3 & $65 \%$ & $31 \%$ & $4 \%$ \\
ABP & 11.8 & --- & $75 \%$ & $17 \%$ & $8 \%$ \\
Akzo Nobel & 13.8 & 11.2 & $57 \%$ & $31 \%$ & $12 \%$ \\
Ballast Nedam & 11.3 & $-\cdots$ & $80 \%$ & $20 \%$ & $0 \%$ \\
Bouwnijverheid & 13.5 & 11.7 & $49 \%$ & $28 \%$ & $23 \%$ \\
\hline
\end{tabular}

This table gives annualized return statistics for a random, small sample of individual pension funds and the asset allocation over the different categories. Source: VB [1997]

To circumvent the possible bias of the asset allocation between categories we will not evaluate the manager by comparing the total return, but we will study the returns for the individual asset classes. This has the advantage that the performance measured will not be influenced by the liabilities anymore. Furthermore, as pension funds usually split the portfolio into the same three categories to carry out an Asset Liability Management study, it makes sense to evaluate the performance along those lines as well. A sub-sequent country allocation is usually not part of such an analysis. In the next sub-sections we will first analyze the performance of the equity portfolio and afterwards explore some of the difficulties for the fixed income and real estate portfolio.

\subsubsection{Equities}

We first analyze the performance of the equity portfolios of the WM-universe. In contrast to the returns usually evaluated of equity mutual funds, survivorship bias and disturbances caused by the expenses are not present in the returns from WM-company. The sample is free of cash holdings, management costs are not deducted from the return, and there is no survivorship bias. The only possible problem is the selection bias that not all pension funds disclose their information. As we believe that especially the poorer performing funds have an incentive not to disclose the information, our estimation of the performance might overestimate the performance. With increasing public pressure for performance reporting, pension funds are increasingly part of the WWM-universe accentuating the bias in the beginning more than at the end of the sample period.

As we argued in the previous section, it is difficult to hold managers responsible for choices between asset categories but we can compare the results on the asset level. For equities this implies that we evaluate the ability of manager to buy and sell the right stocks at the right time. Even within the equity category we can distinguish several decision levels. That is, managers have to decide in which country, in which investment style and eventually in which individual company to invest. Finally managers have to decide on the time and the quantity of the transaction. The managers should be held responsible for these decisions. 
To determine the performance of the index the first step we have to take is the choice of the benchmark. See chapter 2 for an explanation. We know that asset pricing models are very sensitive to the choice of the benchmark (Kandel and Stambaugh [1995]). This issue is also widely debated in the literature on the performance of mutual funds. Lehmann and Modest [1987] were among the first to conclude that the performance is heavily dependent on the choice of the benchmark. To circumvent this problem we will use several benchmarks to evaluate the funds in our samplc.

Table 4.3 compares the total return index of the stock portfolio of the pension fund index with the world MSCI index and the Netherlands MSCI index. It shows that for the total sample period from 1986 till 1997 the WM-universe has a lower return than both the MSCI-World and the MSCI-Netherlands. As management costs are not deducted from these returns, the result suggests that the fund managers do not have any timing- or selection abilities. For the shorter period, 1993 till 1997, we see that the pension funds still underperform the MSCI-Netherlands, but outperform the MSCI-World. This shows that performance measures are sensitive to choices of the benchmark and might change the conclusion as to whether pension fund managers do or do not add value. We can explain this result by the historically overweighing of the Dutch market relative to the weights in the world-index on one hand and the good performance of the Dutch market during the sample period on the other hand. This means that the performance can be attributed to the country allocation. Whether pension funds choose the Dutch market deliberately or not, it does explain the performance found. The problem, however, is that so long as not all pension funds communicate their objective clearly; we cannot differentiate between luck and skill in terms of country allocations. The best way to communicate the objective clearly is to have a pre-specified benchmark for each of the asset classes. As of today these benchmarks are not consistently available for all pension funds. To circumvent this problem we set up a model in which we correct for the country allocation and reduce biases due to the choice of the benchmark. Note that this means that we do not hold the pension funds accountable for the country allocation, which we preferably would do as their added value depends on this decision.

Table 4.3: The Choice of the Benchmark

\begin{tabular}{lcc}
\hline & $1986-1997$ & $1993-1997$ \\
\hline MSCI-World & 13.1 & 14.7 \\
MSCI-Netherlands & 16.0 & 24.9 \\
WM-Universe & 11.1 & 18.7 \\
\hline $\begin{array}{l}\text { This table presents the annualized total return of } \\
\text { three indices for two sub-periods all in Dutch } \\
\text { guilders. }\end{array}$
\end{tabular}

Equation (4.1) presents the model we use to correct for country allocation and benchmark biases. The model should not be confused with an asset-pricing model. The 
$\beta$ 's only measure the allocation to the different indices, but do not indicate anything about the risk exposure. However, $\alpha_{i}$ can still be interpreted as the measure for outperformance.

$$
R_{t}=\alpha_{i}+\sum_{j=1}^{J} \beta_{j} R_{\mu}+\varepsilon_{t}, \quad \text { in which } \sum_{j=1}^{J} \beta_{j}=1
$$

Estimating this model with OLS implies that we can compare funds that invest the majority of their portfolio in the Netherlands with a fund that only invests a small part domestically. It also gives us the opportunity to say something about the absolute performance of the pension funds. We test (4.1) using MSCI total return indices in Dutch Guilders. To correct for country allocations we include an index for the Far East, for North America and one for Europe. As we know that the pension funds have a strong home bias, we also include the MSCI index for the Netherlands. Table 4.4 shows the result for a few tests on the monthly time series of the WM-universe. The first line presents the estimation for the whole sample period on all four indices. We find that the pension funds underperform the market significantly by $2 \%$ on an annualized basis. The estimation of the country weights corresponds with the findings of WM-company ${ }^{12}$. To test the robustness of these results we also estimated (4.1) using different indices and different time periods. In the first two tests we change the set of indices. The estimated values of $\beta$ remain negative, but in the case where we leave out the MSCI-Netherlands the estimate is insignificantly different from zero. The $\mathrm{R}^{2}$ 's are slightly reduced. In the last two tests we split the sample in two equal periods. We find that the underperformance in the first period is significantly different from zero with a value of almost minus three percent. In the latter period we still have a negative estimate of $\beta$, but it is not significantly different anymore. The country allocations of these tests also confirm the well-known characteristic that the pension funds decreased the share of domestic investment. The estimation of $\beta_{\text {netherlands }}$ drops from $46 \%$ in the first period to $38 \%$ in the second period, which means that the funds on average have reduced their investments in the Netherlands from $46 \%$ to $38 \%$. This is in line with estimates of both WM-company and articles in the popular press.

\footnotetext{
12 WM-company publishes every year an overview of the market and presents characteristics of the WMuniverse. In these reports they also publish the portfolio allocation to the different continents, which we compare with our estimations.
} 
Table 4.4: Performance of the Pension Fund Universe

\begin{tabular}{|c|c|c|c|c|c|c|}
\hline Period & $\alpha$ & $\beta_{\text {far exst }}$ & $\beta_{\text {mencic }}$ & $\beta_{\text {curope }}$ & $\beta_{\text {netherlands }}$ & $\overline{\mathrm{R}^{2}}$ \\
\hline $1986-1997$ & $-1.96 \% *$ & $12 \%$ & $22 \%$ & $23 \%$ & $43 \%$ & 0.97 \\
\hline \multicolumn{7}{|c|}{ Sensitivity 'Tests } \\
\hline $1986-1997$ & $-0.20 \%$ & $13 \%$ & $34 \%$ & $53 \%$ & $\cdots$ & 0.93 \\
\hline $1986-1997$ & $-2.51 \% *$ & $13 \%$ & $26 \%$ & $\cdots$ & $61 \%$ & 0.92 \\
\hline $1986-1991$ & $-2.80 \%$ & $11 \%$ & $21 \%$ & $22 \%$ & $46 \%$ & 0.99 \\
\hline $1992-1997$ & $-0.87 \%$ & $12 \%$ & $24 \%$ & $26 \%$ & $38 \%$ & 0.99 \\
\hline
\end{tabular}

This table presents the result for the estimation of (4.1) using the WM-universe index and MSCI indices for the three continents and the Netherlands. The model is estimated using standard OIS techniques. 'The first column presents the period over which we estimated the model. The second column gives the annualized estimate of $\alpha$ in percentages. The * indicates significance at the $5 \%$ level. The other columns give the estimates of the asset allocation and the result of $\mathrm{R}$-squared.

Figure 4.2: Outperformance WM-universe Compared with Mutual
Funds

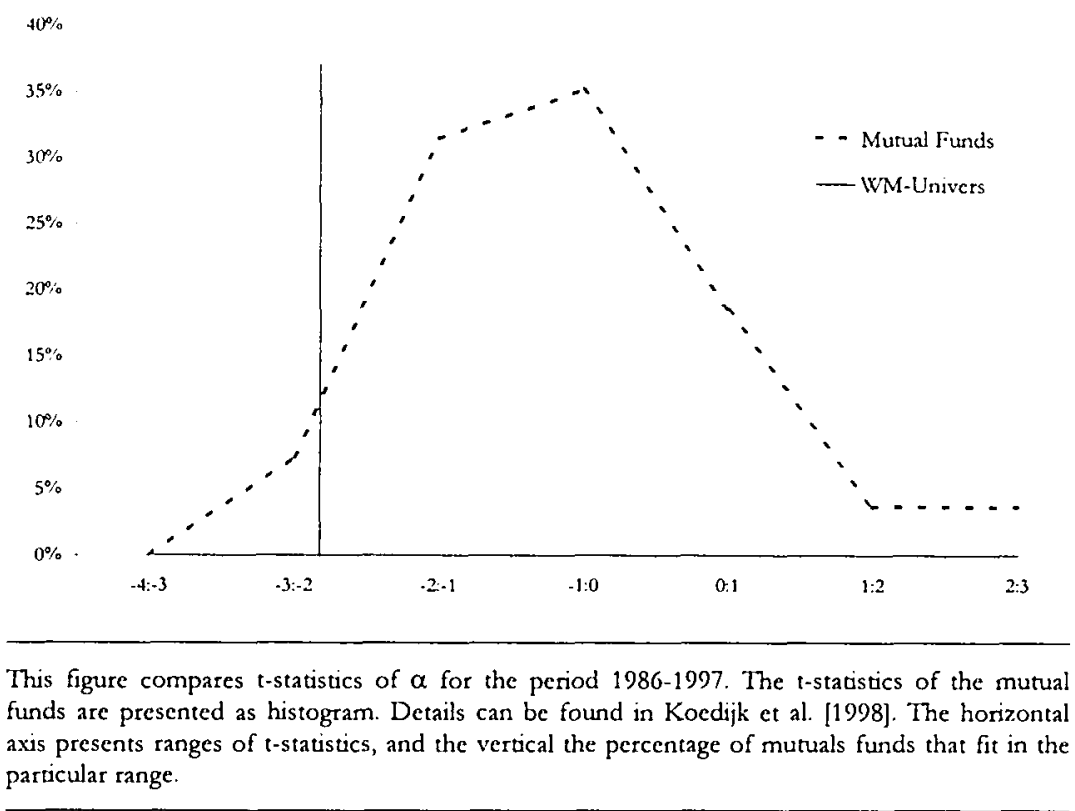

The finding of the underperformance is not surprising, as we know from many studies regarding the performance of mutual funds that these institutional investors underperform the market as well. To compare the performance of the mutual funds with the pension fund sector we use Koedijk et al. [1998] as the benchmark. They have estimated the performance of Dutch mutual funds and also use a method in which they 
correct for the effects of country allocation. Their study incorporates 56 mutual funds for the period between 1986 till 1997. To correct for outliers in the estimates of $\alpha$, we prefer the t-statistic of $\hat{\alpha}$ to compare the two industries. The t-statistics re-scales our estimates in terms of the accurateness of the estimates themselves. Figure 4.2 presents the results. The WM-universe index has a t-statistic of minus 2.44 , which is indicated by the vertical line. As Koedijk et al. [1998] have estimated the outperformance for individual mutual funds we use an histogram to compare the two. The dotted line presents the distribution of the performance measured by the t-statistic of the mutual funds. The horizontal axis indicates the levels of the t-statistics. The vertical axis presents the percentage of funds with a t-statistic in the corresponding box. That is, on the right side of the figure we see that roughly $3 \%$ of the funds have a t-statistic that varies between 2 and 3 . This means that these funds significantly outperform the market.

Figure 4.3: Comparison with Individual Pension Funds

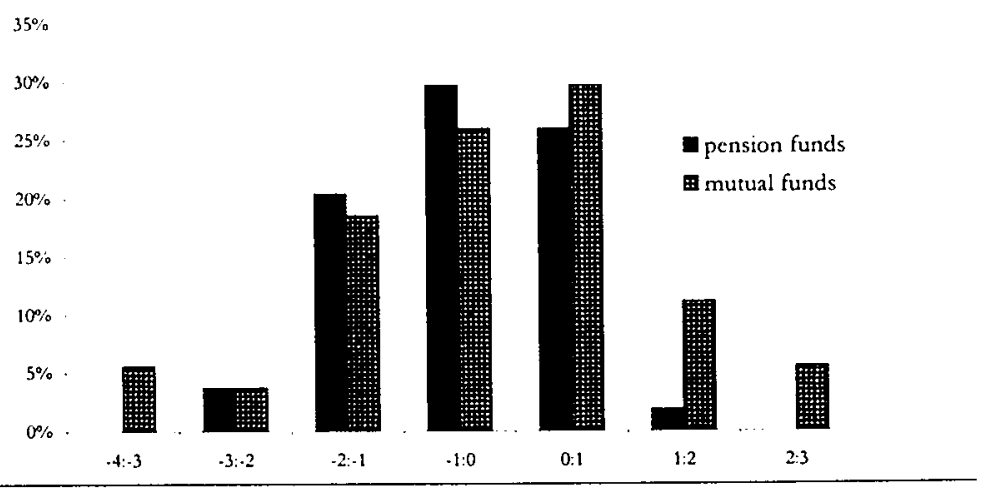

This figure compares t-statistics of $\alpha$ for the period 1993-1997. Details on the mutual funds can be found in Koedijk et al [1998]. The estimation for the pension funds is based using the same methodology as in table 4.4. The axes are identical to the ones in figure 4.2.

The figure clearly shows that most mutual funds perform better than the index of the pension funds. This is surprising as management fees are deducted from the mutual fund returns and not from the pension fund returns. One possible explanation is the existence of survivorship bias in the mutual fund sample, but we believe that the bias will be very small if it exists at all. We believe that the bias should also be offset by the possible selection bias in the pension fund sample. Another explanation for this result could be that some pension funds perform very badly, which lowers the overall performance of the WM-universe index. Given the data on individual pension funds, it is very difficult to correct for cross-sectional differences. To give some idea about these differences we estimated (4.1) for each individual pension fund despite the data limitations.

Figure 4.3 presents the histogram of the t-statistics and compares it with the mutual fund sample. It shows a similar performance of the individual pension funds as the WM- 
universe did before. That is, more than $50 \%$ of the pension funds underperform the benchmark. As the sample size is limited to 20 quarters the result is, however, not significant. The picture also shows that the cross-sectional variation between the pension funds is less than the variation between the mutual funds. This means that the investments of managers of the pension funds have more similarities than the investments of their counterparts at the mutual fund industry. This could be explained by the performance of some of the very specialized mutual funds. In contrast to the pension funds, some mutual funds exist that focus on a particular region, country or sector. A pension fund will always differentiate its assets over these categories.

The results presented in this section suggest that the pension fund managers underperform the market. Tests for horizon sensitivity indicate that the fund managers are improving their performance. Even though the performance of the WM-universe is still negative in the last couple of years it is not significantly different from zero as it was in the beginning of the sample period. The cross-sectional analysis shows that some of the funds were able to outperform the market. The percentage of underperformers, however, was higher than the percentage of pension funds that outperformed the market. In the next sub-sections we discuss the performance of the bond portfolio and the real estate portfolio.

\subsubsection{Bonds}

Fixed income investments are the most important asset category as Dutch pension funds invest on average $52 \%$ of total assets in fixed income securities. We have access to the same data as for the equity portfolios and could perform similar tests. However, these tests are not very informative for bonds since duration effects are very likely to disturb the estimation. Usually the duration is set at the same time as the asset allocation as they are both determined by the structure (and duration) of the liabilities.

\begin{tabular}{|c|c|c|c|}
\hline & $\begin{array}{l}\text { Government } \\
\text { Bond }\end{array}$ & $\begin{array}{c}\text { Corporate } \\
\text { Bond }\end{array}$ & WM-Universe \\
\hline Average & 9.00 & 9.52 & 9.13 \\
\hline Volatility & 3.78 & 4.12 & 3.75 \\
\hline \multicolumn{4}{|c|}{$\begin{array}{l}\text { This table presents the annualized performance statistics } \\
\text { using logarithmic returns for the period between January } \\
1990 \text { and December } 1997 \text {. The volatility is measured as } \\
\text { the annualized standard deviation. The government bond } \\
\text { is the All Government Bond Index for the Netherlands } \\
\text { from Datastream. The corporate bond index is from the } \\
\text { LIFE European Corporate Bond Database. }\end{array}$} \\
\hline
\end{tabular}

To give some idea about the performance of the fixed income portfolio we present some basic return statistics in table 4.5. It shows that the average return of the pension funds is 13 basis points higher than the benchmark and that the volatility is roughly the same. We 
know that the largest part of the portfolio is invested in government bonds, but the pension funds also invest significantly in mortgages, corporate bonds and privately negotiated loans. These investments always have a default premium attached to them, as there is a chance that the debtor is not able to pay back the loan. This means that the difference of the 13 basispoints might be caused by the premium received on more risky fixed income investments. As the public market for corporate bonds has always been very small in the Netherlands and other European countries, there was no benchmark available to evaluate the performance of these assets. However, the Limburg Institute of Financial Economics has developed a database with information about the European corporate bond market. (See Huisman and Schweitzer [1998].) The results show that the return of the corporate bonds is indeed higher than the gevernment bonds but that also the standard deviation, as a measure of risk, is also higher.

Due to the lack of data on the duration of the fixed income investments it is difficult to conclude anything from these data. The summary statistics suggest that funds are able to get returns similar to the market.

\subsubsection{Real Estate}

The real estate portfolio is the smallest of all three categories. Some of the smaller funds do not even have any specific investments in real estate at all. Besides that, it is also more difficult to measure property investment performance due to the lack of well-developed global indices for directly held property. Real estate investments of pension funds are usually in the form of directly held property. This means that they purchase buildings themselves. As the liquidity of the buildings, is very low it is impossible to obtain market values, as transaction prices are not available either. The returns we obtained from WMcompany are based on valuations made by real estate experts. One important characteristic is the very low volatility of these developments. This pattern is clearly visible in figure 4.4, in which we plot the total return index of the real estate investments. The solid, bold line increases each year roughly at same pattern. To put these figures in perspective we could chose between direct and indirect real estate indices. The direct indices are in fact the most applicable as they represent the values of building evaluated by the same method: evaluation through experts. These benchmarks all have a very local nature, and as we know that the pension funds invest internationally we prefer to use the indirect indices developed by Global Property Research as the benchmark. Figure 4.4 compares the performance of the pension funds with several indices from GPR ${ }^{13}$. The figure suggests that the funds are performing as expected as the funds have a performance close to the all-index. The figure also shows that the volatility of the indices is much higher, but this is largely due to the stock market component.

${ }^{13}$ Sec chapter 6 for a more detailed explanation about the indices. 


\subsubsection{Cross-Sectional Analysis: Size Effect?}

An important issue in the literature is the extent to which economies of scale can improve the performance of companies in general. The same holds for institutional investors. For example Dermine and Röller [1992] and Ambachtsheer et al. [1998] show that scale effects do influence the performance of mutual funds and pension funds. Table 4.6 presents an overview of the fixed income portfolio and the stock portfolio for the three size bands. Within the fixed income portfolio we do not see any differences in terms of returns or standard deviations. There is, however, a difference in terms of activity and allocation. The smaller funds trade less and have a larger part of their portfolio invested in bonds. Within the stock portfolios we see a similar picture: performance statistics are roughly the same, smaller funds have less activity and allocate less to stocks.

Figure 4.4: Real Estate Indices

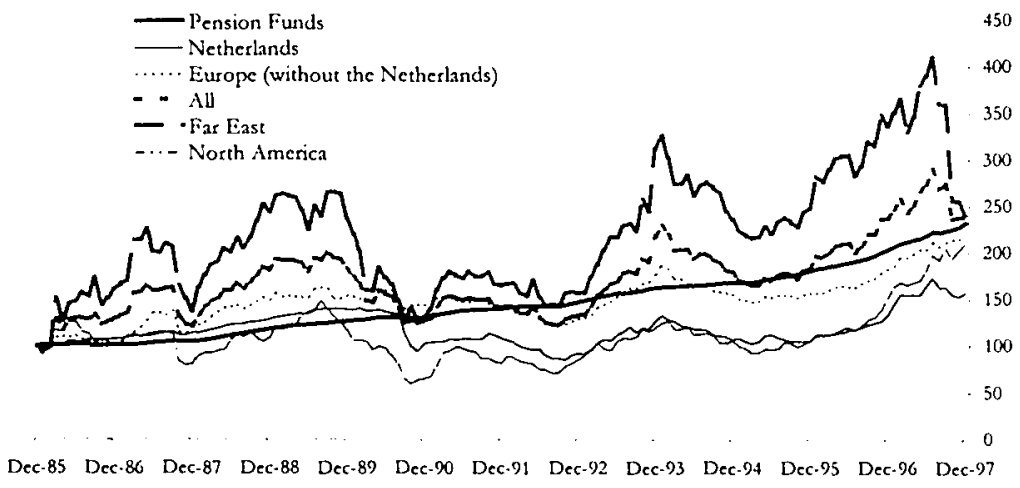

This figure compares the total return indices from Global Property Research for different continents with the total return index for the pension funds in the WM-Universe.

\subsection{Conclusion}

In this chapter we have analyzed the performance of the Dutch pension fund industry using data provided by WM-company. Despite the uniqueness of the data, it is still difficult to infer strong conclusions from it. Given the liability structure of pension funds we cannot hold pension fund managers accountable for the allocation over stocks, bonds and real estate. For the individual categories, however, we are better able to compare the performance even though it would be beneficial if we had benchmarks communicated by the pension funds for all portfolios. In the case of the equity portfolio we were able to carry out informative tests if we corrected for country allocation. This means that we do 
not hold the managers responsible for the country allocation, which would be preferable. The tests show some disappointing results as the funds lose up to $2 \%$ on an annualized basis for the whole sample period despite the correction for country allocation. The data shows that the performance in the beginning of the sample is worse than the performance is the latter period. Due to the limited data availability conclusions for the fixed income and real estate portfolio are misleading. To improve the performance measurement of pension funds it would be necessary for all pension funds to communicate their performance characteristics and benchmarks clearly.

Table 4.6: Existence of Scale Economies?

\begin{tabular}{|c|c|c|c|c|}
\hline & & small & medium & large \\
\hline \multirow[t]{4}{*}{ Fixed Income } & Mean return & 8.25 & 8.43 & 8.67 \\
\hline & Volatility & 4.20 & 4.42 & 4.05 \\
\hline & Activity & 18.11 & 35.84 & 30.23 \\
\hline & Allocation & 68.68 & 57.83 & 56.35 \\
\hline \multirow[t]{4}{*}{ Stocks } & Mean return & 20.44 & 19.10 & 19.35 \\
\hline & Volatility & 12.01 & 12.13 & 12.22 \\
\hline & Activity & 12.32 & 18.50 & 18.13 \\
\hline & Allocation & 25.26 & 29.39 & 29.24 \\
\hline \multicolumn{5}{|c|}{$\begin{array}{l}\text { The table compares the characteristics of the funds in the } \\
\text { different size categories. It compares the stock portfolio and the } \\
\text { bond portfolio. In each category we evaluate the average return, } \\
\text { the standard deviation, the average activity and the allocation to } \\
\text { the asset category. All figures are presented in percentages. }\end{array}$} \\
\hline
\end{tabular}


CHAPTER 5

\section{Performance of European \& US Mutual Funds Compared ${ }^{14}$}

In the last decade the global mutual fund industry has grown dramatically. In the United States the market has grown from about $\$ 0.7$ trillion in 1988 to $\$ 4.5$ trillion in 1997 . The number of funds expanded approximately at the same pace from 1100 in 1988 to 6900 in 199715 . Currently, there are roughly $60 \%$ more mutual funds than listed securities. The importance of mutual funds in society justifies the tremendous number of studies published in the financial press and academia. The issues attracting most attention are performance attribution, timing and selection abilities, benchmark sensitivity, performance persistence, and survivorship bias. See for example Brown et al. [1992], Carhart [1997], Ferson and Schadt [1996], and Grinblatt and Titman [1989, 1994]. All these studies typically focus on the United States, where historic data are easily available and the market is more or less in a mature phase.

In contrast to the United States, the European market has never been studied comprehensively, although several authors studied individual countries and specific aspects. Examples are Dermine [1992], McDonald [1973], Shukla and Imwegen [1995], and Ward and Saunders [1976]. An important explanation for the lack of studies is the institutional setting of the industry in different European countries. Currently, these differences are increasingly disappearing. First of all the European financial markets are becoming more integrated, so differences in institutional characteristics are disappearing, and secondly, the demand for mutual fund services is increasing in Europe. These changes have enabled us to conduct this study regarding the European mutual fund industry.

\footnotetext{
14 This chapter is based on: R. Otten, and M. Schweitzer, " $A$ Comparison between the European and the U.S. Mutual Fund Industry", LIFE working paper, 1999.

15 See FEFSI Staristics 1998.
} 
To explain the behavior of the European mutual fund industry and the demand for its services in a market where conditions are changing, it is essential to include the organizational characteristics of the industry as well. In the literature, however, there is a general lack of studies taking these characteristics into account. A few exceptions are Chordia [1996], Tufano and Sevick [1997], and Walter [1998]. These authors describe and analyze such issues as fee structures, board structures and globalization. In general they find that organizational characteristics do indeed influence the performance.

In this chapter we study the behavior of the European mutual fund industry, compare it with the American mutual fund market and finally test the performance of the funds in our database. Formally, we test the hypothesis that the European mutual fund industry has characteristics like the American mutual fund industry using a traditional structureconduct-performance (SCP) paradigm. (See Bain [1956] and Mason [1939]). The setup of the chapter is as follows. In section 5.1 we provide an overview of the structure of the European mutual fund industry and compare it with the situation in the United States. In section 5.2 we discuss the conduct in the industry and in section 5.3 we bring the structure and conduct together and carry out a performance analysis of the individual mutual funds. Section 5.4 concludes the chapter.

\subsection{The Structure of the Industry in Europe and the United States}

By the end of 1997 there were $\$ 2.1$ trillion of assets under management in European open-ended mutual funds. These were split among 17,000 funds promoted by 1,400 management groups. This means that the European mutual fund industry is the second largest in the world and accounts for $29 \%$ of world fund assets. It is only surpassed by the American industry, which had $\$ 4.5$ trillion assets under management divided among 700 fund groups by the end of $1997^{16}$. In this section we focus on these and other differences between the structure of the European market and the American mutual fund market. We will first analyze the demand for mutual fund services, followed by the supply, and end with the costs involved. As a proxy for the European market we use the 6 most important European mutual fund markets. Together they account for $85 \%$ of total mutual fund assets in Europe ${ }^{17}$. Table 5.1 presents the major characteristics of the two continents and the individual countries.

\footnotetext{
${ }^{16}$ See FEFSI Statistics 1998 and Morningstar.

17 We exclude Luxembourg with $\$ 381$ billion in assets as it mainly serves as an offshore center, which is the result of fiscal and regulatory advantages. The domestic market itself is rather small.
} 
Table 5.1: Characteristics of Major Mutual Fund Markets

\begin{tabular}{lccccccccr}
\hline & Total assets & Number of & Average & \multicolumn{5}{c}{ Asset allocation } \\
\cline { 6 - 10 } & & Funds & Size & Equity & Bond & Balanced & Money & Others \\
\hline United States & $\mathbf{4 , 4 6 5}$ & $\mathbf{6 , 9 0 0}$ & $\mathbf{6 4 7}$ & $\mathbf{5 3 . 0}$ & $\mathbf{1 9 . 5}$ & $\mathbf{2 . 8}$ & $\mathbf{2 4 . 1}$ & $\mathbf{0 . 6}$ \\
& & & & & & & & & \\
Europe & $\mathbf{1 , 3 6 0}$ & $\mathbf{1 0 , 2 6 9}$ & $\mathbf{2 2 6}$ & $\mathbf{3 1 . 8}$ & $\mathbf{3 0 . 4}$ & $\mathbf{1 1 . 3}$ & $\mathbf{2 5 . 7}$ & $\mathbf{0 . 8}$ \\
$\quad$ France & 505 & 5,836 & 87 & 13.6 & 27.2 & 18.7 & $\mathbf{4 0 . 4}$ & 0.1 \\
United Kingdom & 237 & 1,455 & 163 & 85.8 & 6.1 & 7.6 & 0.5 & 0.0 \\
Italy & 210 & 626 & 337 & 20.4 & 44.0 & 6.3 & 25.0 & 4.3 \\
Spain & 179 & 1456 & 123 & 10.5 & 40.9 & 11.1 & 37.5 & 0.0 \\
Germany & 148 & 717 & 207 & 37.9 & 48.2 & 2.8 & 11.1 & 0.0 \\
Netheriands & 78 & 179 & 440 & 53.8 & 30.2 & 5.7 & 10.1 & 0.2 \\
\hline
\end{tabular}

This table presents the characteristics of the major European mutual fund markets and the United States. All figures are obtained from FEFSI and are of December 31, 1997. The first column presents the total market value (billion U.S. dollar). The second column the number of funds, the third column the average size in million U.S. dollar, and the last 5 columns the asset allocation of all mutual funds as percentage of total assets. The balanced funds invest in stocks, bonds, and cash.

Table 5.1 shows that the mutual fund industry in the United States is much larger than the European industry. In contrast, the number of funds is much higher in Europe, which results in a smaller average size of the individual funds in Europe. The mutual funds in the United States have an average fund size of 647 million dollars, almost three times as big as the European mutual funds. They have an average size of 226 million U.S. dollars. Even within Europe there are some differences as the average size of the funds varies between 87 million U.S. dollars in France to 440 million U.S. dollars in the Netherlands. Another difference between the continents is clear in the asset allocation. In the United States more than $50 \%$ of the funds are equity investors, whereas the percentage in Europe is less than a third. This is probably due to the lower demand for equity-related products in Europe, and definitely not to the shortfall of the supply of funds. We believe that a different equity culture, strong presence of banks and a different pension system explain part of the lower demand ${ }^{18}$.

18 We won't explore these issues in more detail, but others have researched them. See for example Poterba, Venti, and Wise [1998]. 
Figure 5.1: Growth in Asset Sizes for Equity Funds 1992 - 1997

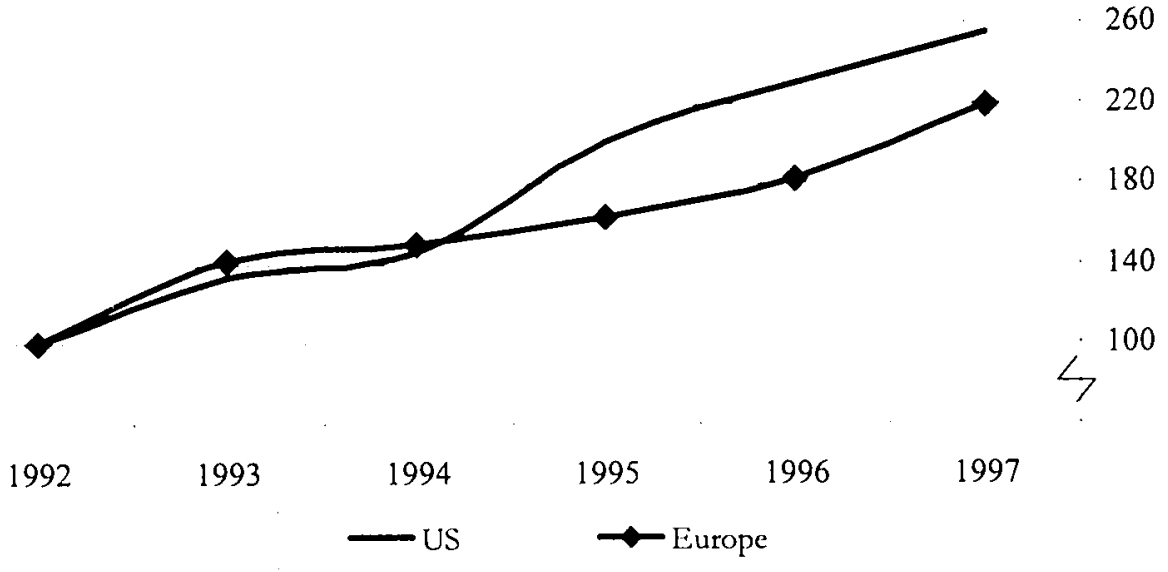

This figure presents the total market capitalization of the equity mutual funds as an index figure with 1992 as the base year.

Figure 5.2: Growth in Equity Mutual Funds 1992-1997

200 .

150

100

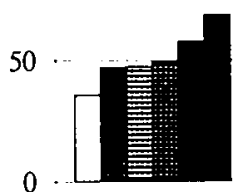

France

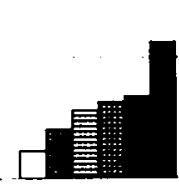

Germany

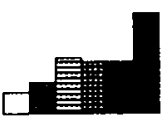

Italy

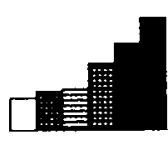

Netherlands

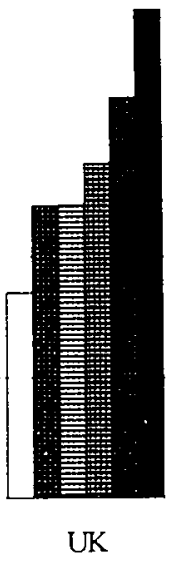

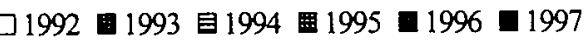

This figure presents the total market capitalization in Billion U.S. dollar of the equity mutual funds for the individual countries. 
Figure 5.1 gives some insight into the development of the demand from individual investors for equity mutual funds. It presents the growth of market capitalization of the equity mutual funds in Europe and the United States berween 1992 and 19971\%. While, clearly the industry is growing in both continents industry growth in the United States has been sharper than in Europe. Europe thus is not only lagging behind the United States in absolute size, but also in growth. To put the picture in perspective, figure 5.2 presents equity mutual fund sizes for the individual European countries over time and shows that some markets are growing very rapidly whereas others are growing at a much lower pace. That is, the United Kingdom and France have the largest mutual fund sector, but also have lower growth rates than the United States. The smaller European countries have growth rates up to $8000 \%$. For instance, we find those high growth rates in countries like Spain and Italy, where mutual funds did not exist in the beginning of the sample period. Thus, despite the lower growth of the European industry, we see that some underdeveloped mutual fund industries are catching up very quickly, and that the demand for mutual fund services is increasing.

Table 5.2: Equity Mutual Funds as a Percentage of Total Market Value

\begin{tabular}{lrrrrrr}
\hline & 1992 & 1993 & 1994 & 1995 & 1996 & 1997 \\
\hline United States & $16 \%$ & $20 \%$ & $22 \%$ & $26 \%$ & $28 \%$ & $26 \%$ \\
& & & & & & \\
Europe & $6 \%$ & $8 \%$ & $8 \%$ & $8 \%$ & $8 \%$ & $11 \%$ \\
$\quad$ France & $13 \%$ & $12 \%$ & $13 \%$ & $11 \%$ & $11 \%$ & $11 \%$ \\
United Kingdom & $10 \%$ & $11 \%$ & $11 \%$ & $11 \%$ & $10 \%$ & $11 \%$ \\
Italy & $8 \%$ & $9 \%$ & $12 \%$ & $11 \%$ & $9 \%$ & $13 \%$ \\
Sprain & $0 \%$ & $1 \%$ & $1 \%$ & $1 \%$ & $2 \%$ & $9 \%$ \\
Germany & $3 \%$ & $5 \%$ & $7 \%$ & $7 \%$ & $6 \%$ & $8 \%$ \\
Netherlands & $6 \%$ & $8 \%$ & $7 \%$ & $9 \%$ & $9 \%$ & $10 \%$ \\
\hline
\end{tabular}

This table presents the total market size of the equity mutual funds as percentage of the total market capitalization on the stock market at the end of the year. Sources are FEFSI and Datastream.

Although mutual funds are less important in Europe than in the United States, it is not necessarily true that European citizens have less exposure to the equity market. They can also purchase equities themselves or through other institutions like pension funds and insurance companies. Table 5.2 presents a statistic that indicates the importance of mutual funds in their domestic equity market. The statistic is calculated as the total market value of all equity mutual funds divided by the market capitalization ${ }^{20}$. The 1997 figure for the United States is $26 \%$, which is roughly two-and-a-half times as big as the average

\footnotetext{
19 'This statistic is not only influenced by the demand for mutual fund services, but also by the bull mathet that occurred at the stock exchanges during the sample period. Even when we discount for the bull market we can show that the demand for mutual services is still growing rapidly. The results of these tests are available upon request.

20 The market capitalization was collected from Datastream and represents the total market including all listed mutual funds itself.
} 
European figure. Therefore the European mutual fund sector is indeed not as important as its American counterpart indicating that individuals possibly purchase equities through other channels. The table shows that the percentage increased through time both in the United States and in Europe.

Besides the demand for mutual fund services, the supply of the product by financial institutions is also important. Mutual funds are usually part of a mutual fund group, which gives customers the possibility to switch easily (and often with lower costs) between funds. This is true for both the United States and Europe. However, if fund groups become too big, they might control the market for financial services, which might have a negative effect on the performance of the industry. In both Europe and the United States the top 5 providers of mutual fund services own less than $20 \%$ of the market. This indicates that Europe and the United States are roughly equal regarding the competition between groups. In table 5.3, however, we also present the statistic per country. The table shows that the percentages are much higher for all individual countries, except for the United Kingdom. This means that within single European countries individual fund groups dominate their domestic market. This might have a negative influence on the conduct and on the performance of the industry.

\begin{tabular}{lc}
\multicolumn{2}{l}{ Table 5.3: Concentration Ratios } \\
\hline United States & $18 \%$ \\
Europe & $19 \%$ \\
France & $62 \%$ \\
Germany & $62 \%$ \\
Italy & $43 \%$ \\
Netherlands & $60 \%$ \\
Spain & $48 \%$ \\
United Kingdom & $20 \%$ \\
\hline This table presents the 1997 concentration ratio \\
calculated as the market value of the five largest \\
fund groups as part of the total mutual fund \\
market. Sources are Datamonitor, Morningstar and \\
Lipper.
\end{tabular}

Turning now to the price individuals pay for the services that mutual funds offer, we assume that the fee paid represents the price of the product. Even though legal structures differ slightly between countries, the basic fee system is now similar. That is, the individual pays a management fee that the asset manager receives to manage the portfolio. Table 5.4 presents the fees charged by mutual funds. Besides the figures for the two continents, we split the sample up by country (panel A) and by investment style (panel B). The average fee in the United States is slightly higher than the average in Europe indicating that with respect to the fee structure the continents do not differ much. However, the difference in maximum and minimum fees is larger in the United States. 
Europe has a higher minimum fee and a lower maximum fee. This might indicate that most European funds follow the same investment strategy, whereas in the United States funds have strategies ranging from pure index funds to highly active strategies, which might lead to a more pronounced differentiation in fees. The results of the individual European countries and the different investment styles, presented in panel $A$ and $B$, confirm these findings.

Recent research by Fitzrovia International, a London-based fund research, showed that the reported costs for the UK-funds are not the same as the true costs as administration costs, legal and audit fees are not included 21 . The company thinks that the best guess would be to double the reported fees to get the true Total Expense Ratio (TER). Currently, they are studying other European countries as well, but the assumption might be that this relation holds for these countries as well. The Investment Company Institute in Washington D.C. has studied the situation in the United States and found that the TERs are declining. This means that we have to be careful interpreting these costs figures.

Table 5.4: Management Fees

\begin{tabular}{|c|c|c|c|c|c|c|}
\hline PANEL A: & \multicolumn{2}{|c|}{ Average } & \multicolumn{2}{|c|}{ Minimum } & \multicolumn{2}{|c|}{ Maximum } \\
\hline United States & \multicolumn{2}{|c|}{1.4} & \multicolumn{2}{|c|}{0.2} & \multicolumn{2}{|c|}{17.7} \\
\hline Europe & \multicolumn{2}{|c|}{1.2} & \multicolumn{2}{|c|}{0.3} & \multicolumn{2}{|c|}{3.0} \\
\hline France & \multicolumn{2}{|c|}{1.2} & \multicolumn{2}{|c|}{0.3} & \multicolumn{2}{|c|}{3.0} \\
\hline Germany & \multicolumn{2}{|c|}{0.8} & \multicolumn{2}{|c|}{0.5} & \multicolumn{2}{|c|}{2.0} \\
\hline Italy & \multicolumn{2}{|c|}{2.0} & \multicolumn{2}{|c|}{0.5} & \multicolumn{2}{|c|}{3.0} \\
\hline Netherlands & \multicolumn{2}{|c|}{0.5} & \multicolumn{2}{|c|}{0.4} & \multicolumn{2}{|c|}{1.0} \\
\hline Spain & \multicolumn{2}{|c|}{2.0} & \multicolumn{2}{|c|}{0.5} & \multicolumn{2}{|c|}{3.0} \\
\hline United Kingdom & \multicolumn{2}{|c|}{1.2} & \multicolumn{2}{|c|}{0.3} & \multicolumn{2}{|c|}{2.0} \\
\hline PANEL B: & US & $\mathrm{EU}$ & US & $\overline{\mathrm{EU}}$ & $\overline{\text { US }}$ & $\overline{\mathrm{EU}}$ \\
\hline Aggressive growth & 1.7 & & 0.7 & & 6.4 & \\
\hline Growth & 1.4 & 1.2 & 0.3 & 0.4 & 11.9 & 2.0 \\
\hline Income & 1.3 & 1.2 & 0.5 & 0.5 & 2.3 & 2.0 \\
\hline Growth/income & 1.2 & 1.1 & 0.2 & 0.3 & 17.7 & 2.0 \\
\hline Small Caps & 1.5 & 1.2 & 0.2 & 0.5 & 7.3 & 2.5 \\
\hline
\end{tabular}

This table shows the average, minimum, and maximum management fees in percentages charged by the individual mutual funds in 1997. Sources are Morningstar, S\&P Micropal, $\triangle B N-A M R O$, Financial Times, and Hoppenstedt. These institutions collect the fees reported in the annual reports and other publications of the mutual funds and fund groups.

In sum, we conclude from the description of the structure that the European mutual fund sector is growing rapidly, but that the importance in the financial market is still not as high as in the United States. This suggests that continued growth of mutual fund services

21 See Economist [1999] for some details. 
in Europe can be expected. An important institutional factor that might influence the speed of the growth is the dominance of the top five fund groups in the individual countries. They control the market, which reduces competition and possibly leads to higher entry barriers. In the next section we analyze the actual conduct of the fund groups and in section 4 the performance of the funds.

\subsection{Conduct in the Industry}

The conduct of the mutual fund industry will be described and discussed along two lines. First we look at the distribution channels the fund groups use to sell their products and secondly how past performance is presented to the general public.

'Table 5.5 shows the importance of specific distribution channels for mutual funds in Europe and the United States. The table clearly shows a big difference between the two continents. European mutual funds predominately use banks as the major distribution channel with a market share of $53 \%$, whereas in the United States their market share is only $8 \%$. The differences between individual European countries are interesting as well (not reported in table format). In most countries the percentage of banks exceeds $50 \%$. The United Kingdom is the only European country where banks have only $10 \%$ of the market. This means that the United Kingdom and the United States have similar characteristics in this respect. As banks are actually not used in those two countries, it means that other channels are more important. In the United Kingdom the distribution of mutual fund services is predominately done through independent agencies. In the United States, brokers and direct sales are the most commonly used channels. Besides these channels we see, especially in the United States, a small but increasing trend towards the provision of mutual fund services through the Internet.

The continents also differ when we look at the use of performance statistics. In the United States league tables are widely published and used by individual investors. For example, Sirri and Tufano [1998] show that when funds receive a 4 or 5-star ranking from Morningstar (based on past performance) money inflow increases in the following year. According to the popular press in Europe, individuals seem to value service (e.g. being friendly and accurate) at least as much as performance in terms of returns relative to the benchmark. This could explain the strong position of banks. However, we see that league tables are currently getting more attention in the European press as well. For instance, S\&P Micropal publishes monthly performance rankings through several oudlets. This will possibly lead to money inflows and outflows, following these publications. As far as we know, a European study on this issue has not been carried out, but it would be a fruitful venue for further research. 
Table 5.5: Distribution Channels

\begin{tabular}{lcc} 
& Europe & United States \\
\hline Banks & $53 \%$ & $8 \%$ \\
Brokers & $11 \%$ & $40 \%$ \\
Direct sales & $9 \%$ & $32 \%$ \\
Other & $27 \%$ & $20 \%$ \\
\hline This table presents the use of a distribution channel \\
as a percentage of the total market in 1998. The \\
category 'Other' includes insurance companies, and \\
independent sales forces. Sources: EFID, \\
Datamonitor, Investment Company Institute.
\end{tabular}

Table 5.6 presents a summary of the analysis of the structure and conduct of the industry, based on the data and the analyses in sections 5.1 and 5.2. In short, the European market itself is not as that in the United States; individual mutual funds in Europe are smaller in absolute size and relative to the stock market, invest less in equities, and charge less to the customer, the concentration of fund groups is higher in the individual countries, banks play an important role and the funds get less publicity. We have to be careful, however, when we compare the business between Europe and the United States, we might conceal some of the differences between the European countries. For these details we refer to the earlier analyses. Despite the generalizations the table restates the conclusion that the European mutual fund industry is still lagging behind the American industry. We found some indication of less competition in Europe, which might possibly diminish performance. In the next section we compare the performance between the continents and see whether a pattern to the structure and conduct in the industry exists.

\subsection{Performance of the Mutual Fund Industry}

In this section we use the third step of the SCP paradigm to study the effects of the structure and conduct on the performance in the industry. The SCP is a framework developed in organizational literature, which focuses on the product and production efficiency. (See Scherer and Ross [1990] for more details.) Traditionally the SCP paradigm measures the performance along the lines of 1) Production and allocative efficiency, 2) Progress, 3) Full employment and 4) Equity. In contrast, the finance literature always uses stock market returns and asset-pricing models to measure performance. In chapter 2 we have already indicated that the main product of a mutual fund is the return on the invested portfolio is. (See also Gruber [1996].) This means that using stock market returns to measure performance accommodates both strands of the literature and gives us an opportunity to compare the performance of mutual funds in the two continents and link it to the structure and conduct in the industry. 
Table 5.6: Mutual funds in United States and Europe Compared

\begin{tabular}{|c|c|c|}
\hline & United States & Europe \\
\hline \multicolumn{3}{|c|}{ Structure of the Mutual Fund Market } \\
\hline Total assets (trillion \$) & 4.5 & 1.4 \\
\hline Average fund size & Large & Small \\
\hline Market importance & High & Low \\
\hline$\%$ invested in equity funds & High & Low* \\
\hline Concentration & Low & High within countries \\
\hline Costs & High & Unclear \\
\hline \multicolumn{3}{|c|}{ Conduct of the Mutual Funds } \\
\hline Distribution & Direct channels & Banks \\
\hline Publicitity/press coverage & High & Lower \\
\hline
\end{tabular}

The temainder of this section is split in 7 sub-sections, which all highlight a particular issue related to the performance. In section 5.3 .1 we discuss the data we use to test the performance; section 5.3.2 presents the summary statistics of the performance; in section 5.3.3 we analyze the development through time of the performance; in 5.3 .4 we correct for asset allocations; in 5.3.5 we test the influence of fees on performance; 5.3.6 takes a detailed look at the underperformance of European index funds and finally in section 5.3.7 we explore the outperformance of small cap funds.

\subsubsection{Data}

We use monthly total logarithmic returns for 506 European and 2096 American openended mutual funds from January 1991 to December 199722 . We restrict our sample to purely domestic equity funds with at least 24 months of data. That is, we exclude balanced and guaranteed funds and equity funds that invest internationally. Limiting the sample size along these lines gives us an excellent possibility to compare the relative performance of the different mutual fund industries. If we include all existing funds, we would have to correct for country allocation, exchange rate policies, and other legal obstructions before we could compare the relative performance.

To calculate the relative performance, we use the following local benchmarks to correct for market developments: 1) CAC for France, 2) DAX for Germany, 3) Mibtel for Italy, 4) AEX for the Netherlands, 5) FTSE All for the United Kingdom, and 6) the S\&P500 for the United States. We collect the indices on a total return basis, which means that we reinvest all dividends. It is well known that the market for small stocks usually has

22 For Spain there were no comprehensive return data available. 
different performance characteristics than the main market. As our sample also includes funds that invest in small caps, we use a small cap index as the benchmark for these funds. For France we use the Midcac, for Germany the Datastream Small Companies Germany, for the Netherlands the Midcap index, for the United Kingdom the Hoare Govett Small Company index and for the United States the Russell 2000. We use the midcap indices for France and the Netherlands, as they represent the actual investment behavior of the funds better than the actual small cap indices. For Italy we don't need a small cap benchmark, as there are no funds concentrating on small companies.

To obtain information regarding the characteristics of the individual equity funds we use several sources: Standard\&Poor's Micropal (France, Italy), Hoppenstedt Fondsführer 1997 (Germany), ABN-AMRO Beleggingsinstellingen (Netherlands), Unit Trust Yearbook 1997 (United Kingdom), and Morningstar (United States). We gather data for several characteristics of each mutual fund: fund type or investment style, total return, size, and fees. Within a country we divide all funds using stated investment styles to test whether this yields differences in performance. Total return data are collected from Datastream International, S\&P Micropal and Morningstar.

As numerous studies have shown before (see for example Brown et al. [1992]), a database that only consists of funds with data available for the whole sample period is subject to survivorship bias, which could severely influence the results. This derives from the fact that funds with bad performance are frequently being shut down or merged into other ones. This "kills" bad track records and gives an overestimation of the average performance as only the surviving funds are used. We are confident that the data for Germany and the Netherlands are largely free of survivorship bias, as Hoppenstedt for Germany and Koedijk et al. [1998] for the Netherlands studied these funds. For the United Kingdom we were able to track disappeared funds through the Unit Trust Yearbook 1997. For France and Italy Micropal was unable to give us the data on the disappeared funds. Morningstar releases the information on these non-surviving funds only at very high costs. 
Table 5.7: Summary Statistics of Individual Countries 1991-1997

\begin{tabular}{|c|c|c|c|c|c|}
\hline & $\mathrm{n}$ & $\mu$ & $\sigma$ & size & costs \\
\hline \multicolumn{6}{|l|}{ France } \\
\hline Growth & 55 & 11.1 & 14.3 & 396 & 1.1 \\
\hline Index & 20 & 10.0 & 17.3 & 65 & 1.2 \\
\hline Smaller Companies & 24 & 11.8 & 14.3 & 81 & 1.3 \\
\hline Totul & 99 & 11.1 & 14.8 & 258 & 1.2 \\
\hline$C A C 40$ & & 11.7 & 17.8 & & \\
\hline Midcac & & 7.5 & 17.7 & & \\
\hline \multicolumn{6}{|l|}{ Germany } \\
\hline Cieneral & 46 & 13.2 & 15.6 & 369 & 0.8 \\
\hline Growth & 5 & 10.7 & 16.2 & 125 & 0.8 \\
\hline Income & 2 & 13.7 & 16.5 & 660 & 1.0 \\
\hline Smaller Companies & 4 & 10.2 & 13.6 & 121 & 0.9 \\
\hline Tolat & 57 & 12.8 & 15.5 & 335 & 0.8 \\
\hline $\mathrm{DAX}$ & & 12.4 & 16.2 & & \\
\hline Datastream Smcos & & 3.1 & 10.2 & & \\
\hline \multicolumn{6}{|l|}{ Italy } \\
\hline Inalian cquity & 21 & 11.8 & 15.2 & 261 & 2.0 \\
\hline Italian specialist & 16 & 13.1 & 17.6 & 223 & 1.8 \\
\hline Tolst & 37 & 12.3 & 16.1 & $2+2$ & 2.0 \\
\hline Mibtel & & 14.0 & 24.0 & & \\
\hline \multicolumn{6}{|l|}{ Netherlands } \\
\hline Growth & 5 & 20.6 & 13.2 & 500 & 0.6 \\
\hline Index & 3 & 20.5 & 15.1 & 50 & 0.4 \\
\hline Smaller Companies & 1 & 21.2 & 12.9 & 505 & 0.6 \\
\hline Tosal & 9 & 20.6 & 13.9 & 350 & 0.5 \\
\hline $\mathrm{AEX}$ & & 21.5 & 14.4 & & \\
\hline Midcap & & 22.9 & 15.9 & & \\
\hline \multicolumn{6}{|l|}{ United Kingdom } \\
\hline Growth/Income & 79 & 124 & 13.1 & 326 & 1.1 \\
\hline Inconie & 72 & 12.6 & 13.3 & 260 & 1.2 \\
\hline Growth & 102 & 12.8 & 13.1 & 215 & 1.3 \\
\hline Smaller Companies & 51 & 13.1 & 13.5 & 222 & 1.3 \\
\hline Total & 304 & 12.7 & 13.2 & 256 & 1.2 \\
\hline FALL & & 14.1 & 13.1 & & \\
\hline Hoare Govett Smcos & & 11.6 & 14.5 & & \\
\hline \multicolumn{6}{|l|}{ United States } \\
\hline Aggressive Growth & 103 & 17.1 & 18.2 & 1027 & 1.7 \\
\hline Growth & 937 & 17.5 & 15.4 & 682 & 1.4 \\
\hline Income & $1+4$ & 17.6 & 12.1 & 781 & 1.3 \\
\hline Growth/Income & 490 & 18.2 & 13.5 & 1175 & 1.2 \\
\hline Smaller Companies & 413 & 18.2 & 17.9 & 345 & 1.5 \\
\hline Total & 2096 & 17.8 & 15.4 & 757 & 1.4 \\
\hline S\&P 500 & & 17.6 & 12.4 & & \\
\hline Russel 2000 & & 18.7 & 13.7 & & \\
\hline
\end{tabular}

This table reports summary statistics on the funds in our sample. The return data are annualized with reinvestment of all distributions and based on local currencies. All returns are net of expenses. The average fund sizes are presented in million US dollars as of $31 / 12 / 1997$. The costs are presented in the fifth column and are presented as a percentage of the assets invested. 


\subsubsection{Summary Statistics}

To get an overview of the data we start our performance analysis with the presentation of table 5.7. It provides summary statistics and fund characteristics together with the performance of the relevant benchmarks.

First of all we see that the number of domestic equiry funds differs from country to country. Whereas the United Kingdom has a total number of 304 domestic equity funds, the Netherlands has only 9 such funds. What is more important, however, is to look at the size of the European funds relative to their American counterparts. While the average European equity fund has about 300 million U.S. dollars in assets, the average American fund amount to 757 million U.S. dollars. Furthermore, the average size of a European index fund is equal to 57 million U.S. dollars, which is relatively small23. In this respect the size of the countries themselves is important. We could assume that the mutual funds investing in international markets are more important in the smaller European countries. Comparing the size statistics from tables 5.1 and 5.7 we find that a similar pictures arises, which means that our analysis is not limited due to the choice for the domestic equity mutual funds.

Table 5.7 also gives a first indication of the performance of the funds. It presents unadjusted annual mean returns and standard deviations for each class of funds. We see that during the whole sample period (1991-1997) the Dutch mutual funds generated the highest annual return (20.6\%) with the second lowest standard deviation of $13.9 \%$. In contrast, French mutual funds earned only $11.1 \%$ on an annual basis, which was the lowest return in the sample. U.K., Italian and German funds earned about the same rates of return, but the last two had a wider dispersion of returns, resulting in higher standard deviations. Furthermore, we also find that mutual funds focusing on smaller companies have a higher return than their benchmark in all countries except the Netherlands and the United States.

\subsubsection{Development through time}

In sections 5.1 and 5.2 we focused on the structure and conduct of the industry, and saw a trend towards an increased importance of both the European and the U.S. mutual fund sector. We now turn to the performance of the industry and test whether this trend has influenced the observed performance in section 5.3. We analyze the development by presenting the annualized difference between the fund performance and the return on the relevant benchmark using a 36-month moving window ${ }^{24}$.

In line with earlier results figure 5.3 shows that both European and U.S. mutual funds underperform their relevant benchmarks. It also points out that the performance in the

${ }^{23}$ Gruber [1996] reports that the average US index fund has $\$ 368$ million in assets. 
United States has dropped during the sample period, whereas the performance of the European mutual fund industry has remained relatively constant. The averages, however, are not significantly different from each other, as standard errors around the trend are roughly $3 \%$.

Figure 5.3: Relative returns of European and US Mutual Funds Through Time

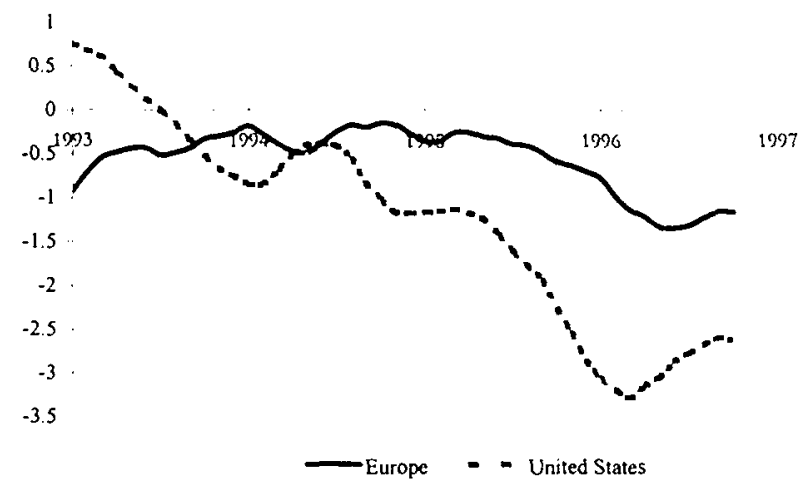

This figure gives the development of the relative returns in percentages per year (fundbenchmark) for both Europe and the US. Plotted are the 36 month moving averages for the $1991-1997$ period. All returns are net of expenses.

24 We calculated the differences for other horizon lengths as well, but as this didn't influence the results, we limit the presentation to the 36 -month period. 
Figure 5.4: Relative Returns of Individual Countries and Investment Style

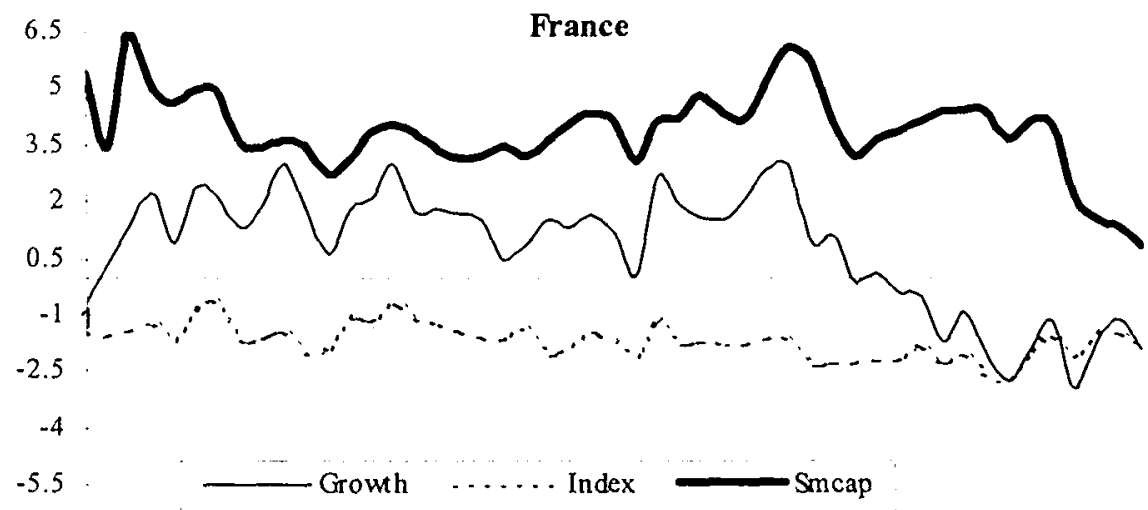

\section{Germany}

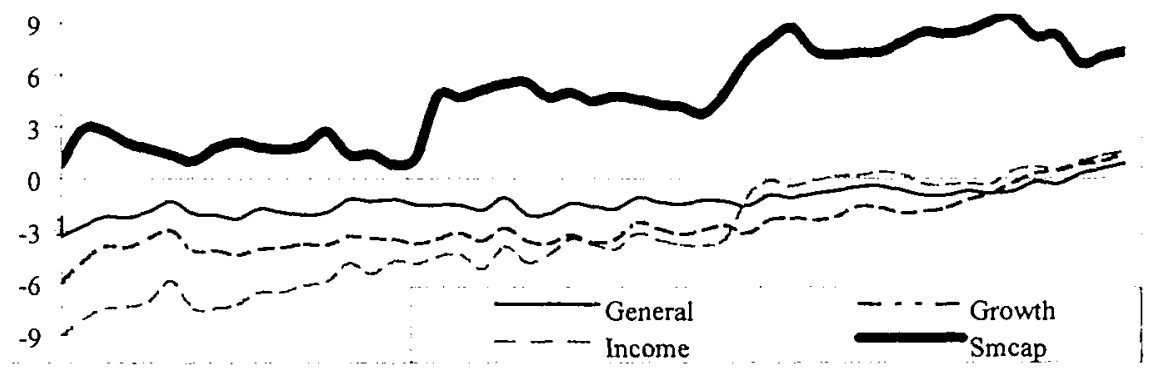

3.5

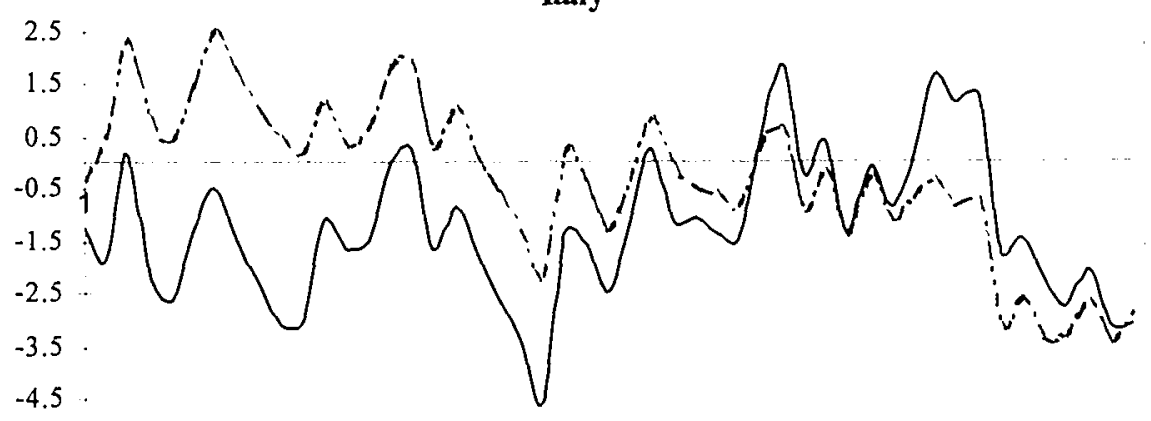

$-5.5 \quad-$ Equity - Equity specialist 
Figure 5.4: (continued)

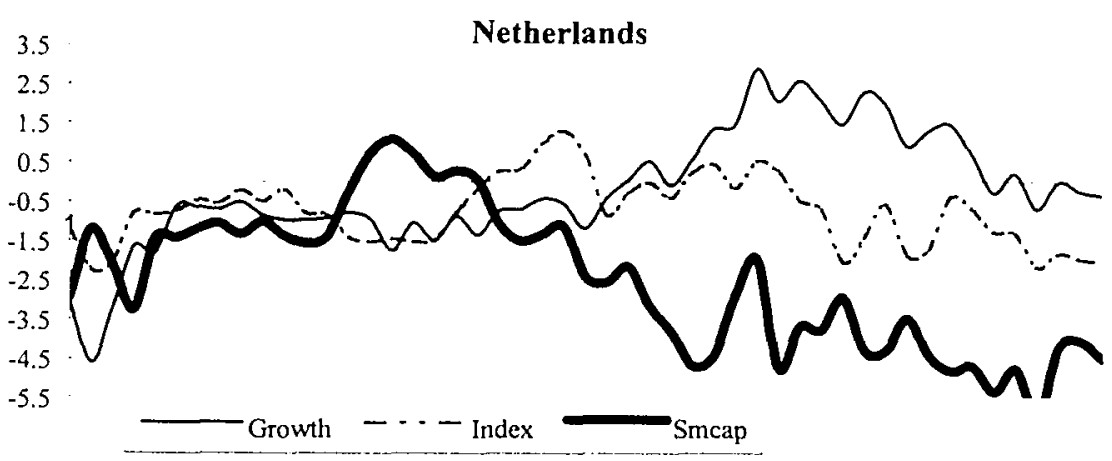

\section{UK}

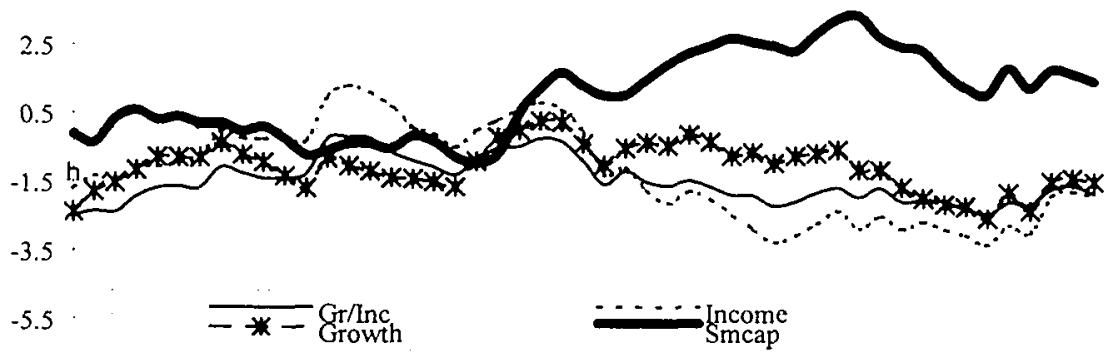

\section{United States}

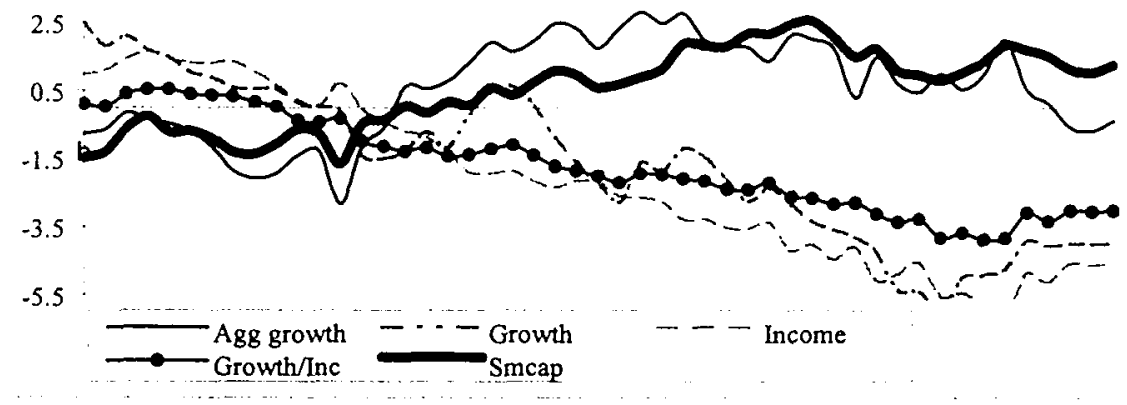

This figure presents the moving window of the average retum difference over 36 months. The retum difference is defined as the return of the fund minus the benchmark. For each country we present the results by investment style. The figures have the same set-up as figure 5.3. 
Besides these differences in the performance trend between the two continents we also look at the development of the individual groups of mutual funds by investment style and by country as we have done in table 5.7. We present these results in figure 5.4 . Performance in France and in Italy is relatively constant through time and confirms the earlier results. The only remarkable fact in France is the underperformance of the index funds.

The most interesting picture is actually provided by the German mutual funds. All classes of funds show a steadily increasing performance relative to their benchmarks. Whereas in the beginning of the sample period German mutual funds were losing on average $6 \%$ on an annual basis, by the end of the sample period the funds were able to beat the benchmark. In the Netherlands we see a picture that is similar to Germany as the performance improves through time. The U.K. mutual funds behave as expected, as they underperform the index on average by an amount equal to the fees they charge. When we look at the American funds it seems that only aggressive growth and small cap mutual funds improve their performance. All other styles show a declining average performance.

\subsubsection{Are Funds Doing What They Are Supposed To?}

Our results suggest that there are performance differences between the two continents, between European countries, and between investment styles. In the previous sub-section we simply compared the mutual fund return to the market return. However, the performance might also be driven by large cash-positions or exposure of mutual funds to the money market ${ }^{25}$. Mutual funds hold cash positions for two reasons. First, they need liquidity to be able to respond to investors who sell their shares in mutual funds. Second, the fund managers might want to engage in market timing. To correct for this behavior we test the sensitivity to different benchmarks and investment horizons. Equation (5.1) presents a model, which is based on Sharpe [1992], and gives us the opportunity to correct for asset allocation. It should not be confused with an asset pricing test as we control for exposures or allocation, but not risk-exposures.

$$
R_{i t}=\alpha_{i}+\beta_{e} R_{m t}+\beta_{b} R_{b t}+\beta_{f} R_{f t}+\varepsilon_{t}, \quad \text { where } \beta_{e}+\beta_{b}+\beta_{f}=1
$$

$R_{i s}$ represents the logarithmic return of fund $i$ in month $t, \alpha$ is the Jensen [1968] measure for outperformance, $\beta_{\varepsilon}$ the exposure to the market index $R_{m t}, \beta_{b}$ the exposure to the bond index $R_{b t}, \beta_{f}$ the exposure to the money market $R_{f t}$, and $\varepsilon_{t}$ the errot term. The model tests the attribution of the different indices to the return of the mutual fund. We use a standard

\footnotetext{
${ }^{25}$ Of course the performance might also be influenced by exposure to foreign stock markets. Tests against European and World indices show that the funds show some exposure to these foreign indices. However, we believe that this is mainly due to cross-listings and international financial integration and that it is not due to investments in foreign shares.
} 
OLS regression to estimate the coefficients. If $\hat{\beta}_{b}$ is not positive or the corresponding tstatistic is lower than one, we estimate (5.1) again without the bond return. As a proxy for the bond return we take the local JP Morgan government bond index and for the money market the local 1-Month-Interbank offer rate.

Table 5.8 presents the results for the whole sample period. Again, we split the sample by country and within a country by investment style. We first analyze the estimation of the equity exposure. As the funds are equity investors, we expect them the average value of $\hat{\beta}_{e}$ to be close to one. This means that funds are doing what they are supposed to do: investing in domestic stocks. Germany, the United Kingdom and the United States have a $\hat{\beta}_{e}$ of 0.93 . This means that the domestic equity mutual funds in these countries follow the market closely. In France, Italy and the Netherlands $\hat{\beta}_{e}$ is much lower, which indicates that the funds also have exposure to other assets markets. For example, we find a high bond exposure in Italy and France ${ }^{26}$. That is, the funds invest relatively a lot of their assets in bonds, despite the fact that they are equity investors. For the Dutch mutual funds it is not clear why the exposures to the local market is so low, but one of the explanations could be the dominance of Royal Dutch in the matket, which has a limited weight in the AEX.

26 We have used different local stock indices to test for benchmark sensitivity, but in contrast to Lehman and Modest [1987] this didn't change our findings. 
Table 5.8: Summary Statistics for Performance Measurement

\begin{tabular}{|c|c|c|c|c|c|c|c|}
\hline & $\hat{\alpha}$ & $T(\alpha)$ & $\hat{\beta}_{e}$ & $\hat{\beta}_{b}$ & $\mathrm{R}^{2}$ & $\mathrm{~N}$ & \%pos/neg \\
\hline \multicolumn{8}{|l|}{ France } \\
\hline Growth & 0.3 .3 & 0.14 & 0.72 & 0.04 & 0.85 & 55 & $2.0 / 0.0$ \\
\hline Index & -1.72 & -1.90 & 0.91 & 0.11 & 0.94 & 20 & $0.0 / 3.0$ \\
\hline Smaller companies & 2.37 & 0.65 & 0.70 & 0.16 & 0.80 & 24 & $21.0 / 0.0$ \\
\hline Total & 0.41 & 0.14 & 0.76 & 0.08 & 0.86 & 99 & $6.0 / 6.0$ \\
\hline \multicolumn{8}{|l|}{ Germany } \\
\hline Genenal & 0.29 & 0.14 & 0.90 & 0.00 & 0.92 & 46 & $9.0 / 2.0$ \\
\hline Growth & -1.87 & -0.93 & 0.93 & 0.00 & 0.88 & 5 & $0.0 / 0.0$ \\
\hline Income & -0.71 & -0.21 & 0.95 & 0.00 & 0.94 & 2 & $0.0 / 0.0$ \\
\hline Smaller companies & 5.72 & 1.27 & 1.25 & 0.17 & 0.82 & 4 & $50.0 / 0.0$ \\
\hline Total & 0.45 & 0.11 & 0.93 & 0.01 & 0.91 & 57 & $3.0 / 5.0$ \\
\hline \multicolumn{8}{|l|}{ Italy } \\
\hline Italian equity & 0.58 & 0.21 & 0.58 & 0.13 & 0.83 & 21 & $5.0 / 5.0$ \\
\hline Italian specialist & 0.24 & 0.09 & 0.73 & 0.06 & 0.90 & 16 & $0.0 / 6.0$ \\
\hline Total & 0.43 & 0.16 & 0.65 & 0.10 & 0.86 & 37 & $3.0 / 5.0$ \\
\hline \multicolumn{8}{|l|}{ Netherlands } \\
\hline Growth & 1.65 & 1.23 & 0.84 & 0.00 & 0.84 & 5 & $0.0 / 0.0$ \\
\hline Index & -1.03 & -0.70 & 0.95 & 0.00 & 0.88 & 3 & $0.0 / 0.0$ \\
\hline Smaller companies & 2.76 & 0.99 & 0.70 & 0.00 & 0.76 & 1 & $0.0 / 0.0$ \\
\hline Total & 0.88 & 0.46 & 0.79 & 0.00 & 0.84 & 9 & $0.0 / 0.0$ \\
\hline \multicolumn{8}{|c|}{ United Kingdom } \\
\hline Growth/Income & -1.83 & -0.67 & 0.95 & 0.03 & 0.86 & 79 & $1.0 / 5.0$ \\
\hline Income & -1.46 & -0.59 & 0.90 & 0.09 & 0.80 & 72 & $1.0 / 10.0$ \\
\hline Growth & -1.22 & -0.41 & 0.93 & 0.01 & 0.81 & 102 & $2.0 / 18.0$ \\
\hline Smaller companies & 1.15 & 0.29 & 0.95 & 0.00 & 0.79 & 51 & $17.0 / 0.0$ \\
\hline Total & -1.04 & -0.33 & 0.93 & 0.03 & 0.82 & 304 & $4.0 / 12.0$ \\
\hline \multicolumn{8}{|l|}{ United States } \\
\hline Aggressive Growth & -1.69 & -0.41 & 1.04 & 0.43 & 0.72 & 103 & $5.0 / 5.0$ \\
\hline Growth & -1.58 & -0.36 & 0.94 & 0.01 & 0.70 & 937 & $2.0 / 16.0$ \\
\hline Income & 0.70 & 0.31 & 0.72 & 0.10 & 0.82 & 144 & $3.0 / 6.0$ \\
\hline Growth/Income & -0.38 & -0.12 & 0.88 & 0.02 & 0.86 & 499 & $4.0 / 22.0$ \\
\hline Smaller companies & 0.83 & 0.14 & 1.02 & 0.08 & 0.81 & 413 & $29.0 / 2.0$ \\
\hline Total & -0.65 & -0.15 & 0.93 & 0.05 & 0.77 & 2096 & $8.0 / 14.0$ \\
\hline
\end{tabular}

This table presents the results of the estimation of (5.1) by country and investment style using monthly data for the period between 1991 and 1997. To test the model directly with OLS we rewrite (5.1) with the corresponding restriction. We then obtain the following expression:

$$
R_{i t}-R_{f t}=\alpha_{i}+\beta_{\text {equity }}\left(R_{m t}-R_{f t}\right)+\beta_{\text {bond }}\left(R_{b t}-R_{f t}\right)+\varepsilon_{t t}
$$

The first column gives the average value of $\alpha$, which is presented in annualized percentage terms. The second column gives the corresponding t-statistic equal to $\bar{\alpha}_{i} / V\left(\alpha_{i}\right)$. The third and fourth give the average of the estimated values for the two $\beta$ 's. The fifth column gives the adjusted $R^{2}$, and the sixth column the number of funds. The last column gives the percentages of significant $\alpha$ 's. 
To be able to analyze changes in the equity exposure, we also calculate the average crosssectional $\hat{\beta}_{e}$ through time using a rolling window of 36 months. Figure 5.5 presents these results, showing that the United States and the United Kingdom both have estimates close to one and constant through time. All other European countries, including the "low beta countries', show an increase of the average $\hat{\beta}_{e}$. This indicates that the funds are increasingly following the domestic equity benchmark. It seems that in the beginning of the period the funds were also investing in other assets than domestic stocks.

\section{Figure 5.5: Average Equity beta's for Individual Countries Through Time}

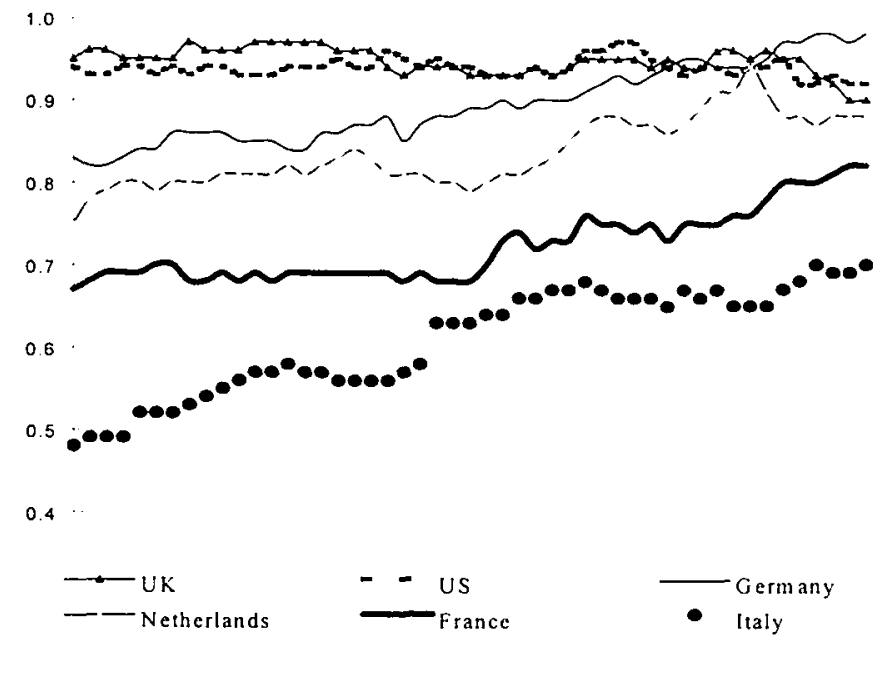

In this figure average $\hat{\beta}_{e}$ 's are plotted through time, by using a 36 -month moving window. The set-up of the figure is the sanc as in figures 5.3 and 5.4 .

Besides the possibility to analyze the equity exposure, our model also enables us to evaluate the performance of the funds by the estimation of $\alpha$. These results are presented in table 5.8 as well. In general the results do not differ from those presented in subsections 5.3.2 en 5.3.3. Again, we find that the average $\hat{\alpha}$ for the European funds is insignificantly different from zero. The United Kingdom and the United States have an annualized $\hat{\alpha}$ of minus $1.04 \%$ and minus $0.65 \%$ respectively. They are the only two countries with a negative performance. Table 5.8 also presents the percentage of funds that have a significant underperformance or outperformance. Again we see that the United Kingdom and the United States are the worst performers. In these countries $12 \%$ and $14 \%$ of the funds respectively underperform the benchmark significantly. 


\subsubsection{The Influence of Fees on Performance}

In tables 5.7 and 5.8 we show that the U.K. and U.S. mutual funds underperformed their relevant benchmarks. We expect to find this underperformance in mature and efficient markets. The underperformance can be completely explained by the costs funds charge. When we add back expenses to all the funds the $\hat{\alpha}$ 's range from $0.1 \%$ for the United Kingdom to $2.5 \%$ for Italy. This means that the negative $\hat{\alpha}$ 's we found for the United Kingdom and the United States become positive. This is in line with the general findings in the literature. Table 5.7 presents the average cost figures for each individual mutual fund class. The average fee varies between $0.5 \%$ for the Netherlands and $2.0 \%$ for Italy. Especially the fee paid for the French index funds is high with an average of $1.2 \%$, where Gruber [1996] reports average fees for American index funds equal to $0.23 \%$.

In the literature authors such as Chordia [1996] and Tufano and Sevick [1997] have studied mutual funds fees. We see that especially in the United States fees are high and moreover are growing each year. The fee of the average equity mutual fund (including international funds) is equal to $1.6 \%$ in 1997, whereas in 1992 the average fee was only $1.4 \%$. It is remarkable that fees are rising while we would expect them to fall because of economies of scale and increased competition. A possible explanation is the proliferation of new funds that tend to have higher expense ratios than older ones. Tufano \& Sevick [1997] offer another explanation why fund fees are high. They report that a higher number of directors on a board leads to higher salaries and quicker approval of higher fees.

\subsubsection{The Underperformance of European Index Funds}

The purpose of an index fund is to follow a particular index. From several studies (see for example Gruber [1996]) we know that activism does not pay and that the existence of index funds is beneficial for the investor. Gruber [1996] showed that, during the period 1990-1994, a sample of 100 S\&P 500 index-funds had $\beta$ s of 1 and $\alpha$ 's close to zero where actively managed funds had an average alpha of $-1.6 \%$ a year. Even after adding back expenses, the difference berween index funds and actively managed funds remained.

In our study we were only able to identify index funds in the Dutch and the French samples. The three Dutch index funds gave a lower performance than we expected with an average $\hat{\alpha}$ of minus 1.03 , a $\hat{\beta}_{e}$ of 0.95 , and an $\mathrm{R}^{2}$ of $88 \%$. The performance of the French index funds is also remarkable with a $\hat{\beta}_{e}$ of 0.91 , and a corresponding $\hat{\alpha}$ of 1.72. Furthermore, the expenses charged by the French funds are at $1.2 \%$ exceptionally 
high for these kinds of funds. Even after we add back these expenses the performance remains negative for both countries.

\subsubsection{The Outperformance of Small Cap Mutual Funds}

In this paragraph we discuss the remarkable result of the mutual funds that focus on smaller companies. In general these mutual funds outperformed their benchmark during the sample period. If we return to table 5.7, we see that in 4 out of 5 countries the return of the fund is higher than the appropriate small cap benchmark. We also see that the average return from these funds is higher than the averages from all other investment styles except for the German small cap funds. This is even more remarkable when we see that in all European countries (except for the Netherlands) the general equity index outperforms the small cap index. The observed outperformance is confirmed in table 5.8 where we present the results for the attribution analysis. The table shows that small company mutual funds have a positive $\hat{\alpha}$ in each country when we include the money and bond market in the regression. The percentage of small cap mutual funds outperforming the market is high as $27 \%$ of the funds have positive $\alpha$ 's significantly different from zeto. Therefore, this suggests that selection and timing abilities do play a role in this field. This might be due to the lower level of market efficiency in these less researched small cap markets.

\subsection{Conclusion}

In this chapter we take a closer look at the European mutual fund market and compare it with the United States using a traditional structure-conduct-performance paradigm. The contribution of the paper is that it is the first study, which analyzes the performance of the European market extensively.

In the paper, we find that Europe is still lagging the American mutual fund industry when it comes to total asset size, average fund size, and market importance. Furthermore, it appears that European citizens have a preference for fixed income mutual funds, whereas the American prefers the mutual funds investing in equity. Besides these findings we show that the mutual fund markets in the individual European countries are dominated by a few large domestic fund groups. This could possibly lead to lower levels of competition.

In our performance tests we observe five interesting findings. First, the European mutual funds have on average a better performance than their American counterparts. This is remarkable as we conclude from the earlier analysis that levels of competition might be lower in Europe. Theoretically we would assume the opposite. Second, we find a dramatic increase in the performance of the German mutual fund sector. Third, we show that the Italian, French, and Dutch mutual funds have a low exposure to their domestic equity benchmark. However, we also observe that this exposure is rising through time, which 
indicates that they are increasingly behaving as we expect them to do. Fourth, the results suggest that European index funds are not following pure index strategies. Finally, small cap mutual funds in both Europe and the United States outperform the benchmark and all other mutual funds. In this market segment mutual funds apparently add more value than their counterparts in the large cap segment. 


\section{CHAPTER 6}

\section{Performance and Information Costs of Real Estate Investments $^{27}$}

International investment can be a very effective way to spread the risk of a property portfolio ${ }^{28}$. Property markets are locally driven, which would suggest that the diversification benefits to be reaped from foreign property holdings can be substantial. Indeed, Eichholtz [1996] has shown that property markets have lower degrees of international correlation than stock and bond markets, and that international property investment is more effective in reducing overall portfolio risk than is the case for international investment in stocks and bonds. Nevertheless, while stock investors quite commonly invest abroad, property investors only do so vary rarely, with UK and Dutch investors as notable exceptions.

This may be caused by the fact that the direct property markets, the private markets for buildings and land, are less efficient than the public stock markets. International investment through non-efficient private markets like those for directly held property involves information costs. We expect that the less informed out-of-town investors may pay too much for properties, and tend to buy more lemons than their better-informed local competitors at these private markets. This would translate into lower risk-adjusted returns. International investors always face a trade-off between diversification benefits and information costs, and the optimal point on that trade-off is determined by the efficiency of the markets in which they operate. If markets are very inefficient, the information costs may be so high that all potential benefits of international diversification are outweighed. In that case, international investment will not occur.

\footnotetext{
27 This chapter is based on P.M.A. Eichholtz., C.G. Koedijk, and M. Schweitzer [1999], Global Property Investments: Public versus Private Markets, Jounal of Intemational Money and Finante, forthcoming.

28 This issue has been thoroughly documented by, among others, Grauer and Hakansson [1987], Liu and Mci [1996], Eichholtz [1996], and Eichholtz, Huisman, Koedijk, and Schuin [1998].
} 
Apart from information costs, international direct property investors face higher monitoring and transactions costs than international stock and bond investors. These costs may also imply a stronger focus on the home market than would be the case if property investments would be channeled through public markets.

If this argument is valid, the home bias of property investors will surely diminish with the development of the global property share market. This public market is probably more informationally efficient than the private property market, and that is why it allows investors to build up foreign property exposure without the information and monitoring costs this would entail in the direct property markets. This implies that the benefits of international diversification can be reaped at much lower costs.

The past 15 years have seen a strong worldwide growth in the number and size of the publicly listed real estate companies. The number of listed property companies has increased from 140 at the end 1984 to 360 in December 1995, while market value during the same period rose from $\$ 30$ billion to approximately $\$ 300$ billion. Listed property companies now exist in at least 30 countries $^{29}$. Publicly listed real estate companies come in two varieties: those which only invest in their own countries, and those which also invest abroad. These funds give us the opportunity to examine the difference between private and public markets and test our hypothesis that an international portfolio of companies which are only active in their own country provides a performance superior to a portfolio of international property companies.

To investigate the difference in performance between direct and indirect international real estate investment strategies, we start the chapter in section 6.1 with a short overview of the development of the international real estate securities market in the last 15 years. In section 6.2 we describe the data we use, which is from the GPR Global Real Estate Securities Database, and we present a first comparison between international real estate companies and portfolios of domestic companies. Section 6.3 is about research methods. We present different performance measures, and the way we use them for our purposes. Results are presented in section 6.4 , while section 6.5 gives some explanation for the results. Section 6.6 concludes the chapter.

\footnotetext{
29 All information is from the Real Estate Securities Database of Global Property Research (GPR). The database contains information about some 600 publicly listed real estate companies in 30 countries all over the world. In Europe - Austria, Belgium, Denmark, France, Germany, Ireland, Italy, the Netherlands, Norway, Portugal, Spain, Sweden, Switzerland, and the United Kingdom; in North America - Canada and the United States; in the Far East - Australia, Hong Kong, Indonesia, Japan, Malaysia, New Zealand, the Philippines, Singapore, Sri Lanka, and Thailand; and in the rest of the world - Argentina, Israel, Mexico, and South $A$ frica. For all property companies, the performance is tracked. Mote information about these indices can be found in Eichholtz and Koedijk [1996].
} 


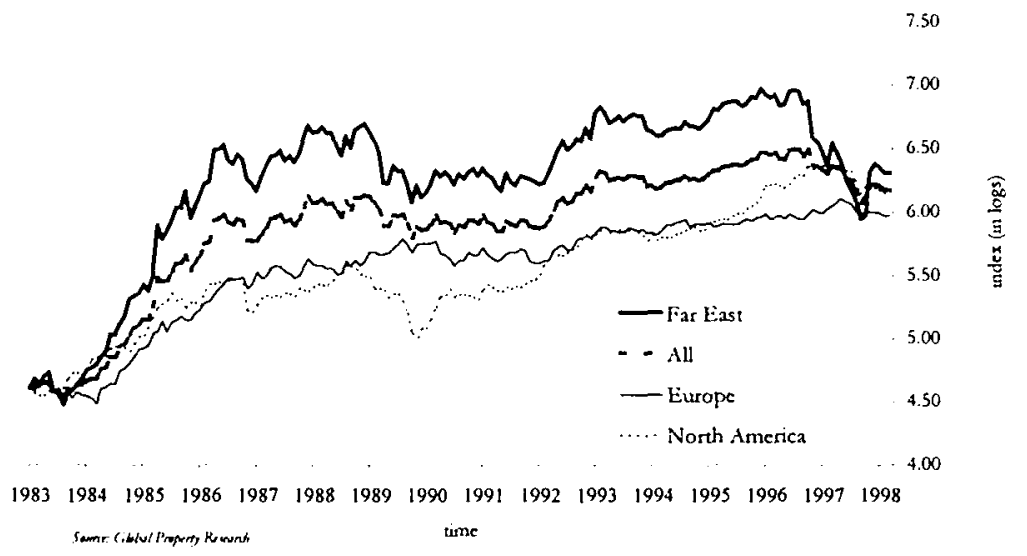

\subsection{The International Real Estate Securities Market}

The last decade has seen a remarkable growth in the number and size of the listed real estate securities. The performance of the real estate securities markets has differed markedly across continents. Figure 6.1 presents the GPR General real estate securities indices for the world and three continents. The indices are built in such a way that they represent the developments of the local markets. The indices are market-weighted total returns and presented in figure 6.1a. in US dollar and in figure 6.1.b in local currencies. Both figures present a similar picture. Survivorship bias is always an issue if the return of a company is evaluated against a benchmark. Global Property Research argues that their index is largely free of survivorship bias as they have checked for the existence of different property companies over the years and leave companies in the index for 12 months after the market capitalization dropped below the threshold level of 50 million US dollars. From figure 6.1 we see that the market in the Far East performed best until the downturn in 1997. Even before that time it also experienced the highest volatility. After 1993 the Far Eastern market was strongly influenced by the performance of the Hong Kong market, whereas in the end of the 1980s Japan dominated the market. North America and Europe show a less volatile performance. Table 6.1 shows that the standard deviation of the real estate securities returns in the Far East was 31 percent in the sample period, while it was only around 14 percent in Europe and North America. 


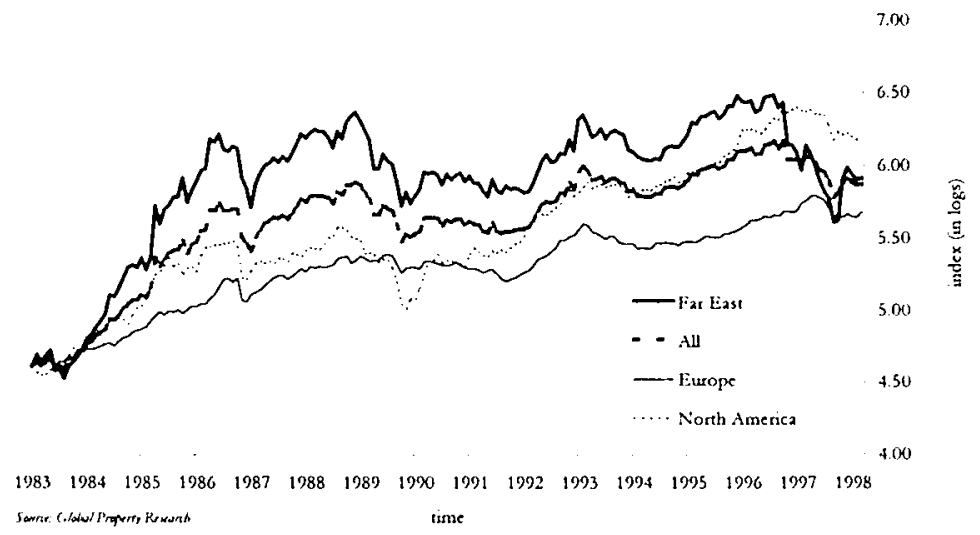

Table 6.1: Summary Statistics Indices, 1984-1998

\begin{tabular}{lrrrr}
\hline & $\begin{array}{r}\text { North } \\
\text { America }\end{array}$ & Europe & Far East & Global \\
\hline Average return & 10.44 & 9.23 & 11.64 & 10.67 \\
Standard deviation & 15.10 & 13.34 & 30.73 & 17.92 \\
\hline & & & & \\
Correlation coefficients & & & & \\
\hline Europe & 0.26 & & & \\
Far East & 0.29 & 0.33 & & \\
Global & 0.43 & 0.58 & 0.94 & \\
\hline
\end{tabular}

The upper panel of this table gives annualized average returns and standard deviations of the GPR-General and of three continental sub-indices in US dollats. The lower panel gives correlation coefficients between the different indices.

Table 6.1 also provides information on average returns and return correlation coefficients between real estate securities markets. The Far Eastern property securities markets generated an average annual return of 11.6 percent, while North America showed a 10.4 percent average return in the sample period. Table 6.1 also shows that the correlation coefficients between the continents are positive but rather low, with an average of around 0.35. This suggests a strong risk reduction potential for international real estate diversification and confirms earlier results by Sweeney [1989], Giliberto [1990], Gordon [1992] and Eichholtz [1996]. The correlation between the Far East and the world is very high with a level of 0.94 . We can explain this with the very volatile and dominant movements in the Far Eastern market. 


\subsection{International and Domestic Property Companies}

As we mentioned earlier, most property companies invest only or mainly in their own country. However, there are also a number of listed property companies with an international real estate portfolio. Many of these companies have been around for a long time. Before the expansion of the global real estate securities market, investing in these companies was the only practical way private and small institutional investors could build up international real estate exposure. This was probably the main reason for some property companies to follow an international investment strategy.

Before investigating the performance of these companies, we will first describe them in more detail. First, we have to decide where to draw the line between domestic and international property companies. We classify a company as domestic if it invests at least 75 percent of the portfolio in the country in which it has its main stock market listing. By the same definition, internationals invest at least 25 percent of their portfolio in one or more foreign countries ${ }^{30}$. Based on this classification, we select all 36 international property companies from the GPR Global Real Estate Securities Database. Appendix 6.A gives an overview of these companies.

\footnotetext{
30 Internationals therefore include both the companies that invest only in one forcign country and the companies that diversify by investing in more foreign countries. The cut-off point of $75 \%$ is rather arbitrary, but tests where we use a different cut-off point do not influence the results qualitative.
} 


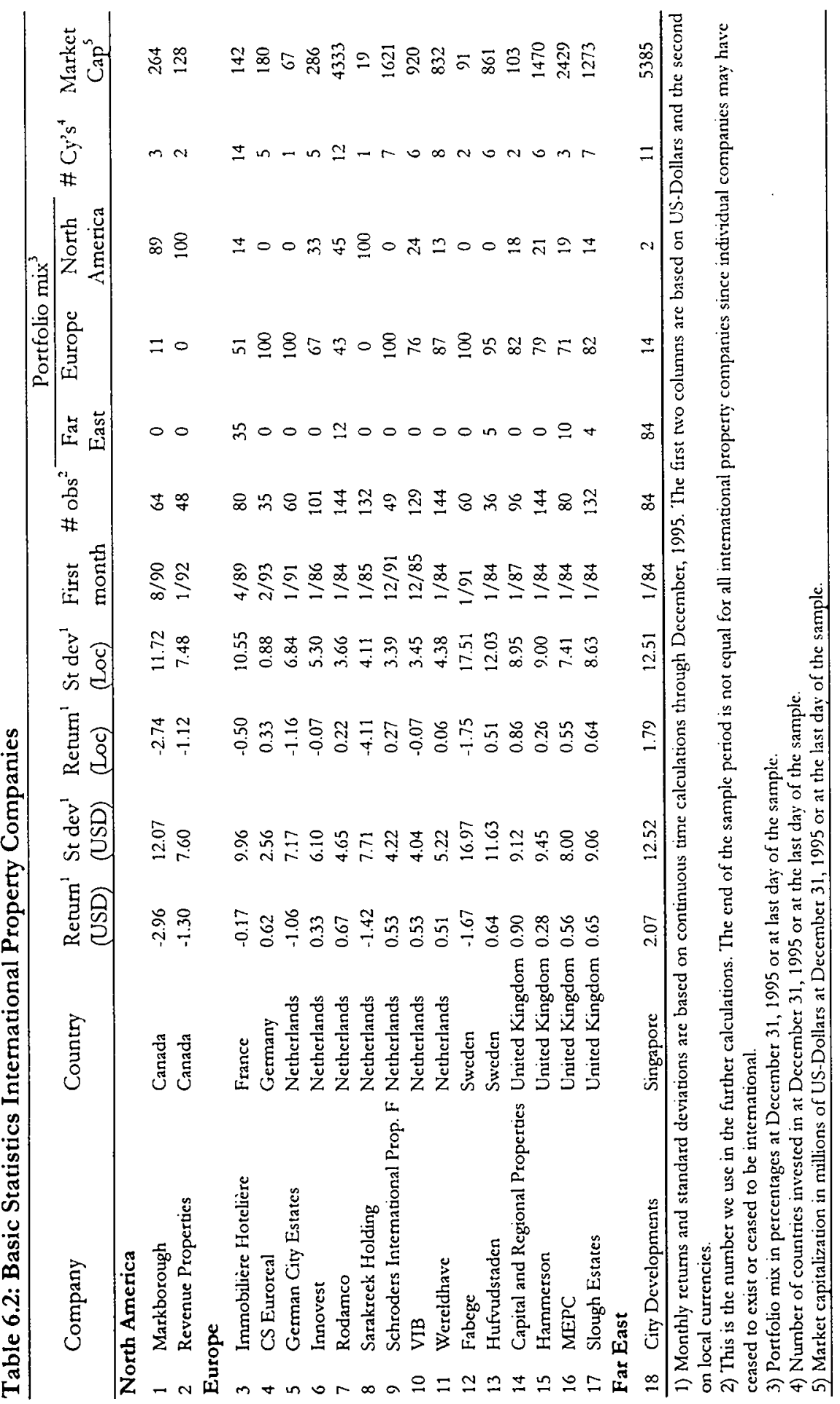


In the next step we teduce the number of internationals in our sample to 18 for two reasons. First, we exclude international Hong Kong property companies investing in mainland China since the close links between the two countries make it reasonable to assume that those companies are really domestic. Secondly, we leave out companies that do not meet all the criteria for inclusion in the GPR-General ${ }^{31}$. Table 6.2 lists the remaining 18 international property investment companies sorted by country. The table also provides sample statistics and basic information about their size and portfolio mix. All numbers are in nominal dollar terms.

As the table shows, most internationals originate from the Netherlands and the United Kingdom. Both countries have a long tradition of international investment, not only in property, but also in stocks, bonds and other assets. Columns $3,4,5$ and 6 of table 6.2 give mean returns, standard deviations, the first month for which we have an observation and the number of observations over which the statistics have been calculated. The average monthly returns of the international property companies have varied greatly in the sample period. The best performer was City Developments, with an average monthly return of 2.07 percent. There were 6 companies with a negative return in the sample period. Volatilities also differ substantially. Returns of German and Dutch property companies have been most stable with standard deviations of 2.56 and 4 to 8 percent respectively. Companies like Fabege (Swedish), City Developments (Singapore) and Markborough (British) have a much more volatile performance, with standard deviations of $16.97,12.52$ and 12.07 , respectively.

The next five columns in table 6.2 give information about the portfolio mix of the internationals, the number of countries they invest in and the market capitalization. These columns show that there are great differences in the portfolio composition of the international property companies. Some have all their assets in only one continent, or are very concentrated in only one continent, while others, like Rodamco (Dutch), Immobilière Hotelière (French) and MEPC (British) are truly globally diversified. The number of countries in which assets are held varies from 1 to 14 . In that regard, Immobilière Hotelière (French), Rodamco (Dutch), and City Developments (Singapore) are most diversified. The market caps of the internationals are higher than the average market cap of domestic property companies. That is, in December 1995 the international property companies had an average market capitalization of almost $\$ 1200$ million, whereas the domestic companies had about half: $\$ 700$ million. This could indicate that internationals were partly established to benefit from scale advantages. City Developments (Singapore), Rodamco (Dutch) and MEPC (British) are the largest international companies. The table does not show a clear relationship between the number of countries invested in and the sample statistics, or the market size of the companies.

\footnotetext{
${ }^{31}$ The main criteria for a company to be included in the index is a market capitalization of $\$ 50$ million.
} 


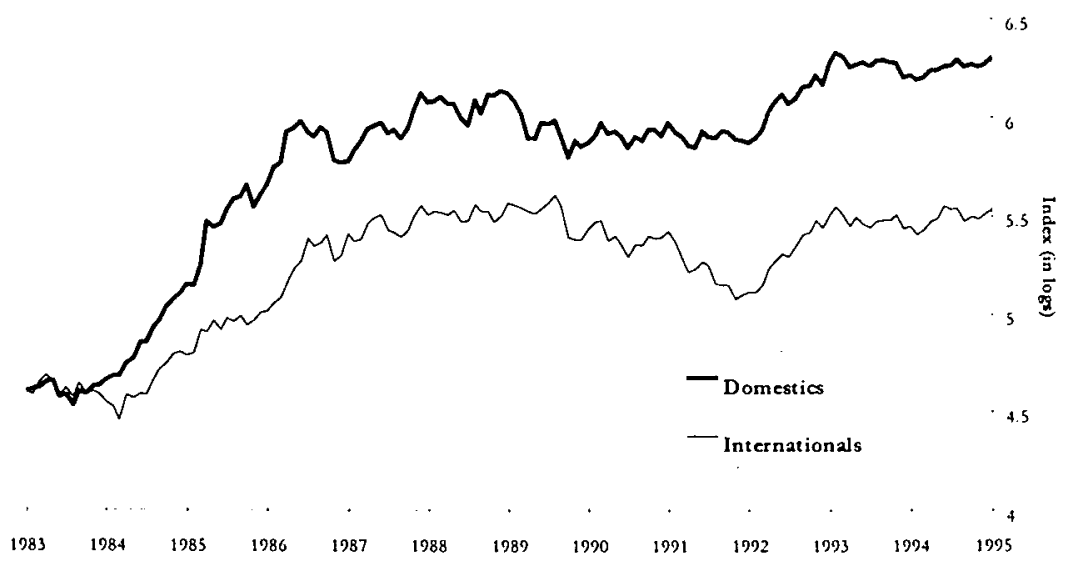

To get a first impression of the performance of these international property companies relative to the performance of the domestic companies, and to get a basic insight into our question of whether direct or indirect international property investment is better, we construct two indices combining the returns of all companies within each group. Figure 6.2 presents graphs of these two indices in log scales. This chart clearly shows that the domestic companies have performed much better on an overall basis. That is, the internationals have an annual average returns of 7.72 percent in contrast to 14.13 percent for the domestic index, or a return difference of 6.41 percent.

Table 6.3 gives annualized returns and standard deviations for the complete sample period and three 4-year sub-periods. Between 1984 and 1995, the standard deviations of the global index, the international index and the domestic index are 17.69 percent, 17.25 percent and 18.46 percent, respectively. The sample statistics for sub-periods show that the superior average return of domestic property companies relative to the internationals is consistent over time. Domestics have a higher average return than the internationals in all three sub-periods that we investigate. In the first and second sub-periods, the higher returns for the domestic indices come with higher standard deviations, but in the last subperiod the internationals have a standard deviation of 15.35 percent, which is higher than the 13.86 percent for the global index and 13.48 percent for the domestic indices. In all these periods, the intemationals are outperformed on a risk-adjusted basis. The results imply that the difference in performance between internationals and domestic property companies is not due to lower risk taken by the former. Thus, we may conclude that the worse performance of the internationals relative to the domestic property companies is evidence in favor of our hypothesis that internationals suffer from an information 
disadvantage that adversely affects their performance. In the next section we set up the empirical framework to investigate this issue more formally.

Table 6.3: Sample Statistics Internationals and Indices

\begin{tabular}{lcccccccc}
\hline & \multicolumn{2}{c}{$1984-1995$} & \multicolumn{2}{c}{$1984-1987$} & \multicolumn{2}{c}{$1988-1991$} & \multicolumn{2}{c}{$1992-1995$} \\
& Mean & St. dev & Mean & St.dev & Mean & St.dev & Mean & St.dev \\
\hline Global & 13.67 & 17.69 & 28.01 & 19.77 & 4.74 & 18.50 & 8.25 & 13.86 \\
Internationals & 7.72 & 17.25 & 20.28 & 19.34 & 0.26 & 16.61 & 2.63 & 15.35 \\
Domestics & 14.13 & 18.46 & 29.35 & 21.09 & 4.83 & 19.48 & 8.20 & 13.48 \\
\hline
\end{tabular}

The table gives annualized sample statisucs for the whole period and three different sub-periods based on monthly logarithmic returns in US Dollars and presents them in percentage terms.

\subsection{More formal tests of the price for information}

The previous section has given some preliminary evidence of the superior performance of domestic property investment companies relative to the internationals. However, the above comparison is rather crude, since it may well be that the total combined portfolio of the internationals has a different composition than the combined portfolio of the domestic companies. The difference in performance we find between these two groups could therefore be a consequence of diverging portfolio compositions instead of investment strategies. In fact, as can be seen from table 6.2, internationals as a group invest relatively little in the Far East, and as we showed in table 6.1, the returns in this continent have been much higher than in the other continents. To deal with this, we build for each international real estate company a mimicking index including only domestic companies, with the same combined portfolio composition as that particular international company. This mimicking index reflects the performance the international company would have had if it had not bought, managed and sold its properties itself but had selected local (domestic) property companies to do that for it. In this approach, we therefore compare real estate portfolios that are equal in composition. They only differ in how they are built up: through direct international real estate investment or through indirect investment. Comparing these portfolios directly tests our hypothesis.

For all property companies we collect monthly performance data from January 1984 through December 1995. We take share prices at the last day of the month and reinvest all dividends. All indices are constructed in US dollar terms. The information about the portfolio allocation of the internationals is collected from the annual reports. Hence, we change the composition of the mimicking indices annually at the reporting day in the annual report. We collect portfolio information about the geographical spread of investments on the country level. However if a company only presents the composition on a continental level we use that. In most cases the annual reports present the geographical spread of the portfolio in terms of asset value. If the reports do not present 
the value of the investments directly, we use the square feet of the properties as a proxy. This information is available for all companies in the sample, and the only assumption that we have to make is that the value of each square foot is equal over the different countries.

First, we construct a total return index in US dollars for each international property company:

$$
I_{t}=I_{t-1}\left(1+\frac{P_{t}-P_{t-1}+D V_{t}}{P_{t-1}}+\frac{P_{t}+D V_{t}}{P_{t-1}} R_{s t}\right)
$$

In which $P_{t}$ is the stock price at the end of month $t, D V /$ is the dividend in month $t, R_{t}$ is the depreciation of the dollar relative to the company's home currency, and $I_{0}=100$.

Then, we calculate a customized mimicking index for each international property company, based on the returns of the domestic property companies, but with the portfolio weights of that particular international:

$$
I_{t}=I_{t-1}\left(1+\sum_{i=0}^{i=m t}\left(w_{i t} * R_{t t}\right)\right)
$$

In which $w_{i t}$ is the percentage invested in country or continent $i$ in month $t$ by the international company, $R_{i t}$ is the return of domestic index $i$, expressed in US dollars, $I_{t=0}$ is 100 , and $n t$ is the total number of countries in which the company has invested in month t.

We compare the internationals with their customized indices using two performance measures: the Sharpe ratio and Jensen's alpha. Both measures are derived from the Capital Asset Pricing Model, but in this chapter mainly used a general description. The Sharpe measure gives an indication of the return in respect to the total risk of an asset measured by the standard error of the returns. A higher ratio indicates a better performance since it implies a higher return for a given level of risk. The following formula represents the Sharpe ratio:

$$
S=\frac{R_{i}-R_{f}}{s_{i}}
$$

In which $R_{i}$ is the average return of the individual company or index, $R_{f}$ is the risk free rate, and $s_{i}$ is the standard deviation of the return. 
For each international and its corresponding customized index, we calculate the Sharpe measure. As we denominated all share prices in US dollars we use the US risk free rate. As a proxy for the latter we use the 1 -month T-bill rate.

The Jensen Alpha determines whether a company out- or underperforms the market or an index by investigating whether the performance is significantly different from what we would expect from the security market line. It measures the performance difference by $\alpha$ in $(6.4)$ :

$$
R_{i t}-R_{f i}=\alpha_{i}+\beta_{i}\left(R_{m t}-R_{f t}\right)+\varepsilon_{i t}
$$

Where $R_{i t}$ is the continuously calculated return of the international property company, $R_{f t}$ is the risk free rate, $R_{m t}$ is the return of the market index, and $\varepsilon_{i t}$ is an error term.

In asset pricing tests it is always difficult to determine which benchmark to use. In the first test we use our mimicking index as the market index. Doing this enables us to compare the performance of international property companies with the domestic property companies directly. We present the results in section 6.4 and in section 6.5 we extend the tests to account for possible biases.

\subsection{Results}

In this section we present the results of the performance tests and see whether there is indeed a cost to diversification in markets with private information. Before presenting the Sharpe Ratio and the Jensen Alpha, we present and discuss figure 6.3, which compares international and domestic property companies while correcting for the country allocation of the internationals. In figure 6.2 we presented the performance of all domestic companies versus the performance of the 18 internationals. We explained that the better performance by the domestic companies could be due to overweighing the Far East market, as the internationals did not invest as much in the Far East. Therefore, we recalculate the index of the domestic companies with a correction for country allocation decisions. It is simply the market-weighted summation of all mimicking indices. Figure 6.3 shows that the internationals are still outperformed by the domestics. The index of the internationals is exactly the same and increases from 100 in 1984 to 252 in 1995 , whereas the aggregate mimicking index increases from 100 in 1984 to 348 in 1995. The average annual returns are 7.7 percent and 10.4 percent respectively. If we make the comparison with figure 6.2, we see that the internationals are still outperformed by the domestic companies, but that indeed some of the difference was due to the country allocation. The remaining average difference of 2.7 percent annually is an indication of the cost of international diversification in non-public markets. This result suggests that international diversification is not a free lunch in private markets. 
Figure 6.3: Internationals and Aggregate Customized Index

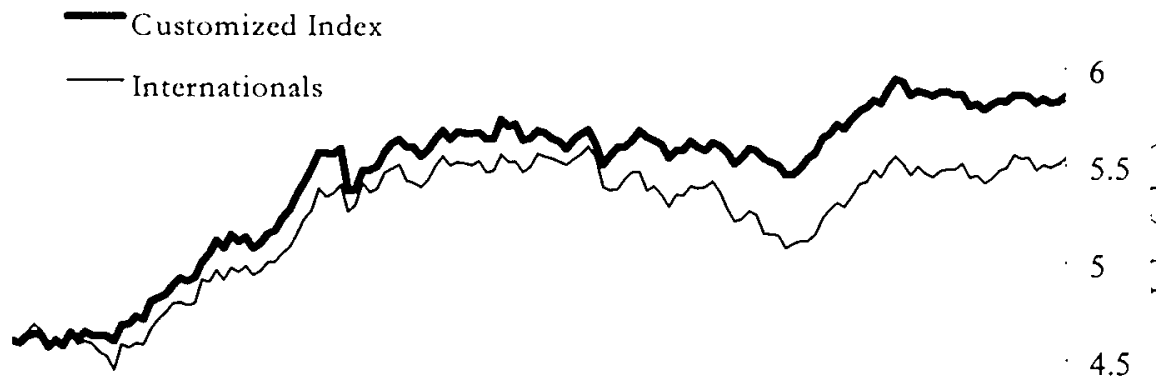

4

$\begin{array}{lllllllllllll}1983 & 1984 & 1985 & 1986 & 1987 & 1988 & 1989 & 1990 & 1991 & 1992 & 1993 & 1994 & 1995\end{array}$

Table 6.4 presents the summary statistics for these two indices. This once again shows that the domestic property companies outperform the internationals. We also present in this table the Sharpe ratio of the combined international index and of the aggregate mimicking index. These are 0.04 and 0.09 respectively, which is further evidence for the better performance of the domestics.

Table 6.4: Performance at Portfolio level

\begin{tabular}{lllllllllllll}
\hline \multicolumn{3}{c}{$1984-1995$} & \multicolumn{3}{c}{$1984-1987$} & \multicolumn{3}{c}{$1988-1991$} & \multicolumn{3}{c}{$1992-1995$} \\
& Mean & St.dev & Sharpe & Mean & St.dev & Sharpe & Mean & St.dev & Sharpe & Mean & St.dev & Sharpe \\
\hline Internationals & 7.72 & 17.25 & 0.04 & 20.28 & 19.34 & 0.20 & 0.26 & 16.61 & -0.11 & 2.63 & 15.35 & -0.02 \\
Customized & 10.41 & 15.44 & 0.09 & 21.90 & 18.47 & 0.24 & 3.63 & 14.91 & -0.06 & 5.69 & 12.04 & 0.05 \\
Difference & 2.70 & & & 1.62 & & & 3.37 & & & 3.06 & &
\end{tabular}

The table gives annualized monthly summary statistics (mean and standard deviation) in percentages for the portfolio of the international property companies and the market-weighted combination of all customized indices. The Sharpe ratios are calculated on a monthly basis

To get a more detailed picture of this outperformance, we present Sharpe ratios for the individual international property companies versus the ratios for the corresponding mimicking indices in figure 6.4. The Sharpe measures of the internationals are given on the horizontal axis, while the $\mathrm{Y}$-axis gives the Sharpe measures of the corresponding mimicking indices. Thus, a dot to the right of the 45-degree line implies superior performance for the internationals. The figure shows that only 4 internationals show this superior performance relative to their customized index. The other 14 are beaten by it. The outperformers are Fabege and Hufvudstaden (Sweden), City Developments (Singapore), and Schroders (Netherlands). It seems that the Swedish companies were able to deal with the crash of the domestic real estate market very effectively. Using a onesample binomial test, we investigate whether the outperformance of the domestic 
mimicking portfolios is significant. We find a test statistic of 5.56 , which has a $\chi^{2}$ distribution with one degree of freedom and which therefore implies significance at the 97.5 percent level. As a summary measure we also present in figure 6.4 the Sharpe ratios of the overall portfolios of indirect and direct real estate investment. This is the solid point in the graph.

Figure 6.4: Sharpe Ratios 1984-1995

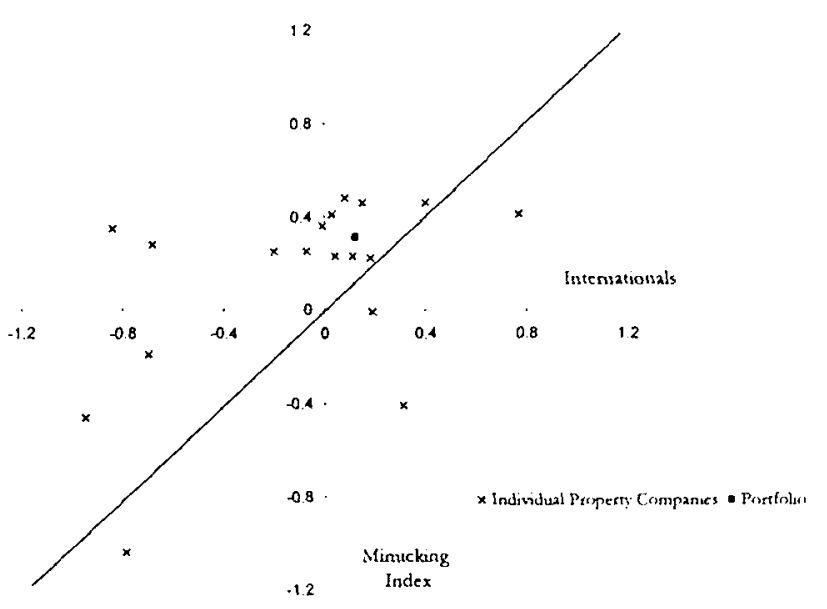

Table 6.5 presents the results of the regression of (6.4). It clearly shows that most companies have a negative Jensen $\alpha$, which suggests that the internationals underperform their own domestic customized indices. However, only Sarakreek has an $\alpha$ that is significantly negative. There are five companies that have a positive $\alpha$, but none of these values is significant. Three out of the four companies that had a higher Sharpe ratio than their mimicking index have a positive $\alpha$ as well. Only Fabege had a higher Sharpe ratio, but a lower Jensen $\alpha$. CS Euroreal and Capital \& Regional Properties have a positive $\alpha$, but had a lower Sharpe ratio than their corresponding index. 
Table 6.5: Performance Based on Market Risk

\begin{tabular}{lrrrrrrl}
\hline & \multicolumn{1}{c}{$\alpha$} & \multicolumn{1}{c}{$\mathrm{t}$} & $\beta$ & $\mathrm{t}_{\beta}=0$ & $\mathrm{t}_{\beta=1}$ & $\mathrm{n}$ & $\mathrm{R}^{2}$ \\
\hline Markborough & -2.40 & -1.92 & 1.57 & 5.76 & 2.10 & 64 & 0.35 \\
Revenue Properties & -1.57 & -1.35 & 0.27 & 0.85 & -2.26 & 48 & 0.02 \\
Immobilière Hoteliere & -0.72 & -0.65 & 0.49 & 1.74 & -1.81 & 80 & 0.04 \\
CS Euroreal & 0.05 & 0.15 & 0.67 & 6.32 & -3.08 & 35 & 0.55 \\
German City Estates & -1.62 & -1.82 & 0.73 & 2.78 & -1.01 & 60 & 0.12 \\
Innovest & -0.36 & -0.59 & 0.91 & 5.28 & -0.54 & 101 & 0.22 \\
Rodamco & -0.03 & -0.07 & 0.44 & 4.71 & -5.96 & 144 & 0.14 \\
Sarakreek Holding & -1.96 & -2.90 & 0.17 & 1.20 & -5.76 & 132 & 0.01 \\
Schroders & 0.24 & 0.52 & 0.75 & 6.22 & -2.04 & 49 & 0.45 \\
VIB & -0.22 & -0.71 & 0.66 & 7.38 & -3.80 & 129 & 0.30 \\
Wereldhave & -0.28 & -0.75 & 0.73 & 7.32 & -2.67 & 144 & 0.27 \\
Fabege & -2.24 & -0.85 & 0.42 & 3.35 & -4.71 & 60 & 0.16 \\
Hufvudstaden & 2.05 & 1.04 & 0.32 & 3.59 & -7.75 & 36 & 0.27 \\
Capital and Regional Properties & 0.17 & 0.21 & 0.99 & 0.46 & -0.08 & 96 & 0.31 \\
Hammerson & -0.71 & -1.37 & 1.56 & 13.86 & 5.00 & 144 & 0.58 \\
MEPC & -0.38 & -1.15 & 1.18 & 21.06 & 3.19 & 80 & 0.76 \\
Slough Estates & -0.19 & -0.39 & 1.23 & 15.76 & 2.99 & 132 & 0.66 \\
City Developments & 1.28 & 1.80 & 1.02 & 9.36 & 0.17 & 84 & 0.52 \\
Internationals Index & -0.21 & -1.05 & 0.98 & 21.37 & -0.53 & 144 & 0.76 \\
\hline
\end{tabular}

This table gives the results of the estimation of equation 4. Column 2 gives the estrimation of $\alpha$ in percentages per month. Column 3 gives the corresponding t-statistic. Column 4 gives the $\beta$ estimation. Column 5 gives the $t$-statistic for $\beta$ equal to zero and column 6 gives the t-statistic for $\beta$ equal to one. Column 7 gives the sample size and column 8 the $\mathrm{R}^{2}$.

To test whether the $\alpha$ 's together are significantly different from zero we use a methodology developed by Gibbons et. al (1989). The test statistic reads as follows: $\mathrm{J}=\hat{\alpha}^{\prime}(\operatorname{Var}(\hat{\alpha}))^{-1} \hat{\alpha}$, where $\hat{\alpha}$ is a vector of the estimated $\alpha^{\prime}$ 's for all international property companies. If we calculate the statistic for the whole sample period we get a value of 34.02 which has a $\chi^{2}$ distribution with 18 degrees of freedom and is therefore significant at the 5 percent level. This means that the international property companies indeed underperform the domestic property companies. 


\subsection{Explanation of the test results}

In this section we discuss our test results. We will give several possible explanations and discuss and test their impact on our information hypothesis.

\subsubsection{Transaction costs}

A possible difference in performance might be caused by the transaction costs. Even though there is quite a huge literature on index tracking, which means that the funds don't have to buy all funds in the index to have roughly the same return characteristics as the index itself, they still have to buy many individual property companies to mimick the portfolio ${ }^{32}$. The cost to mimick the portfolio was not included in the analysis so far, whereas for the international property companies these costs are already reflected in the stock returns. To correct for this possible bias we calculate the monthly changes in the weights of the portfolio.

$$
\Delta W=\frac{\sum_{i=1}^{N}\left|w_{i, t}-w_{i, t-1}\right|}{N}
$$

In which $N$ is the number of datapoints that we have (the summation of the number of months for one fund over the different funds), $w$ is the weight of the parricular property company in a single country. In our sample we have a total of 1702 datapoints (from 18 companies with a maximum of 144 months), which gives a $\Delta W$ equal to $1.36 \%$. This means that $0.68 \%$ of the total portfolio is bought and sold each month. If we annualize this figure we get a $16.32 \%$ change in the portfolio each year. This number does not incorporate the initial purchase of the portfolio or possible expansion of the portfolio. To estimate the cost involved with this change in the portfolio we surveyed some banks in Europe and asked them for the transaction cost they use in their calculations. For Europe they use $0.50 \%$ as an estimate for the cost to buy stocks, $0.75 \%$ for stocks in the United States, and $1.00 \%$ for stocks in the Far East. If we combine these figures with the change of the portfolio we get a total cost figure of maximum $0.20 \%$, which we should subtract from the difference between the internationals index and the mimicked index. This means that the calculated difference of $2.7 \%$ should be reduced to $2.5 \%$, which is still a very significant number. The cost to mimick the portfolio is therefore not a possible explanations for the underperformance of the international property companies.

\footnotetext{
32 Another possible explanation for the difference in performance could be the service international propert: companies offer investors. By buying the shares of international property companies investors don't have to face transaction costs to purchase different properties themselves. It could be possible that they are willing to pay a premium for this service.
} 


\subsubsection{Currengy and leverage effects}

The international propercy companies might influence the performance by hedging some of the currency risk and by using debt to finance the properties as well. We calculated the mimicked index in all previous tests on an unhedged basis. This means that these indices do not incur the cost to hedge the portfolio. Furthermore, the internationals as well as the domestic property companies might use debt to finance the operations, which might influence the results. To correct for these effects several tests are possible. We chose, to be consistent with our previous tests, to expand (6.4) in the following way:

$$
R_{u}-R_{f t}=\alpha_{i}+\beta_{i}\left(R_{m t}-R_{f t}\right)+\gamma_{l} R_{b j, l}+\gamma_{Y e n} R_{Y e n, t}+\gamma_{D M} R_{D M, t}+\varepsilon_{t t}
$$

In which the last three $\mathrm{R}$ terms are added to the equation. The first variable corrects for the leverage and the last two for the currency. We estimate this equation for each fund with OLS as all variables are orthogonal to the error term. For $R_{b j, t}$ we use the monthly yield on the all lives government bond index for the United States calculated by Datastream. $R_{y r n,}$ and $R_{D m}$, represent the logarithmic return on exchange rates between the US dollar with the Japanese Yen and the German Mark respectively. We chose these currencies as they capture most variation in the exchange rate market. 
Table 6.6: Estimation of the Extended Model

\begin{tabular}{|c|c|c|c|c|c|c|c|}
\hline & $\alpha$ & $\beta$ & $T_{\text {lcv }}$ & tYen & $\mathrm{td}_{\mathrm{m}}$ & $\mathrm{R}^{2}$ & $Q_{\text {stat }}$ \\
\hline Markborough & $\begin{array}{c}-8.56 \\
(-0.77)\end{array}$ & $\begin{array}{c}1.61 \\
(5.64)\end{array}$ & 0.55 & .0 .14 & 0.36 & 0.35 & 12.08 \\
\hline Revenue Properties & $\begin{array}{c}9.32 \\
(0.70)\end{array}$ & $\begin{array}{c}0.22 \\
(0.62)\end{array}$ & -0.82 & -0.11 & 1.08 & 0.07 & 11.02 \\
\hline Immobilière Hotelière & $\begin{array}{c}-5.99 \\
(-0.66)\end{array}$ & $\begin{array}{c}0.93 \\
(2.60)\end{array}$ & 0.61 & 1.55 & 0.86 & 0.10 & 5.43 \\
\hline CS Euroreal & $\begin{array}{c}-1.22 \\
(-0.69)\end{array}$ & $\begin{array}{c}0.14 \\
(1.54)\end{array}$ & 0.70 & 0.30 & -7.51 & 0.87 & 2.40 \\
\hline German City Estates & $\begin{array}{c}5.02 \\
(0.60)\end{array}$ & $\begin{array}{c}0.45 \\
(0.30)\end{array}$ & -0.77 & 1.07 & -0.32 & 0.15 & 7.64 \\
\hline Innovest & $\begin{array}{c}1.43 \\
(0.31)\end{array}$ & $\begin{array}{c}0.64 \\
(3.31)\end{array}$ & -0.46 & -1.84 & -1.14 & 0.31 & 11.35 \\
\hline Rodamco & $\begin{array}{c}0.52 \\
(0.34)\end{array}$ & $\begin{array}{c}0.28 \\
(3.53)\end{array}$ & -0.54 & -0.16 & -6.40 & 0.44 & 17.30 \\
\hline Sarakreek Holding & $\begin{array}{c}-7.00 \\
(-1.59)\end{array}$ & $\begin{array}{c}0.19 \\
(1.32)\end{array}$ & 1.15 & -0.73 & 0.49 & 0.03 & 12.06 \\
\hline Schroders & $\begin{array}{c}-0.67 \\
(-0.14)\end{array}$ & $\begin{array}{c}0.60 \\
(4.40)\end{array}$ & 0.16 & 0.77 & -3.84 & 0.61 & 14.88 \\
\hline VIB & $\begin{array}{c}-2.00 \\
(-1.03)\end{array}$ & $\begin{array}{c}0.38 \\
(3.60)\end{array}$ & 0.85 & -0.54 & -3.22 & 0.41 & 19.71 \\
\hline Wercldhave & $\begin{array}{c}-0.99 \\
(-0.55)\end{array}$ & $\begin{array}{c}0.42 \\
(3.30)\end{array}$ & 0.32 & -1.14 & -3.14 & 0.37 & 11.21 \\
\hline Fabege & $\begin{array}{l}17.31 \\
(0.73)\end{array}$ & $\begin{array}{c}0.37 \\
(2.83)\end{array}$ & -0.86 & -1.14 & 1.53 & 0.21 & 30.02 \\
\hline Hufvudstaden & $\begin{array}{l}32.86 \\
(1.71)\end{array}$ & $\begin{array}{c}0.35 \\
(3.62)\end{array}$ & -1.61 & 0.69 & -0.83 & 0.34 & 13.10 \\
\hline Capital and Regional Properties & $\begin{array}{c}-4.04 \\
(-0.62)\end{array}$ & $\begin{array}{c}1.00 \\
(6.23)\end{array}$ & 0.65 & -0.28 & -0.24 & 0.31 & 13.03 \\
\hline Hammerson & $\begin{array}{c}-2.67 \\
(-1.01)\end{array}$ & $\begin{array}{c}1.53 \\
(12.97)\end{array}$ & 0.72 & -1.11 & 0.01 & 0.58 & 13.80 \\
\hline MEPC & $\begin{array}{c}-1.48 \\
(-0.87)\end{array}$ & $\begin{array}{c}1.16 \\
(19.44)\end{array}$ & 0.63 & -0.58 & -0.42 & 0.76 & 20.10 \\
\hline Slough Estates & $\begin{array}{c}-1.15 \\
(-0.46)\end{array}$ & $\begin{array}{c}1.24 \\
(15.12)\end{array}$ & 0.36 & -2.21 & 2.39 & 0.67 & 8.37 \\
\hline City Developments & $\begin{array}{c}6.21 \\
(1.14)\end{array}$ & $\begin{array}{c}1.01 \\
(8.99)\end{array}$ & -0.91 & 0.10 & 0.33 & 0.52 & 18.10 \\
\hline Internationals index & $\begin{array}{c}-0.13 \\
(-0.14)\end{array}$ & $\begin{array}{c}0.89 \\
(20.33) \\
\end{array}$ & -0.22 & -0.56 & -4.11 & 0.81 & 8.12 \\
\hline \multicolumn{8}{|c|}{$\begin{array}{l}\text { This table gives the results of the estimation of equation } 6 \text {. Column } 2 \text { and } 3 \text { give the estimation of the annualized } \alpha \text { and } \\
\beta \text {. The t-statistics are in parenthesis. Columns } 4 \text { through } 6 \text { give t-statistic for the leverage effect, the exchange rate with } \\
\text { the Japanese Yen, and the German Mark. Both exchange rates are stated in foreign eurrency per } 1 \text { U.S. dollar. Column } \\
\text { gives the } R^{2} \text { and the last column the Q-statistic. We calculated this value with } 10 \text { lags, which gives a critical value of } 18.3 \\
\text { with a confidence level of } 95 \% \text {. The statistic is } \chi \text {-distributed. For our sample this means that for most companies the } \\
\text { error terms are white noise. }\end{array}$} \\
\hline
\end{tabular}

Table 6.6 presents the results of the estimation of (6.6) for all funds. For the three factors, we extend the model with, we present the $t$-statistics to see whether they influence the analysis. The first factor is the yield on the U.S. government bond, correcting for leverage effects. For none of the companies the coefficient is significant and is thus not affecting the regression. In contrast to our expectations for only seven companies the value is negative. We expected that the value would be negative as the property companies are 
financing their operations with debt as well. In this case an increasing yield would have a negative effect on performance. The currency effects are larger. Especially the German Mark has a significant impact on the performance of 6 companies and the Japanese Yen on one. In our sample 10 companies have a negative coefficient, which means that the performance is negatively affected if the exchange rate increases.

The use of the correcting factors has an effect on our measure of outperformance as well. First of all none of the companies give a significant out- or underperformance anymore. Secondly, the number of companies with a positive value of $\alpha$ increased to seven. This means that the factors indeed do explain parts of the performance of the property companies.

To test whether the error terms are white noise we use a Q-statistic. The critical value for 10 lags is 18.31. In table 6.6 we see that we reject the hypothesis for white noise for three companies. These companies are Schroders, Wereldhave and Hammerson. The residual return of all other property companies does not exhibit autocorrelation.

\subsubsection{Size effects}

An effect that gives investors the possibility to reduce the cost of information is to grow in size. Our hypothesis is that international property companies can overcome the information disadvantage as they grow larger. In this way they can become so big that they are actually a local player. As a fact we can show that there exists a positive correlation between market capitalization and the $\alpha$ of a property company by doing the following regression:

$$
\alpha_{t}=\gamma_{0}+\gamma_{1} X_{t}+\eta_{i}
$$

In which $\alpha_{i}$ is the result of (6.4) for company $i$, and $X_{i}$ the average market size of property company $i$. We assume that the market capitalization is a proxy for the size of the portfolio, which might introduce a bias as internationals have different debt ratios.

The output of the regression of $(6.10)$ shows that the value of $\gamma_{1}$ is significantly positive at a 5 percent confidence interval. This means that a property company can benefit from scale advantages to deal with the information problems more effectively. This could be a reason for the higher market capitalization of internationals compared to domestic companies as shown in section 6.2 .

\subsubsection{Influence of local stock market developments}

Using our mimicking index assumes that stock performance is solely determined by cash flows generated by the investments in foreign buildings and properties. As the fund is, however, listed at their domestic exchange the performance might also be affected by local sentiments. To check for this possible bias we calculate a domestic index excluding 
the internationals and compare that with the international property company. We found that 6 out of 18 companies outperformed their domestic index whereas the other 12 still underperform the market. This shows that information costs do indeed influence the performance of international real estate operations.

\subsection{Conclusion}

It is well-known stylized fact that international diversification can improve investment performance. An important question that has not received much research attention is how to implement an international investment strategy. In the past this was not really an issue as there was only one way to do this: directly. That is to buy the investment object yourself in the private market. Whereas currently, with increased securitization, the investor can also take what is called the indirect route, that is buying securities listed on an exchange. In this chapter we use an unique data-set of listed property companies that provide us with the possibility to compare direct and indirect international investment strategies. Our results indicate that indirect investment strategies are clearly superior. They outperform the so-called direct strategies with $2.7 \%$ on an annual basis. The tests that were carried out to correct for possible biases did not change this conclusion at all. 
APPENDIX 6.A:

\section{Database Internationals}

\begin{tabular}{|c|c|c|c|}
\hline Name & Country & incl. & reason if not included \\
\hline \multicolumn{4}{|l|}{ North America } \\
\hline 1 Carena Development & Canada & $\mathrm{n}$ & capital market transactions disturb the picture \\
\hline 2 Revenue Prop. & Canada & y & \\
\hline 3 Trizec & Canada & n & $\begin{array}{l}\text { capital market transactions disturb the } \\
\text { picture }\end{array}$ \\
\hline \multicolumn{4}{|l|}{ Europe } \\
\hline 4 Immob. Hoteliere & France & $y$ & \\
\hline 5 Arico & Germany & $\mathrm{n}$ & does not fulfill criteria GPR index \\
\hline 6 CS Euroreal & Germany & y & \\
\hline 7 Jolly Hotcls S.p.a. & Italy & $\mathrm{n}$ & does not fulfill criteria GPR index \\
\hline 8 German City Estates & Netherlands & $y$ & \\
\hline 9 Innovest & Netherlands & $y$ & \\
\hline 10 Rodamco & Netherlands & y & \\
\hline 11 Sarakreck Holding & Netherlands & y & \\
\hline 12 Schroders Intemational Property Fund & Netherlands & y & \\
\hline $13 \mathrm{VIB}$ & Netherlands & y & \\
\hline 14 Wereldhave & Netherlands & y & \\
\hline $15 \mathrm{ZOM}$ Flonda Fund & Netherlands & $\mathrm{n}$ & does not fulfill criteria GPR index \\
\hline 16 Fabege & Sweden & y & \\
\hline 17 Hufvudstaden & Sweden & y & \\
\hline 18 Intershop Holding $\lambda G$ & Suritzerland & $\mathrm{n}$ & docs not fulfill criteria GPR index \\
\hline 19 Capital and Regional Properties & United Kingdom & y & \\
\hline 20 Hammerson & United Kingdom & y & \\
\hline 21 Markborough & United Kingdom & y & \\
\hline 22 MEPC & United Kingdom & $y^{\prime}$ & \\
\hline 23 Slough Estates & United Kingdom & y & \\
\hline \multicolumn{4}{|l|}{ Far East } \\
\hline 24 Ansal Properties \& Industries Ltd. & India & $n$ & does not fulfill criteria GPR index \\
\hline 25 Asian Properties Linuted & Hong Kong & $n$ & does not fulfill criteria GPR index \\
\hline 26 CDL Hotels International Limited & Hong Kong & $\mathrm{n}$ & does not fulfill criteria GPR index \\
\hline 27 Henderson Land. Dev & Hong Kong & $\mathrm{n}$ & invests mainly in China \\
\hline 28 Hong Kong China Ltd. & Hong Kong & $\mathrm{n}$ & invests mainly in China \\
\hline 29 Keck Seng Investments & Hong Kong & $n$ & invests mainly in China \\
\hline 30 Kumagai Gumi & Hong Kong & $\mathrm{n}$ & does not fulfill criteria GPR index \\
\hline 31 Ryoden Holding & Hong Kong & $\mathrm{n}$ & invests mainly in China \\
\hline 32 The Kwong Sang Hong Intemational & Hong Kong & $\mathrm{n}$ & invests mainly in China \\
\hline 33 Tian An China & Hong Kong & n & invests mainly in China \\
\hline 34 City Developments Limited & Singapore & y & \\
\hline 35 DBS L_and & Singapore & n & does not fulfill criteria GPR index \\
\hline 36 Malayan Credit Lid & Singapore & $\mathrm{n}$ & does not fulfill criteria GPR index \\
\hline
\end{tabular}

This appendix presents the sample of all international property companies that we evaluate to derive at our sample. 


\section{REIT Performance: Does Managerial Specialization Pay? ${ }^{33}$}

In this chapter we extend chapter 6 as we investigate whether managerial specialization explains performance in investment portfolios using a latger population. We combine two strands of the literature. To study the causes of out- and underperformance we first look at the literature concerning financial performance measurement and then at the literature about managerial specialization or focus.

The literature about the performance measurement of mutual funds is quite extensive. Most studies use measures derived from the Capital Asset Pricing Model to determine the performance of a fund relative to a benchmark, which corrects for priced and unpriced risk. Studies like Lehmann and Modest [1987], Grinblatt and Titman [1989], Malkiel [1995], Coggin, Fabozzi and Rahman [1993], Grinblatt and Titman [1994], Brown and Goetzmann [1995], and Ferson and Schadt [1996] define outperformance as the deviation of the mutual fund's return from the security market line. This measure of outperformance is the well-known Jensen $\alpha$ Jensen [1969]). In an informationally efficient capital market, $\alpha$ should not be significantly greater than zero since no fund manager should be able to outperform the market consistently. In that case, having superior information or specialized knowledge is irrelevant for performance. However, most of the empirical studies mentioned above have found significant $\alpha$ 's.

The literature trying to explain the empirically observed outperformance of mutual funds has two main branches. One branch starts from the premise that the observed outperformance is due to measurement error and tries to find the causes for this error. The other branch builds on the notion that consistent outperformance is really possible,

${ }^{33}$ This chapter is based on: P.M.A. Eichholta, H. Op 't Veld, and M. Schweitzer, "REIT' Performance: Does Managerial Specialization Pay?", Pefformance of Financial Insfitutions, edited by P. Harker and S. Zenios, Cambridge University Press, 2000. 
and tries to find economic explanations for outperformance. We will briefly discuss both strands of the literature.

Malkiel [1995] investigates whether outperformance is due to survivorship bias: the fact that the well-performing funds survive whereas the bad performers disappear. He concludes that the outperformance found in previous studies is indeed influenced by survivorship bias. He also concludes that persistence in outperformance is period-specific. The choice of the performance benchmark is another source of measurement error. This issue is discussed and tested for mutual funds by Lehmann and Modest [1987]. They do not find any significant benchmark sensitivity.

An example of a study in which mutual fund performance is explained by economic variables is Ferson and Schadt [1996], which shows that performance is influenced by changing economic conditions. These can change the calculated $\beta$ 's and thus also the $\alpha$ 's, the measure for outperformance. Selection and timing ability of the fundmanagers is discussed in chapter 2 and by Grinblatt and Titman [1989, 1994 and 1995]. They find evidence of timing ability of the mutual funds in their sample. Brown and Goetzmann [1995] discuss persistence in outperformance. They show that outperformance in one year makes outperformance in the next year more likely. This indicates that there are indeed some structural factors affecting the performance of mutual funds. This issue is regarded as a venue for further research by Grinblatt and Titman [1995] and Brown and Goetzmann [1995].

More insights in these structural factors can be found in the literature about managerial focus and specialization of industrials firms. Whereas in the past usually the potential benefits of diversification were discussed, more recently the potential costs of diversification get more attention. Berger and Ofek [1995], Comment and Jarrell [1995], John and Ofek [1995] and Denis, Denis and Sarin [1997] are recent examples of this. One of the main questions these studies address is why firms are still diversifying when agency problems preclude them from fully realizing the diversification potential. It seems that diversification enables managers to accrue private benefits which do not translate into firm value or stock returns.

In this chapter we test whether managerial specialization can explain persistence in performance in the investment industry. As explained in chapter 2 we prefer to measure performance by looking at excess stock returns. The study will validate the hypothesis that managerial specialization affects investment performance. Measuring specialization and comparing performance between companies in general is difficult as branch and individual firm characteristics disturb empirical tests. In empirical studies, which are limited to one particular branch, the sample size is usually quite small. We believe we can get around these problems by using data of United States Real Estate Investment Trusts (REITs). REITs are hybrid financial institutions with characteristics both of mutual funds 
and corporations. They manage money like mutual funds, but invest in real assets like common corporations. This makes them eminently suitable to investigate the effects of managerial specialization. REITs also have the advantage that the level of managerial specialization can be measured in a straightforward way by looking at the investment portfolio. Furthermore, since all companies in our sample have a similar structure to qualify as a REIT and since they own and manage their properties themselves, it is possible to compare them and test the significance of managerial specialization in an effective way.

The combination of management style and performance has not yet received a lot of attention in the literature. Coggin, Fabozzi and Rahman [1993] find that the investment styles of money managers affect performance. Shukla and Van Inwegen [1995] show that local fund managers outperform foreign managers, which suggests that specialized knowledge can help to outperform the market. Ito, Lyons and Melvin [1997] reveal that even on the foreign exchange market, traders do have some private information, which they can use to their benefit. It is likely that traders and fund managers will have more private information when they specialize. As REITs invest in assets through private markets, our study directly investigates the effects of private information and managerial specialization. We expect a specialized firm to have this private information, which it can use to outperform the market persistently. In chapter 3 we have already shown that within an international framework domestic property companies, with better access to nonpublic information, have a better performance than international property companies. This indicates that specialization gives access to private information, which enables managers to generate persistent outperformance.

The chapter is organized as follows: in section 7.1 we discuss the data we use regarding the performance and portfolio compositions of REITs. Section 7.2 deals with the way we measure specialization, while section 7.3 concerns the measurement of performance. In section 7.4 we present the results of a regression model in which specialization is directly linked to performance. This model is expanded in section 7.5 to include other variables, which may affect performance. In that section we employ a panel methodology to test our hypothesis in a more robust way. Section 7.6 concludes the chapter and gives some suggestions for further research.

\subsection{Data Description}

REITs have existed since the signing of the Real Estate Investment Trust Tax Provisions Act in 1960, but only since the beginning of the 1990's has the number and total market value of listed REITs increased dramatically. In the beginning of 1990 some 53 equity 
REITs existed with a total market value of $\$ 8.5$ billion dollars (in 1996 dollars), whereas at the end of 1996150 equity REITs had a combined market value of $\$ 69.6$ billion $^{34}$.

In order to qualify as a REIT, a real estate investment company has to follow strict rules like a minimum of 100 shareholders, a payout ratio of $95 \%$ of earnings and at least $75 \%$ of total assets in real estate. The main benefit is that the REITs don't pay corporate taxes.

All REITs are members of the National Association of Real Estate Investment Trusts (NAREIT). This association collects information about different characteristics of all REITs and publishes it annually in a handbook. The information distributed by NAREIT includes details regarding the balance sheets and the character of all listed REITs. Most important for us is that it indicates for each REIT the size and composition of the real estate portfolio, by giving the number of properties in the different states and real estate categories. We use the handbooks of 1990-1996 to accumulate data about the level of specialization by property type and by state. Besides this information we collect the book value of total assets, total equity and leverage ratio annually. As we include all equity REITs mentioned in any one of the handbooks, our sample is largely free of survivorship bias. In appendix 7.A, we present a list of all 150 equity REITs we use. We checked the collected information about portfolio construction with figures from company reports, and the information for capital structure with data from Datastream.

We collect returns, dividends and market capitalization for all REITs. For this, we use the Real Estate Securities Database of Global Property Research and collect total monthly returns from January 1990 through December 1996. Again, we checked the collected data with the annual reports, other company publications and Datastream.

We use two performance benchmarks. The first is a market-weighted index based on all REITs in our sample and the second is the S\&P 500 Composite total return index. As a proxy for the risk-free rate we take the 1-month Treasury Bill rate. Table 7.1 and figure 7.1 give insight in the performance of the REITs in our sample and the S\&P 500. Figure 7.1 shows that both indices follow similar patterns in time, but differ somewhat in value. While both indices are set at 100 at December 1989, our REIT index ends with a value of 284 in December 1996, and the S\&P 500 total return index with a value of 257.

Table 7.1 gives the summary statistics for the whole period and two equal sub-periods. The table puts the figure a bit more into perspective. Over the complete sample period, the stock index has a lower return and a lower standard deviation than the REIT index. In the last sub-period stocks have a higher average return: $16.87 \%$ versus $14.53 \%$ for the REITs. Their standard deviation is lower in both sub-periods, which suggests that an

\footnotetext{
${ }^{34}$ This only represents the number of REITs we use in our sample. The total REIT market consists of almost 300 listed REITs at the end of 1996, but those include mortgage REITs as well. Furthermore the REIT market expanded as many IPOs took place in 1996, which we did not include either.
} 
investment in common stocks is less risky than an investment in real estate investment companies. Over the whole period, the correlation between the monthly returns on the two indices is 0.47 .

\section{Figure 7.1: Market Indices}

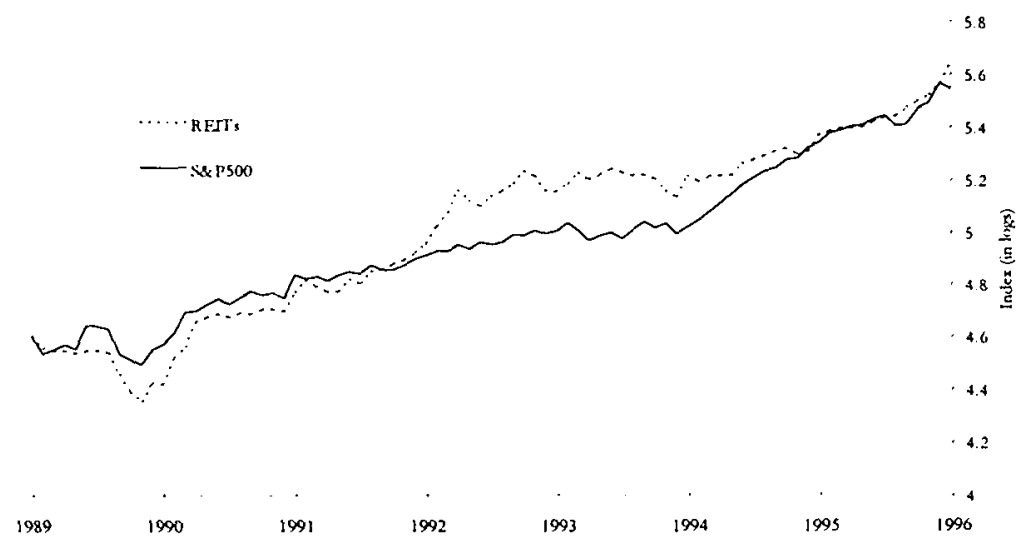

Table 7.1: Summary Statistics

\begin{tabular}{llcc}
\hline & & REITs & S\&P 500 \\
\hline $1990: 1-1996: 12$ & $\mu$ & 14.92 & 13.46 \\
& $\sigma$ & 12.37 & 10.61 \\
$1990: 1-1993: 6$ & $\mu$ & 15.32 & 10.06 \\
& $\sigma$ & 14.37 & 12.22 \\
$1993: 7-1996: 12$ & $\mu$ & 14.53 & 16.87 \\
& $\sigma$ & 10.16 & 8.75
\end{tabular}

The table gives average annualized logarithmic total returns and standard deviations for the whole period and two 42-month sub-periods for the REIT index and the S\&P 500 composite index.

These numbers give information regarding the performance of the REIT market as a whole and about REIT performance relative to the stock market in general. Within the REIT market, we expect the specialized REITs to be better risk-adjusted performers than the diversified REITs. In order to find out more about that, we first have to measure specialization. In the next section we explain how we do that. 


\subsection{Measuring Specialization}

Financial institutions, like all corporations, can diversify in product and geographic dimensions. As we noted in the introduction, measuring the level of specialization and diversification and their effects on performance may be hard for financial institutions in general. For REITs, however, that is not the case as their diversification strategy and their performance is clearly measurable.

Figure 7.2: Histogram Geographical Herfindah!

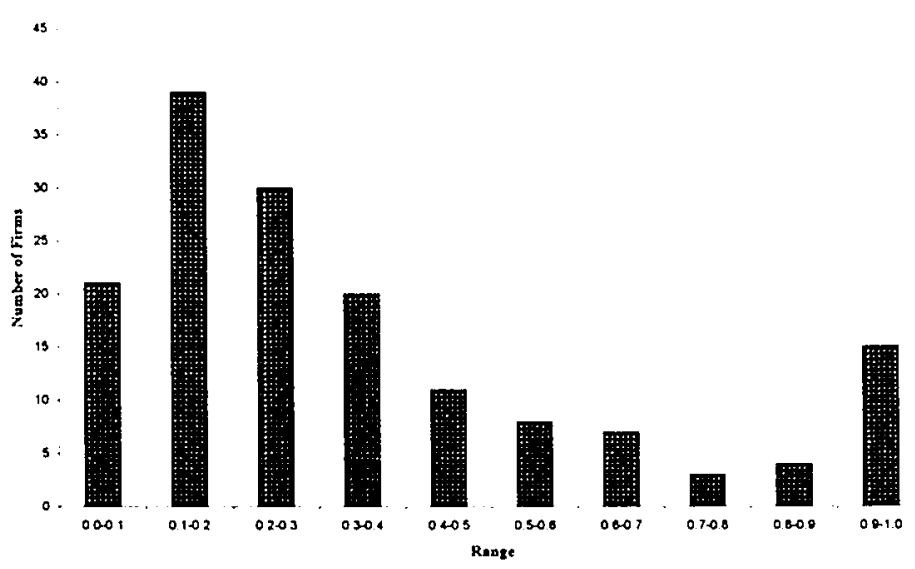

In the case of real estate, property type and geographic region are meaningful ways to measure specialization. First of all, the different property types are heterogeneous and require different managerial skills. For example, the retail sector is quite different from the residential sector regarding rental contracts. In the residential sector the rents are fixed for some time and tenants are flexible in moving away. This is in contrast to the retail sector where in some occasions rents are dependent on the total sales of the store and tenants can not move out of a building during the duration of the lease without incurring costs. Other major differences are in the scale and nature of properties, the type of tenants, the type of locations, and the degree of landlord involvement in the management of the properties. In other words, the economics of property investment are to a large extent determined by property type. This implies that specialized knowledge regarding a certain property type could be important in owning and managing properties and that, consequently, there may be information costs involved in operating in several sectors. Similarly, geography is an important driver of property performance. Real estate returns are strongly influenced by locational factors, and real estate markets show important regional differences. For example, the timing of cyclical developments in the real estate 
markets differs considerably across regions. Again, this implies potential benefits of managerial focus and costs related to diversification.

Figure 7.3: Histogram Property Type Herfindahl

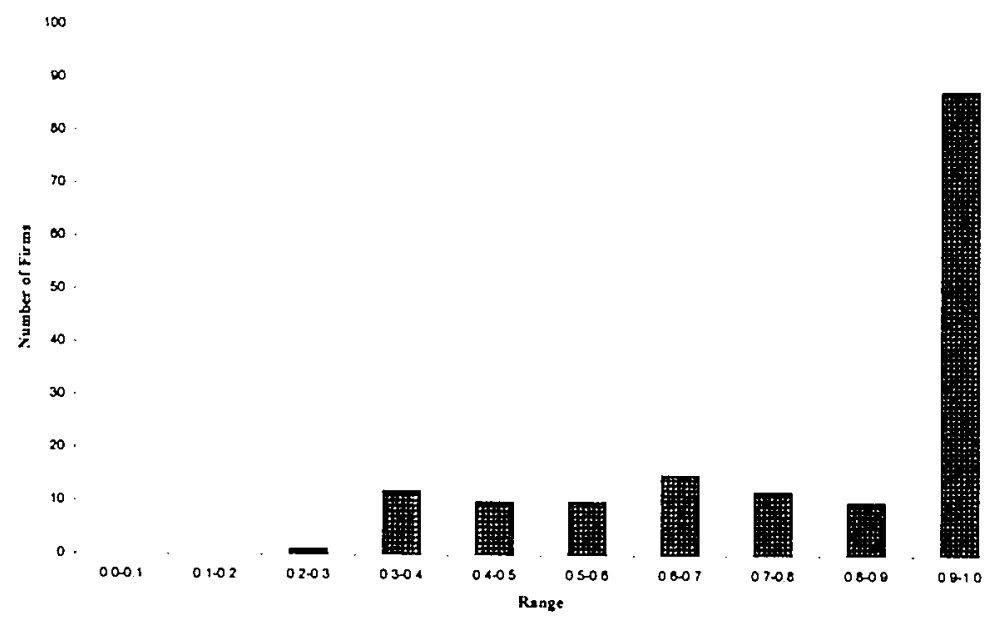

On the other hand, we know from the literature that there are indeed diversification benefits to be gained through investment in different sectors and regions. Miles and McCue [1984] and Hartzell, Hekman and Miles [1986] are examples of studies, which show how beneficial diversification over these two dimensions can be. Therefore, there is a trade-off between the costs and the benefits of diversification, both through property type and through region.

We rank the REITs by specialization using the Herfindahl index. We calculate Herfindahl indices for each individual REIT and for two dimensions of specialization: geographical and by property type ${ }^{35}$. In line with NAREIT, we distinguish 7 property types: retail, residential, office, hotel, healthcare, industrial and other. With respect to the geographical specialization measure we distinguish 50 different states $^{36}$.

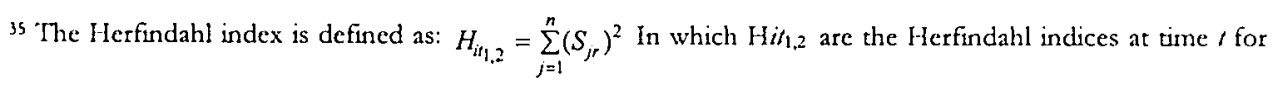
REIT $i, j$ is the state or the property type REIT $i$ invests in, $n$ is either the total number of states or the number of property types REIT $i$ invests in, and $S_{j r}=X_{j k} / X_{j}$, where $\mathrm{X}_{j n}$ is either the number of properties in a specific state or the number of properties in one class of property type and $X_{j}$ is the total number of states or property types.

36 The fact that we use the state as the geographical distinction is mainly driven by the availability of information regarding REIT portfolios. Some regions like New-England, may share similar characteristics across scveral states, whereas some states like Califomia may consist of several different property markets. 
Figure 7.4: Time Series of Average Herfindahl Index

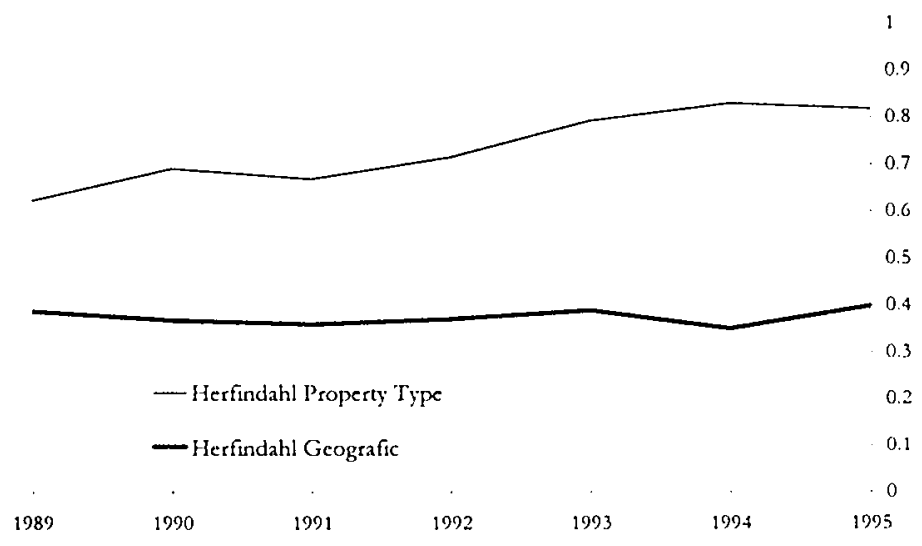

In figures 7.2 and 7.3 we present the frequency diagrams for the average Herfindahl indices for the complete sample period. Figure 7.2 shows that the REITs are geographically diversified, with $61 \%$ of the REITs having an index value below 0.35 . In contrast, figure 7.3 reveals that most REITs are specialized in property type, since $56 \%$ of the companies have an index value between 0.90 and $1.00^{37}$.

Figure 7.4 shows that the Herfindahl indices were relatively stable in time. The annual averages over all Herfindahl indices in the sample indicate a slight upward trend for the property type specialization of the REIT industry. Between 1989 and 1995 the average sector Herfindahl increased from 0.63 to 0.82 . The pattern for the geographical Herfindahl is more stable, indicating that the level of regional specialization has remained rather constant in the sample period.

\subsection{Measuring Outperformance}

We link the specialization measures calculated in the previous section to a performance measure derived from the Capital Asset Pricing Model: the Jensen $\alpha$ (Jensen [1969]). As in all other chapters the model is derived from CAPM, but should not be interpreted as a test against the model. In general, this measure is used to correct for differences in exposures to the market between individual REITs. The model used to measure the Jensen $\alpha$ is:

\footnotetext{
${ }^{37}$ REITs that specialize in a certain property type usually remain invested in that same property type during our sample period. We find specialized REI'Ts in all property categories, which is necessary to investigate the effects of specialization. If all specialized REITs would be invested in, say, offices, we would not measure the effect of specialization but rather the performance of the office market.
} 


$$
\left(R_{i t}-R_{f t}\right)=\alpha_{1}+\beta_{1}\left(R_{m t}-R_{f t}\right)+\varepsilon_{u}
$$

In which $R_{t}$ is the teturn of asset $i$ in year $t, R_{y t}$ is the risk-free rate at time $t$, and $R_{m}$ is the return of the market at time $t$. Risk that can not be diversified away will be rewarded with a higher expected return, which translates in a higher $\beta_{i}$ within the framework of the model. Diversifiable tisk that is not diversified away translates into a higher noise term $\varepsilon_{i}$. Within the framework of an informationally efficient capital market the fund managers are not expected to out- or underperform the market. This means that the expected value of $\alpha_{i}$ is zero. In the case of outperformance the $\alpha_{i}$ will be positive. Therefore, the first important step is to calculate $\alpha$ by a simple OLS regression of (7.1).

To correct for possible benchmark sensitivities we use two different indices as a proxy for the market return $R_{m}$. We use the S\&P 500 Composite total return index, and our own market-weighted REIT total return index. First, we calculate $\alpha_{i}$ for each fund individually at the longest possible horizon. The specialization measure is fairly stable for each REIT and we calculate it for the same horizon as the $\alpha_{i}$ of the specific REIT. This enables us to test our hypothesis by estimating the relationship between $\alpha_{i}$ and the two dimensions of specialization in a cross-sectional OLS regression.

$$
\alpha_{i}=\gamma_{0}+\gamma_{g e o} H_{\text {geo }}+\gamma_{\text {prop }} H_{\text {prop }}+\eta_{i}
$$

In which $\alpha_{i}$ is the Jensen $\alpha$ of REIT $i$ and $\gamma_{o}$ is a constant, which is expected to be zero if the model is correctly specified and there are no omitted variables. $H_{g e o}$ and $H_{\text {prop }}$ are the Herfindahl measures of geographical and property type specialization, $\gamma_{g c o}, \gamma_{\text {prop }}$ the coefficients to be estimated, and $\eta_{i}$ the error term. We also estimate whether the significance of $\alpha_{i}$ influences the results by regressing the t-statistic of $\alpha_{i}$ on the factors. Using this method we correct for the significance of $\alpha_{i}$ as a significant $\alpha_{i}$ gets more weight. The next section presents the results of the empirical estimation of the relationship between specialization and outperformance. 


\subsection{Results}

We start by briefly presenting the results of the estimation of (7.1). Thereafter we discuss the relation between the estimated $\alpha_{i}$ and the specialization measures.

Figure 7.5: Distribution of Alpha

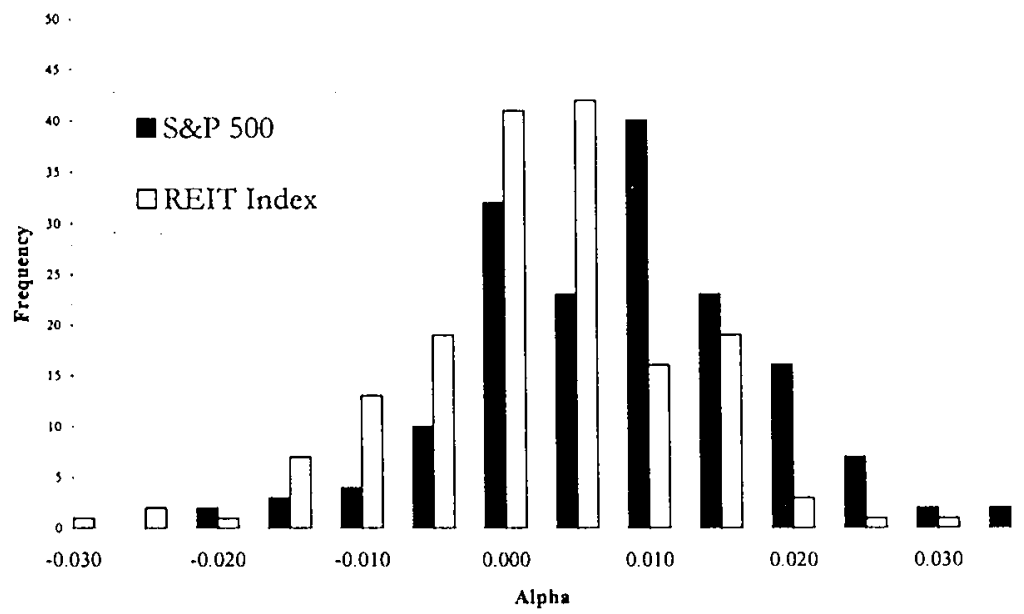

Figure 7.6: Distribution of Beta

25

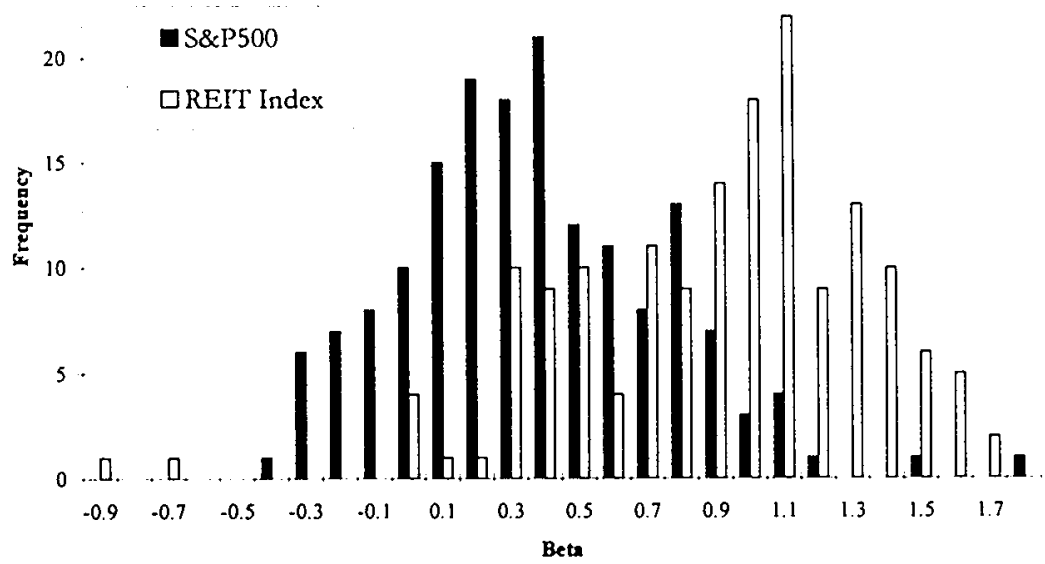


As said before, we run the regression twice; once with the S\&P 500, and once with a market-weighted index of all REITs we have in our sample. We limit ourselves to just presenting Figures 7.5, 7.6 and 7.7, which give the distributions of $\alpha$ and $\beta$ and the significance of $\alpha$. Figure 7.5 shows that both $\alpha_{i}$-estimates give the same pattern for the S\&P 500 and the REIT index. The average $\alpha$ estimated with the S\&P gives an annual outperformance of $5.74 \%$, and estimated with the REIT index an outperformance of $0.40 \%$.

The result that the S\&P is outperformed by the individual REITs is quite surprising when we compare it with the summary statistics in table 7.1. This result is explained when looking at figure 7.6, in which we show the distribution of the $\beta$ s estimated with the $\mathrm{S} \& \mathrm{P}$. This figure tells us that the lower $\beta_{i}$ s were responsible for the higher $\alpha_{i} \mathrm{~s}$. Figure 7.7 shows that only 13 REITs significantly out- or underperform the market.

We now turn to the relationship between $\alpha_{i}$ and the Herfindahl indices. We start in table 7.2 by presenting the correlation coefficients between them. For each benchmark we present four figures: the correlation between the two Herfindahl indices on the one hand and the $\alpha_{i}$ and the t-statistic of $\alpha_{i}$ on the other ${ }^{38}$. It becomes immediately clear that specialization into a specific state does not pay. The correlation between $\alpha$, and the geographical Herfindahl index is negative. On the other hand property type specialization does seem to be a strategy to obtain outperformance since it has a positive correlation in all occasions. Some of these results are confurmed in the real estate literature. See for example Goetzmann and Wachter [1995] and Capozza and Seguin [1997]. Table 7.2 shows that only in two instances the correlation coefficient is significantly different from zero. These results are both obtained when the test is performed with the S\&P 500. This is probably a result of the higher average $\alpha_{i}$ s when the S\&P is used as benchmark. It is clear that the results are not sensitive whether the test is performed with $\alpha_{i}$ or with the $t$ statistic of $\alpha_{i}$.

38 We use the t-statistics to control for possible outliers in the performance measure which might drive the results. 
30

25

20

15

10

5

0 .

$<-20$

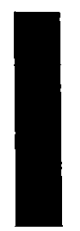

$-2.0-1.5$
Figure 7.7: Distribution of T-statistic

(estimated with REIT index)

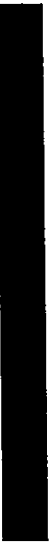

$0.0-0.5$

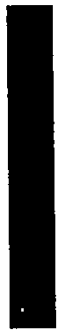

$0.5-1.0$

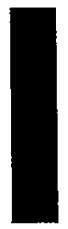

$1.0-1.5 \quad 1.5-20$

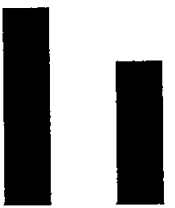

$>2.0$

Table 7.2: Correlation: Herfindahl and Outperformance

\begin{tabular}{|c|c|c|c|}
\hline & & Geographical Herfindahl & $\begin{array}{l}\text { Property Type } \\
\text { Herfindahl }\end{array}$ \\
\hline \multirow[t]{2}{*}{ S\&P 500} & $\overline{\alpha_{i}}$ & $-0.14^{*}$ & $0.18^{* *}$ \\
\hline & $T_{\alpha_{i}}$ & $-0.18^{* * *}$ & $0.16^{*}$ \\
\hline \multirow[t]{2}{*}{ REITs } & $\alpha_{i}$ & $-0.13^{*}$ & $0.15^{*}$ \\
\hline & $T_{a_{i}}$ & $-0.13^{*}$ & $0.13^{*}$ \\
\hline \multicolumn{4}{|c|}{$\begin{array}{l}\text { This table gives the correlation coefficients between the average Herfindahl } \\
\text { index and the measure for outperformance using two benchmarks. These } \\
\text { figures are calculated individually for each REIT over the maximum sample- } \\
\text { size of } 150 \text {. The ** denotes coefficients significantly different from zero at the } \\
5 \% \text { confidence level }\left(1.96 / \sqrt{ }_{150}=0.16\right) \text { and * denotes significance at the } 10 \% \\
\text { level }\left(1.65 / \sqrt{150}_{15}=0.13\right) \text {. }\end{array}$} \\
\hline
\end{tabular}

In table 7.3 we give the results of the more formal hypothesis test: the OLS regression of (2). We have repeated the regression four times: two regressions for each benchmark: one for $\alpha_{i}$ and one for the t-value of $\alpha_{i}$. The results confirm the patterns found in the correlation coefficients presented in the previous table. The coefficients measuring the effect of geographical specialization have a negative sign and the coefficients for the 
effect of specialization by property index a positive sign. This suggests that specialization by property type pays, whereas geographical specialization does not. To correct for a possible heteroskedasticity problem we calculate normal and White [1980] standard errors and present the latter in table 7.3. Heteroskedasticity in the regression residuals does not seem to be present since the conventional and White standard errors are virtually the same.

Besides the results for $\gamma_{g e o}$ and $\gamma_{\text {prop }}$ we see that the constant $\gamma_{0}$ is not significantly different from zero, which suggests that our regression is correctly specified. Nevertheless, the adjusted $R^{2}$ is relatively low and to improve the analysis we will expand the regression model to include factors, which have been found to have an effect on stock returns. In the next section we will present the method and discuss the results at the same time.

Table 7.3: Specialization and Performance

\begin{tabular}{|c|c|c|c|c|c|}
\hline & & $\gamma_{0}^{*}$ & $\gamma_{\mathrm{gco}}{ }^{*}$ & $\gamma_{\text {prop }}{ }^{*}$ & $R^{2}$ (adj) \\
\hline \multirow[t]{2}{*}{$S \& P 500$} & $\alpha_{i}$ & $\begin{array}{c}0.08 \\
(0.31)\end{array}$ & $\begin{array}{c}-0.43 \\
(-1.57)\end{array}$ & $\begin{array}{c}0.68 \\
(2.20)\end{array}$ & 0.04 \\
\hline & $\mathrm{T}_{\alpha \mathrm{i}}$ & $\begin{array}{l}28.12 \\
(0.95)\end{array}$ & $\begin{array}{l}-69.40 \\
(-2.35)\end{array}$ & $\begin{array}{l}70.24 \\
(2.02)\end{array}$ & 0.05 \\
\hline \multirow[t]{2}{*}{ REIT index } & $\alpha_{i}$ & $\begin{array}{c}-0.02 \\
(-1.11)\end{array}$ & $\begin{array}{c}-0.36 \\
(-1.53)\end{array}$ & $\begin{array}{c}0.47 \\
(1.67)\end{array}$ & 0.03 \\
\hline & $\mathrm{T}_{\alpha \mathrm{i}}$ & $\begin{array}{l}-23.22 \\
(-0.79)\end{array}$ & $\begin{array}{l}-56.55 \\
(-1.80)\end{array}$ & $\begin{array}{l}58.55 \\
(1.63)\end{array}$ & 0.03 \\
\hline
\end{tabular}

This table gives the basic results of the estimation of (7.3), for the two specialization factors. $\alpha_{1}$ refers to the Jensen $\alpha$ estimated with (7.2) and $T_{\alpha_{i}}$ refers to the t-statistic of the $\alpha_{1}$ estimate. The number in parentheses represents the t-statistic based on White [1980] standard errors of the estimated $\gamma$ coefficient. The estimated coefficients are presented as percentages and the sample size is 150 .

\subsection{Other Factors Generating Performance}

In the finance literature a debate has been going on whether other factors besides the market retum influence the performance of an individual stock. (See for example Fama and French [1992]). The question whether those factors represent priced risk factors or anomalies is beyond the focus of this chapter, but since we are interested to know whether it is specialization that drives performance or the other factors studied in the 
literature, it is important to include those factors and the degree of specialization in the same model. The factors we incorporate are the book-to-market ratio, the price/earnings ratio, firm size, and leverage. As these factors are not constant in time we cannot simply include them in (7.2) and estimate it using average factor values over the complete sample period for each REIT. The factors mentioned have a high variance around their average values, which might bias the estimation. For this reason we use a panel model that enables us to use the data in an efficient way. We use a one-step procedure in which the $\alpha$, the effects of the specialization measures, and the effects of the time-series anomalies studied in the literature are simultaneously estimated. The factors have a monthly frequency, and since the Herfindahl measures are only available at an annual basis we use a constant Herfindahl index for the 12 months after the month it is measured. In formal terms, we use an OLS regression to estimate the following equation:

$$
\left(R_{t t}-R_{f t}\right)=\alpha+\beta_{i}\left(R_{m t}-R_{f t}\right)+\gamma_{1} F_{1 u}+\ldots+\gamma_{k} F_{k t t}+\varepsilon_{t t}
$$

In this setup, $\alpha$ is expected to be zero since we assume that all determinants of firm performance are included in the model. The $\beta_{i}$ coefficient measures the sensitivity of the individual firm to market developments and the $\gamma_{1 . k}$ measures the effect of firm characteristics. In line with Fama and French [1992] we use fixed $\gamma^{\prime} s$ to measure factor sensitivities. $F_{t_{t} \ldots . .} F_{k t t}$ are the factors that we employ in a particular estimation. All these factors are measured at the end of the month, and are related to excess returns obtained in the next month. Each time we perform the regression we utilize different combinations of factors, but we always include the Herfindahl measures. For possible multicollinearity reasons we both perform the regression for individual factors and for all factors combined. Furthermore we assume that there is no autocorrelation in the error term over $t$, which is confirmed by the autocorrelation coefficients, which are insignificantly different from zero. The coefficients are presented in the last column of Table $4^{39}$.

Table 7.4 presents the results of the panel model ${ }^{+0}$. As we first look at the estimation of the effect of the geographical Herfindahl we see that the coefficient is negative in all occasions and that it is significant at a $95 \%$ confidence interval. The results confirm our earlier results that geographical specialization does not pay. It also tells us that possible distortion caused by values as leverage and book-to-market do not really disturb the estimation of the specialization effects. The same story holds for the property type

39 To estimate the significance and the $t$-statistic of the estimated coefficients we have to estimate the variance of the coefficients as well. We do this by using the following equation:

$$
\operatorname{Var}\left(\alpha, \beta_{i}, \gamma\right)=\left(\frac{1}{i t-k-i} \sum_{i} \sum_{i} \varepsilon_{i t}^{2}\right)\left(X^{\prime} X\right)^{-1}
$$

In which $i$ is the number of REITs, $f$ is the number of months, $k$ is the number of factors that we include, and $X$ is a matrix including all data on explanatory variables, which we also used to estimate the coefficients. ${ }^{40} W_{c}$ have estumated the model using the S\&P 500 index and the REIT index. As the results are very similar, we only present those for the REIT index. 
Herfindahl index. In each regression the coefficient is positive and almost always significant at a $95 \%$ confidence interval, which indicates that property type specialization is indeed positively related to risk-adjusted returns.

Table 7.4: Results of the Panel Model

\begin{tabular}{|c|c|c|c|c|c|c|c|c|c|}
\hline$\#$ & $\alpha$ & $\gamma_{b t m}$ & $\gamma_{p c}$ & $\gamma_{\text {size }}$ & $\gamma_{\text {levenge }}$ & $\gamma_{\mathrm{gco}}$ & $\gamma_{\text {prop }}$ & $\mathrm{R}^{2}$ & $\rho$ \\
\hline 1 & $\begin{array}{l}-1.13 \\
(-0.79)\end{array}$ & --- & --- & $\cdots$ & $\cdots$ & $\begin{array}{l}-6.55 \\
(-2.44)\end{array}$ & $\begin{array}{l}3.70 \\
(1.85)\end{array}$ & 0.24 & -0.15 \\
\hline 2 & $\begin{array}{l}-1.12 \\
(-0.78)\end{array}$ & $\begin{array}{l}0.00 \\
(0.01)\end{array}$ & -.. & --. & -- & $\begin{array}{l}-6.55 \\
(-2.44)\end{array}$ & $\begin{array}{l}3.70 \\
(1.85)\end{array}$ & 0.24 & -0.15 \\
\hline 3 & $\begin{array}{l}-1.01 \\
(-0.70)\end{array}$ & -- & $\begin{array}{l}-0.01 \\
(-0.80)\end{array}$ & --- & -.- & $\begin{array}{l}-6.45 \\
(-2.40)\end{array}$ & $\begin{array}{l}3.75 \\
(1.87)\end{array}$ & 0.24 & -0.15 \\
\hline 4 & $\begin{array}{l}6.17 \\
(2.32)\end{array}$ & --- & --- & $\begin{array}{l}-1.77 \\
(-3.27)\end{array}$ & --. & $\begin{array}{l}-7.24 \\
(2.67)\end{array}$ & $\begin{array}{l}5.54 \\
(2.66)\end{array}$ & 0.24 & -0.15 \\
\hline 5 & $\begin{array}{l}0.40 \\
(0.24)\end{array}$ & --- & --- & --- & $\begin{array}{l}-4.87 \\
(-1.80)\end{array}$ & $\begin{array}{l}-5.92 \\
(-2.19)\end{array}$ & $\begin{array}{l}4.13 \\
(2.04)\end{array}$ & 0.24 & -0.15 \\
\hline 6 & $\begin{array}{l}7.07 \\
(2.61)\end{array}$ & $\begin{array}{l}0.05 \\
(0.32)\end{array}$ & $\begin{array}{l}-0.01 \\
(-0.69)\end{array}$ & $\begin{array}{l}-1.67 \\
(-3.07)\end{array}$ & $\begin{array}{l}-3.93 \\
(-1.44)\end{array}$ & $\begin{array}{l}-6.64 \\
(-2.45)\end{array}$ & $\begin{array}{l}5.82 \\
(2.78)\end{array}$ & 0.24 & -0.14 \\
\hline
\end{tabular}

This table shows the results of the panel-regressions. The columns present the estimated coefficients and the t-statistic between parenthesis. The '-..' indicates that the factor was not used in the regression. We use the following symbols to indicate the factors: ' $\gamma_{\mathrm{bmm}}$ ' is the book to market, ' $\gamma_{\mathrm{pe}}$ ' is the price earnings, ' $\gamma_{\text {size }}$ ' is the market value of the company, ' $\gamma_{\text {leveragc }}$ ' is the ratio debt to total assets, ' $\gamma_{g e 0}$ ' is the geographic Herfindahl, and ' $\gamma_{\text {prop }}$ ' is the property type Herfindahl. All factors arc presented in percentages at an annual basis. The $R^{2}$ gives the average individual $R^{2}$. The $\rho$ gives the average autocorrelation for each individual company.

Even though the other factors do not influence the effect of specialization very much, we will briefly discuss them next. First of all we see that the book-to-market coefficient is insignificantly positive. A higher book-to-market value will give a higher return in the future. The price-earnings ratio shows a negative relationship with future returns, which confirms earlier results as well. The well-known size effect is also statistically significant in our sample. The negative coefficient implies that the small firms outperform large firms. The only finding that seems to contradict the literature is the sign of the leverage coefficient. It is negative and insignificant, but the negative sign indicates that more debt is related to lower performance. However, this may be explained by the fact that REI'Ts don't pay corporate taxes and are therefore not able to benefit from tax shields. Thus, the negative sign can be explained by arguing that more debt indicates more risk and a higher interest rate on the outstanding debt and thus a lower performance. 
Besides the statistical significance of our estimation it is also important to discuss the effects of our specialization measure for the performance of the real estate companies. In table 3.5 we present the effects for different starting situations and extensions of the portfolio. In the first two cases we start from a totally specialized portfolio, with a Herfindahl of one for each measure. In the first case these measures drop to 0.50 as the portfolio after the extension consists of two properties. If the portfolio extension is done into a new state but in the same property type, the average performance will increase by $3.28 \%$ on annual basis. If the new building is bought in the same state but in a different sector the performance decreases by $1.86 \%$. Obviously, if we combine the two the performance will increase by $1.42 \%$.

Table 7.5: Effects on Performance

\begin{tabular}{l|ccc}
\hline Existing portfolio of a REIT & \multicolumn{3}{|c}{ Adding one new property in: } \\
& new state & $\begin{array}{l}\text { new property } \\
\text { type }\end{array}$ & $\begin{array}{c}\text { both state and } \\
\text { property type }\end{array}$ \\
\hline 1 property in 1 state and 1 property type & 3.28 & -1.86 & 1.42 \\
4 properties in 1 state and 1 property type & 2.10 & -1.19 & 0.91 \\
4 properties in 2 states and 2 property types & 0.92 & -0.52 & 0.40 \\
\hline
\end{tabular}

This table presents the effects of adding a new property to the existing portfolio. The effects are presented in annualized percentages and use the result of (7.4), without any other factors besides the Herfindahl measures (version 1).

In the second case we statt from a portfolio of four properties of the same type in only one state. In that case, adding one new property to the portfolio implies a drop of the Herfindahl indices from 1.00 to 0.68 . If the new property is in another state, this results in an increase of $2.10 \%$ in the annual excess return of the portfolio. If it involves a new property type in the same state, the annual excess return will decrease by $1.19 \%$.

In the third case, starting from a portfolio of four properties distributed over two states and two property types, the Herfindahl measures drop from 0.50 to 0.36 . In this case, the effects of unfocusing the portfolio are rather small and do not exceed $1 \%$. Of course if the investor sells a property and becomes more specialized the sign of the calculated percentages will be the opposite.

\subsection{Conclusion}

The results we find in this chapter are straightforward. Building on the literature regarding mutual fund performance measurement and managerial focus we argue that specialization may be related to the persistent outperformance of investment funds. We study the Real Estate Investment Trust industry in the United States since it comprises a unique sample of 150 companies working in the same industry, all having a comparable structure. Managerial specialization can easily be measured by looking at the portfolio of each 
REIT. We find companies that specialize in a specific property type to outperform the market, whereas geographically specialized companies underperform on average. This indicates that the question whether the cost of diversification can outweigh the benefits depends on the dimension along which the diversification takes place.

The results suggest that real estate investors should specialize in one property type, and diversify across regions. Investors who also want to diversify across property types can do so by buying the shares of different REITs, each specialized in a different property type. The property companies should use this knowledge and diversify their portfolios geographically, and focus on one property type only. In fact the current average portfolio composition of the REITs in our sample shows that they already do this.

Besides these practical implications for investors, this study also makes a major contribution to the literature regarding focus and managerial specialization. It shows that the way specialization is measured is crucial for the question whether specialization pays or not. We measure specialization in two ways and find opposite effects. This suggests that the trade-off between the costs and the benefits of specialization or diversification should be investigated very carefully, and that researchers are well advised to look at various ways to measure specialization. This issue is a worthwhile venue for further research. 
APPENDIX 7

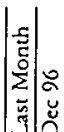

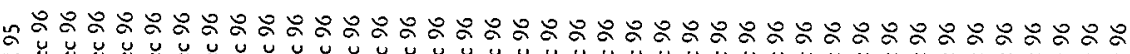

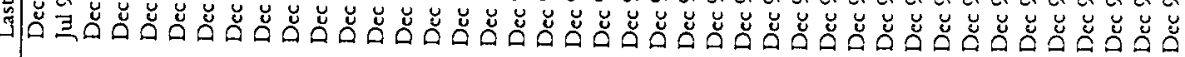

甹

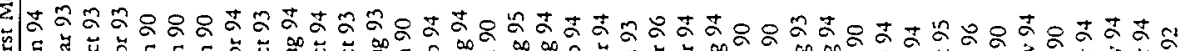

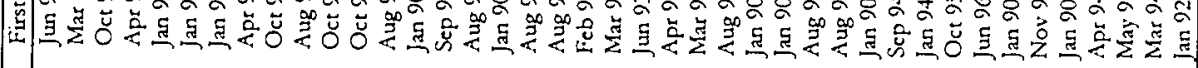

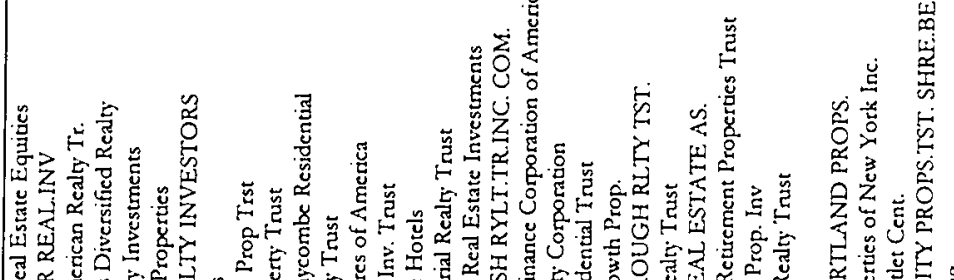

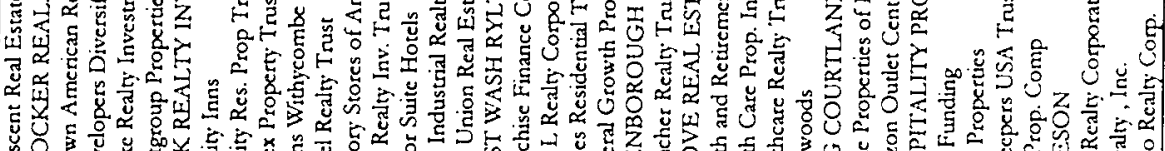

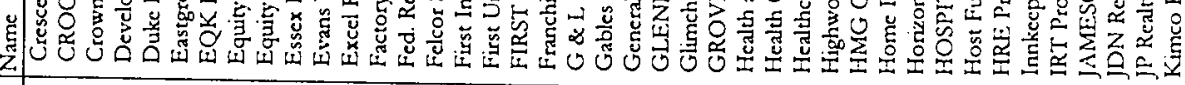

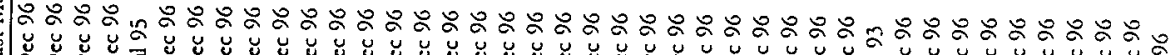

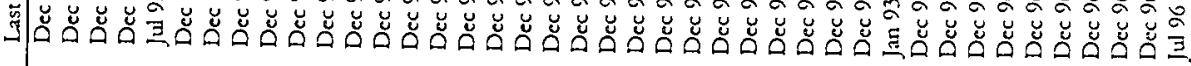

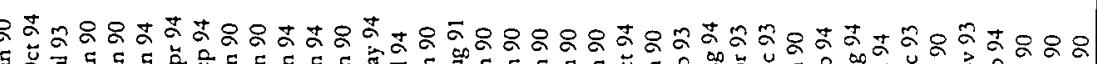

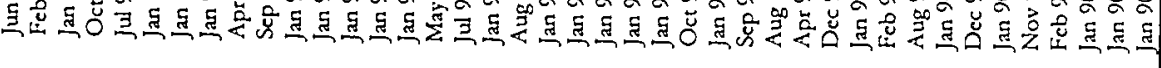

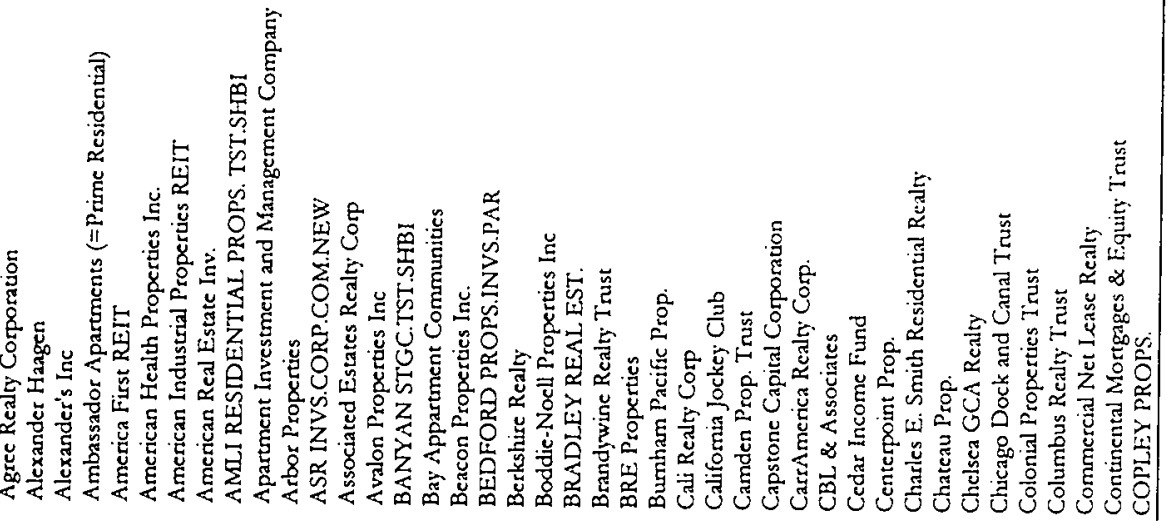


感

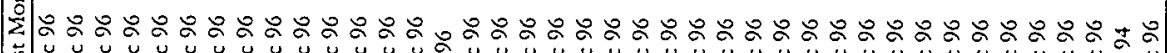

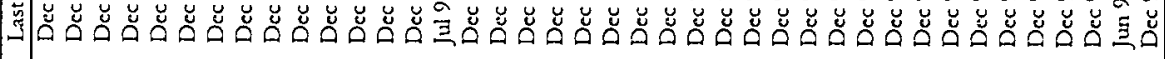
忽

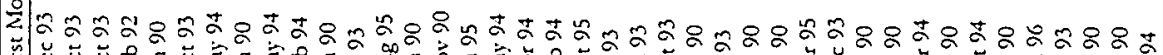

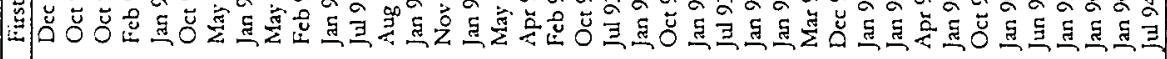

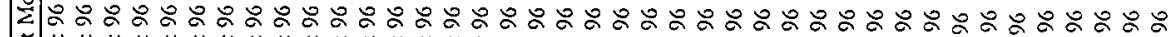

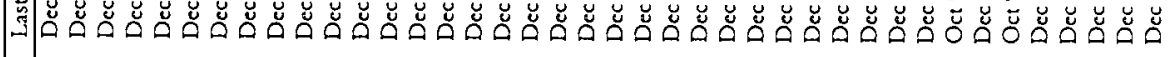

$\mathfrak{\xi}$

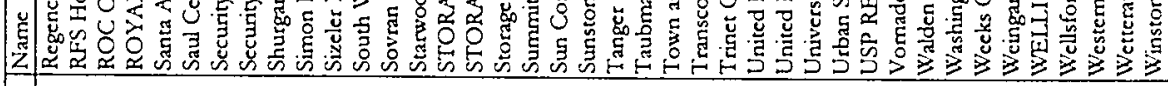

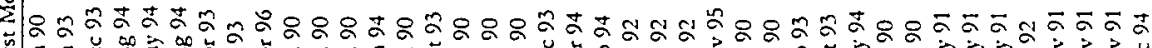

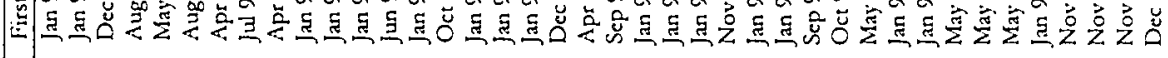

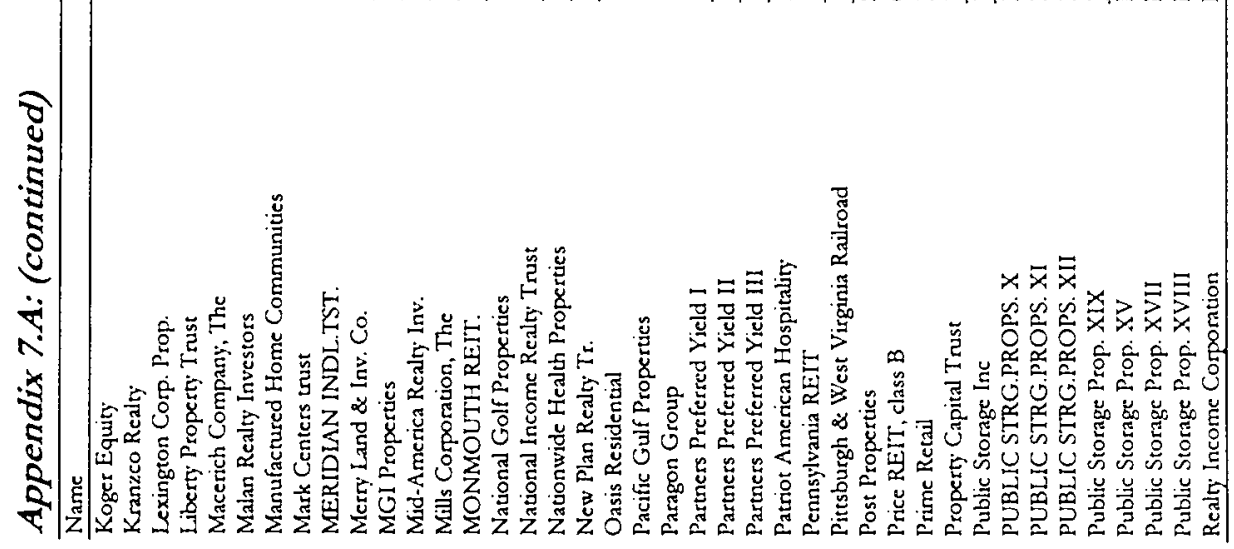


CHAPTER 8

\section{Summary}

Reading newspapers and following the news teaches us that in the last few decades there has been an increased tendency towards a critical assessment of services or products provided at both the corporate and private levels. In general, it is important to ensure yourself that services or products you pay for are up to standard and possibly have a higher value for money than the products you decided not to buy. This is what we call 'performance measurement'. In many industries performance is difficult to assess. The financial services industry, however, is one of the few where it is relatively easy to measure and compare the performance of different providers. That is exactly what this thesis does. The focus is on the financial performance of several types of institutional investors. The question is not solely whether the investors performed up to standard, but also how the performance can be explained and to what it can be attributed.

Clearly, these issues have already received a lot attention in the literature. In many occasions, however, the focus was on issues related to questions how performance should be measured and compared. Especially studies on asset pricing and tests of models using mutual funds as a reference dominate the literature. Chapter 2 provides a more extensive overview of the theoretical insights about performance measurement. The chapter starts from a broad perspective and shows that the performance of institutional investors can be measured efficiently and effectively by its stock performance. Furthermore, the chapter pictures the different value-drivers and indicates that these drivers deserve more study. Chapter 3 examines the issue on horizon sensitivity closely as, arguably, this is one of the theoretical challenges important for performance measurement systems. The chapter uses the example of the relation between inflation and stock return, but the findings are applicable for performance measurement as well. In terms of future research it would be informative also to develop these horizon models for the standard performance measurement exercises. 
Chapters 4 through 7 , the empirical chapters, leave the issue about asset pricing models aside and explore other equally important stepping-stones to a better understanding and explanation where performance comes from. The first issue is directly related to the use of different data-sets and the second deals with the attribution of the performance. We will discuss the issues independently.

The first issue is the analysis of other data-sets than the U.S. mutual funds. Actually, it is logical that the literature in general uses and refers to these data as they are readily available and have already been extensively used. Nevertheless, this is a limited scope and introduces a restriction to the analysis. Therefore, we analyze the Dutch pension fund industry in chapter 4 and the European mutual fund industry in chapter 5. However, chapter 4 is limited in the sense that it only calculates the performance of the pension funds. In that sense, however, it is unique, as data on pension funds are not publicly available at all. In the past Dutch pension funds were not obliged to disclose information at all, and even now when legal requirements are in place it is still difficult to measure and analyze the performance in depth. Therefore, it is important that (large) financial institutions are increasingly willing to cooperate with universities to share their experiences and data for research purposes.

Chapter 5 reports a more in-depth analysis as it analyses data on European mutual funds and compares that with the situation in the United States. Data-sources for the European mutual fund industry are already much better than the data on the pension funds, but they remain relatively scarce compared to the United States. The level of the analysis makes chapter 5 unique. It is the first study to analyze the performance of the European industry in a comprehensive manner. Previously all studies had focused on a single country. Increasing technological developments will enable customers to shop around and make it easy to invest personal savings abroad using international suppliers. This will increase competition among the players. The chapter shows that the European mutual fund industry actually has a better performance than the industry in the United States. This is remarkable as the chapter also shows that European mutual fund suppliers are faced with lower levels of competition.

Chapters 6 and 7 present and extend the analysis of the second issue in an attempt to explain the performance found and seek to attribute it. The analysis is performed on a well developed and scrutinized data-set of listed property companies. The enormous growth of listed property shares and the comprehensive information available gives us the opportunity both to calculate the performance of the companies and to examine different performance drivers at the same time. In fact, both chapters analyze the effects of portfolio allocation and the level of specialization on the performance. We conclude that focus and specialized knowledge about the market is crucial for the entrepreneur. We expect this to hold for other industries as well. Additionally, it is important to note that an instirutional investor, like any other investor, should still diversify its portfolio. This means that it should also invest in areas where it does not have the specialist knowledge. 
We believe that the most appropriate method to do this is to invest in stocks of listed companies. If stocks are not available, an investor should be very careful in picking the means to invest in areas it is not the specialist. 


\section{REFERENCES}

ABN AMRO Asset Management, Beleggingsinstellingen 1997, Amsterdam, March 1997.

Adler, M. and B. Dumas, "International Portfolio Choice and Corporation Finance: A Synthesis", Joumal of Finance, 38, 1983, 925-984.

Ambachtheer, K.P., and D.D. Ezra, Pension Fund Excellence, Canada, 1998.

Ambachtsheer, K.P., R. Capelle, and T. Scheibelhut, "Improving Pension Fund Performance", Financial Analysts Joumal, November/December 1998, 15-21.

Bain, J.S., Barriers to New Competition, Cambridge, 1956.

Bain, W.G., Investment Performance Measurement, Cambridge, 1996.

Barsky, R.B., "The Fisher Hypothesis and the Forecastability and Persistence of Inflation", Joumal of Monetary Economics 19, 1987, 3-24.

Berger, P.G., and E. Ofek, "Diversification's Effect on Firm Value", Journal of Financial Economics 37, 1995, 39-65.

Blake, D., B.N. Lehmann, and A. Timmermann, "Performance Measurement using Multiple Asset Class Portfolio Data: A Study of UK Pension Funds", CEPR Discussion Paper 1618, 1997.

Bodie, Z., "Common Stocks as a Hedge Against Inflation", Joumal of Finance 31, No. 2, May 1976, 459-470.

Boudoukh, J., and M. Richardson, "Stock Returns and Inflation: A Long Horizon Perspective", American Economic Review 83, No. 5, December 1993, 1346-1355.

Brown, K.C., W.V. Harlow, and L.T. Starks, "Of Tournaments and Temptations: An Analysis of Managerial Incentives in the Mutual Fund Industry", Joumal of Finance 51, 1996, 85-110.

Brown, S., and W. Goetzmann, R. Ibbotson and S. Ross, "Survivorship Bias in Performance Sudies, Review of Financial Studies 5, 1992, 553-580.

"Rejoinder: The J-Shape of Performance Persistence Given Survivorship Bias", Review of Economics and Statistics, 1997, 167-170 
Brown, S., and W. Goetzmann, "Performance Persistence", Journal of Finance 50, No. 2, 1995, 679-698.

"Mutual Fund Styles", Jourmal of Financial Economics 43, 1997, 373-399.

BZIW, The Dutch Equity-Bond Study, 1994.

Campbell, J.Y., and R.J. Shiller, "Stock Prices, Earnings, and Expected Dividends", Journal of Finance 43, 1988, 661-676.

Campbell, J.Y., A.W. Lo, and A.C. Mackinlay, The Econometrics of Financial Markets, 1997.

Capozza, D.R., and P.S. Seguin, "Why Focus Matters", working paper, 1997.

Carhart M., "On Persistence in Mutual fund Performance", Joumal of Finance 52, 57-82, 1997.

Chordia, T., "The Structure of Mutual Fund Charges", Journal of Financial Economics 41, pages 3-39, 1996.

Coggin, T.D., F.J. Fabozzi, and S. Rahman, "The Investment Performance of U.S. Equity Pension Fund Managers: An Empirical Investigation", Journal of Finance 48, No. 3, 1993, 1039-1055.

Comment, R., and G.A. Jarrell, "Corporate Focus and Stock Returns", Jourmal of Finanial Economics 37, 1995, 67-87.

Daniel, K., M. Grinblatt, S. Titman, and R. Wermers, "Measuring Mutual Fund Performance with Characteristic-Based Benchmarks", Joumal of Finance 52, 1997, 1035-1058.

Denis, D.J., D.K. Denis, and A. Sarin, "Agency Problems, Equity Owership, and Corporate Diversification", Journal of Finance 52, No. 1, 1997.

Dermine, D, and L-H. Röller, "Economies of Scale and Scope in French Mutual Funds", Joumal of Financial Intermediation 2, 1992, 83-93.

Economist, Aux armes, investisseurs, 1999, February 13, 83.

Eichholtz, P.M.A., "Does International Diversification Work Better for Real Estate than for Stocks and Bonds?", Financial Analysts Jourmal, January/February 1996, 56-62.

Eichholtz, P.M.A. and C.G. Koedijk, "International Real Estate Securities Indices", Real Estate Finance 12, Winter 1996, 42-50.

"The Global Real Estate Securities Market", Real Estate Finance 13, Spring 1996, 76-82.

Eichholtz, P.M.A., R. Huisman, C.G. Koedijk and L. Schuin, 'Continental Factors in International Real Estate Returns', Real Estate Economics 26, 1998, 493-509.

Elton, E.J., M.J. Gruber, and C.R. Blake, "Survivorship Bias and Mutual Fund Performance", Review of Financial Studies 9, 1996, 1097-1120.

Evans, M.D.D., and K.K. Lewis, "Do Expected Shifts in Inflation Affect Estimates of the Long-Run Fisher Relation?", Joumal of Finance 50, No.1, March 1995, 225-253.

Fama, E.F., "Short-term Interest Rates as Predictors of Inflation", American Economic Review, June 1975, 269-282.

"Stock Returns, Real Activity, Inflation, and Money", American Economic Review 71, 1981, 545-565.

"Stock Returns, Expected Returns, and Real Activity", Joumal of Finance 45, No. 4., September 1990, 1089-1108. 
Fama, E.F., and K.R. French, "The Cross-Section of Expected Stock Returns", Journal of Finance 47, no 2, 1992, 427-465.

Fama, E.F., and G.W. Schwert, "Asset Returns and Inflation", Journal of Financial Economics 5, 1977, 115-146.

Féderation Européenne des Fonds et Societés d'Investissement (FEFSI), 1996 Annual Statistics, July 1997.

Ferson, W.E., and C.R. Harvey, "Conditioning Variables and the Cross-Section of Stock Returns", working paper, 1996.

Ferson, W.E., and R.W. Schadt, "Measuring Fund Strategy and Performance in Changing Economic Conditions", Journal of Finance 51, No. 2, 1996, 425-461.

Financial Times Unit Trist Yearbook 1997, Financial Times Publishing, London, 1997.

Fisher, I., The Theory of Interest, MacMillan, New York, 1930.

French, K.R., and J.M. Poterba, "Investor diversification and international equity markets", American Economic Review, 1991, 222-226.

Geske, R., and R. Roll, "The Fiscal and Monetary Linkage between Stock Returns and Inflation", Joumal of Finance 38, 1983, 1-33.

Gibbons, M.R., S.A. Ross, and J. Shanken, 'A Test of the Efficiency of a Given Portfolio', Econometrica, Vol 57, 1989, 1121-1152.

Giliberto, S.M., "Global Real Estate Securities: Index Performance and Diversified Portfolios", Salomon Brothers Real Estate Research, February 1990.

Giliberto, S.M. and F.N. Sidoroff, "Real Estate Stock Indices", Real Estate Finance 11, Spring 1995, 56-62.

Glen, K., and P. Jorion, "Currency Hedging for International Portfolios", Journal of Finance 48, 1993, 1865-1886.

Goetzmann, W.N., and S.M. Wachter, "Clustering Methods for Real Estate Portfolios", Real Estate Economics 23, No. 3, 1995, 273-310.

Goetzmann, W.N., and M. Massa, "Index Funds and Stock Market Growth", working paper, 1999

Gordon, J.N., "The Diversification Potential of International Property Investments", Real Estate Finance Journal 7, Fall 1992, 42-48.

Grauer, R.R. and N.H. Hakansson, 'Gains from International Diversification: 1968-85 Returns on Portfolios of Stocks and Bonds', Joumal of Finance 42, 1987, 721-741.

Grinblatt, M., and S. Titman, "Portfolio Performance Evaluation: Old Issues and New Insights", Review of Financial Studies 2, No. 3, 1989a, 393-421.

"Mutual fund performance: An Analysis of quarterly portfolio holdings", Journal of Business 62, 1989b, 393-416.

"The Persistence of Mutual Fund Performance Evaluation", Joumal of Finance 47, 1992, 1979-1984.

"Performance Measurement without Benchmatks: An Examination of Mutual Fund Returns", Joumal of Business, 1993, 47-68.

"A Study of Monthly Mutual Fund Returns and Performance Evaluation Techniques", Journal of Financial and Quantitative Analysis 29, 1994, 419-444. 
"Performance Evaluation", Handbooks in Operations Research and Management Science 9, R.A. Jarrow, V. Maksimovic, and W.T. Ziemba, 1995.

Grinblatt., M., S. Titman, and R. Wermers, "Momentum Investment Strategies, Portfolio Performance, and Herding: A Study of Mutual Fund Behavior", American Economic Review 85, 1995, 1088-1105.

Grubel, H.G., "Internationally Diversified Portfolios", American Economic Review 58, 1968 , 1299-1314.

Grubel, H.G. and K. Fadner, "The Interdependence of International Equity Markets", Journal of Finance 26, 1971, 89-94.

Gruber M., "Another Puzzle: The Growth in Actively Managed Mutual Funds", Journal of Finance 51, 783-807, 1996.

Haldrup, N., "A Review of the Econometric Analysis of I(2) Variables", Working Paper, 1997.

Hartzell, D., J. Hekman, and M. Miles, "Diversification Categories in Investment Real Estate", AREUEA Journal 14, No. 2, 1986, 230-254.

Hendricks, D., J. Patel, and R. Zeckhauser, "Hot Hands in Mutual Funds: Short-Run Persistence of Relative Performance, 1974-1988", Joumal of Finance 48, 1993, 93 130.

"The J-Shape of Performance Persistence Given Survivorship Bias", Review of Economics and Statistics, 1997, 161-166.

Hoppenstedt Fondsführer 1997, Verlag Hoppenstedt, Darmstadt, 1997.

Huisman. R., and M. Schweitzer, "Dutch Corporate Bonds in a Mixed Asset Portfolio", VBA Journaal, 1999.

Ibbotson Associates, Stocks Bonds Bills and Inflation, 1998.

International Monetary Fund, Intermational Financial Statistics Yearbook 1997, 1997, 855.

Ito, T., R.K. Lyons, and M.T. Melvin, "Is There Private Information in the FX Market? The Tokyo Experiment", Working Paper, 1997.

Jagannathan, R, and Z. Wang, "The Conditional CAPM and the Cross-Section of Expected Returns", Journal of Finance 51, 1996, 3-53.

James, C., S. Koreisha, and M. Partch, "A VARMA Analysis of the Causal Relations Among Stock Returns, Real Output, and Nominal Interest Rates", Joumal of Finance 40, No. 5, December 1985, 1375-1384.

Jensen, M.C., "The performance of mutual funds in the period 1945-1964", Journal of Finance 23, 1968, 389-416.

"Risk, the Pricing of Capital Assets, and the Evaluation of Investment Portfolios" Journal of Business 42, 1969, 167-247.

John, K., and E. Ofek, "Asset Sales and Increase in Focus", Journal of Financial Economics 37, 1995, 105-126.

Juselius, K., "Do purchasing power parity and uncovered interest rate parity hold in the long run? An example of likelihood inference in a multivariate time-series model.", Jourmal of Econometrics 69, 1995, 211-240.

Kandel, S., and R.F. Stambaugh, "Portfolio Inefficiency and the Cross-Section of Expected Returns", Joumal of Finance 50, 1995, 157-184. 
Koedijk, C.G., P.C. Schotman, and M. Schweitzer, "The Performance of the Dutch Mutual Fund Sector", LIFE working paper, 1998.

Lakonishok, J., A. Shleifer, and R.W. Vishny, "The Structure and Performance of the Money Management Industry", Brookings Papers: Macroeconomics, 1992, 339-391.

Lee, B., "Causal Relations Among Stock Returns, Interest Rates, Real Activity, and Inflation", Journal of Finance 47, No. 4, 1992, 1591-1603.

Lehman, B., and D. Modest, "Mutual Fund Performance Evaluation: A Comparison of Benchmarks and Benchmark Comparisons", Journal of Finance 42, No. 2, 1987 , 233-265.

Lessard, D.R., "International Portfolio Diversification: Multivariate Analysis for a Group of Latin American Countries", Journal of Finance 28, 1973, 619-633.

Levy, H. and M. Sarnat, "International Diversification of Investment Portfolios", American Economic Review 60, 1970, 668-675.

Liu, C.H. and J.P. Mei, "The Predictability of International Real Estate Markets, Exchange Risks, and Diversification Consequences', Real Estate Economics 26, 1996, 3-39.

Malkiel, B.G., "Returns from Investing in Equity Mutual Funds 1971 to 1991", Journal of Finance 50, No. 2, 1995, 549-572.

Mason, E.S., "Price and Production Policies of Large-scale Enterprise", American Economic Review 29, 1939, 61-74.

McDonald, J.G., "French Mutual Fund Performance: Evaluation of InternationallyDiversified Portfolios", Joumal of Finance 28, 1973, 1161-1180.

Miles, M., and T. McCue, "Diversification in the Real Estate Portfolio", Journal of Financial Research 7, No.1, 1984, 57-68.

Modigliani, F., and L.Modigliani, "Risk-Adjusted Performance", Journal of Portfolio Management, Winter 1997, 45-54.

Poterba, J.M., S.F. Venti, and D.A. Wise, "401(k) Plans and Future Pattems of Retirement Saving”, American Economic Review 88, No. 2., 1998, 179-184.

Roll, R., "Ambiguity when Performance is Measured by the Securities Market Line", Journal of Finance 33, 1978, 1051-1069.

Ross, S.A., R.W. Westerfield, and J. Jaffe, Corporate Finance, McGraw Hill, 4th edition, 1996.

Scherer, F.M., and D. Ross, Industrial Market Structure and Economic Performance, 1990.

Sharpe, W.F., "Mutual Fund Performance", Joumal of Business, Supplement on Security Prices, 39, 1966.

"Asset Allocation: Management Style and Performance Measurement", Journal of Portfolio Management 46, 1992, 7-19.

Shukla, R.K., and G.B. van Inwegen, "Do Locals Perform Better Than Foreigners?: An Analysis of UK and US Mutual Fund Managers", Journal of Economics and Business 47, 1995, 241-254.

Sirri, E.R., and P. Tufano, "Costly Search and Mutual Fund Flows", Joumal of Finance 53, No. 5, 1998, 1589-1622.

Solnik, B.H., "Why not Diversify Internationally Rather than Domestically?", Financial Analysts' Joumal 30, 1974a, 48-54. 
"An Equilibrium Model of the International Capital Market', Joumal of Economic Theory, 8 July/August 1974b.

"The Performance of International Asset Allocation Strategies Using Conditioning Information", Journal of Empirical Finance 1, 1993, 33-55.

Stewart, G.B., The Quest for I'alue, Harper Collins, 1991.

Tufano P., and M. Sevick, "Board structure and fee-setting in the US mutual fund industry", Journal of Financial Economics 46, 1997, 321-355.

VBA, VBA Performance Presentatie Standaarden, 1998.

Vereniging van Bedrijfspensioenfondsen, $V B$ contact, mei 1998.

Verzekeringskamer, Financiële gegevens pensioenfondsen, 1996.

Wahal, S., "Pension Fund Activism and Firm Performance", Journal of Financial and Quantitative Analysis 31, 1996, 1-23.

Walter, I., "The Global Asset Management Industry: Competitive Structure, Conduct, and Performance, Stern Working Paper FIN-98-072, 1998.

Ward, C., and A. Saunders, "UK Unit Trust performance 1964-1974", Joumal of Business Finance and Accounting 3 / 4, 1976, 83-97.

White, H., "A Heteroskedasticity-Consistent Covariance Matrix Estimator and a Direct Test for Heteroskedasticity", Econometrica 48, 1980, 817-838. 


\section{Nederlandse Samenvatting}

In de laatste decennia is ex op verschillende terreinen in onze maatschappij een trend ontstaan die gekenmerkt wordt door een kritische houding ten opzichte van aangeboden producten en diensten. Dit gebeurt zowel door bedrijven als consumenten. Een koper van een product stelt zich steeds vaker de vraag of een product wel een goede prijskwaliteit verhouding heeft. Men zou dit al performancemeting kunnen noemen. Het gaat immers om de vraag hoe goed de prestaties van de producten zijn in vergelijking tot anderen. In veel gevallen is het echter moeilijk om een dergelijke vergelijking op kwantitatieve en consistente wijze uit te voeren en wordt een beslissing vaak op gevoel genomen. De prestaties van vermogensbeheerders, oftewel de institutionele beleggers, gelden hier echter als uitzondering. Voor hen is het namelijk veel eenvoudiger om te bepalen of de producent waar voor zijn geld geeft. Data is eenvoudig voorhanden hetgeen een kwantitative beoordeling mogelijk maakt. In dit proefschrift gebruik ik deze mogelijkheid dan ook en analyseer databestanden van verschillende institutionele beleggers. De relevantie van een dergelijk onderzoek laat zich simpelweg verklaren aan de hand van het belang van de sector. Alleen al in Nederland beleggen deze beleggers meer dan 1 biljoen gulden voor eigenlijk alle 15 miljoen inwoners.

Uiteraard heeft de prestatiemeting van institutionele beleggers ook veel aandacht gekregen in de economische literatuur. In veel gevallen ging het om onderzoek gericht op hoe de prestaties gemeten en vergeleken dienden te worden. Met name de zogenaamde 'asset pricing modellen' kregen veel aandacht. Dergelijke modellen maakten eigenlijk enkel en alleen gebruik van de presaties van beleggingsfondsen. In dit proefschrift verbreed ik deze horizon en laat aan de hand van andere databronnen een nieuw licht schijnen op de institutionele beleggers in de breedste zin van het woord. Hoofdstuk 2 geeft een uitgebreid overzicht van de bestaande theoretische inzichten, die in de overige hoofdstukken gebruikt worden. Het hoofdstuk begint met een bewijs dat de prestaties van institutionele beleggers, in tegenstelling tot bedrijven uit andere sectoren, zeer goed gemeten kunnen worden aan de hand van de aandelenkoers. Het hoofdstuk presenteert 
daarnaast nog een aantal methodieken om prestaties kwantitatief vast te leggen en om de zogenaamde 'value drivers' te bepalen.

Hoofdstuk 3 breidt het theoretische kader uit en laat zien wat het effect is van het kiezen van een horizon. Het hoofdstuk gebruikt de relatie tussen aandelenrendementen en inflatie om dit effect duidelijk te maken. Het gepresenteerde model laat zien dat de negatieve hedge relatie, die in de literatuur altijd gevonden is, positief wordt op het moment dat een langere beleggingshorizon gekozen wordt. In de overige hoofdstukken maak ik geen gebruik van deze effecten, maar ben wel van mening dat dit een uitermate interessante uitbreiding van de literanuur is.

In hoofdstuk 4 tot en met 7 bekijk ik de prestaties van verschillende institutionele beleggers. Ten eerste kijk ik, geheel conform de literatuur, naar de beleggingsfondsen in de Verenigde Staten en vergelijk deze met een unieke dataset van Europese beleggingsfondsen. De resultaten van dit onderzoek presenteer ik in hoofdstuk 5 . Het blijkt dat de Europese fondsen beter presteren dan de Amerikaanse partijen, terwijl de concurrentie in de Verenigde Staten juist groter is. Vanuit standaard economische theorie zou men juist een omgekeerde relatie verwachten.

Hoofdstuk 5 wordt voorafgegaan door een analyse van een dataset van de prestaties van Nederlandse pensioenfondsèn. Het hoofdstuk makt gebruik van een toegenomen openheid van de Nederlandse pensioenfondsen. In het verleden hoefden de fondsen de prestaties niet openbaar te maken, maar sinds kort doen en moeten ze dat wel. De fondsen worden ondersteund door WM-company die zorgt dat de rendementen te vergelijken zijn. Voor het onderzoek had ik toegang tot een anonieme dataset van 45 fondsen met 5 jaar historische gegevens. Het bleek dat de fondsen op het gebied van de aandelenbeleggingen slechter presteren dan men zou verwachten. Een duidelijke verklaring is helaas niet te vinden, want we zouden kunnen verwachten dat de fondsen in elk geval de index zouden kunnen volgen. Om het onderzoek in de toekomst een stap verder te helpen is het niet alleen van belang dat de fondsen de rendementen rapporteren maar doe ik ook de aanbeveling dat de fondsen ook heel duidelijk de benchmark vooraf bekendmaken. Met een vooraf gekozen benchmark laat het fonds duidelijk zien welke opdracht ze zal vervullen.

Hoofdstuk 6 en 7 maakt gebruik van een uitgebreide dataset van Global Property Research met gegevens van alle beursgenoteerde vastgoedfondsen ter wereld. Deze fondsen vertegenwoordigen een speciaal soort institutionele beleggers aangezien ze het gehele vermogen in vastgoed investeren. De rijkdom van de dataset maakt het mogelijk om niet alleen de prestaties te meten, maar deze ook te kunnen verklaren aan de hand van een aantal karakteristieken. In hoofdstuk 6 laat ik zien dat de kosten van een internationale beleggingsstrategie erg hoog zijn als de belegger overal ter wereld het vastgoed zelf verhandelt en geen gebruik maakt van de beursgenoteerde markt. Men heeft namelijk last van hogere informatiekosten en lagere liquiditeit. Het verschil tussen de 
'insider' en de 'outsider' ligt hieraan ten grondslag. De vastgoedbelegger moet er zeker van $z i j n$ 'insider' te zijn om de markt te kunnen volgen of zelfs te verslaan.

Een dergelijk verband wordt ook aangetoond in hoofdstuk 7 waar ik de prestaties van een grote groep Amerikaanse vastgoedfondsen analyseer. Ook hier laat ik zien dat de fondsen die gespecialiseetd zijn in een bepaalde sector beter presteren dan de fondsen die in verschillende sectoren actief zijn. Als verklaring vind ik hier dat een ondernemer een bepaalde specialiteit heeft en er verstanding aan doet deze te gebruiken en uit te bouwen. Als belegger daarentegen blijft het cruciaal om verschillende specialisten aan het werk te zetten om de nodige diversificatie te bewerkstelligen. Dit geeft de beursgenoteerde vastgoedfondsen ook precies hun bestaanrecht en zorgt voor de onderbouwing van de stelling dat de groei van de beursgenoteerde vastgoedmarkt de economie zal stimuleren. 


\section{Curriculum Vitae}

Mark Schweitzer (1970) received his Master's degree in economics at Maastricht University in March 1996. He immediately joined the finance department at the same institution as a $\mathrm{PhD}$ student. In 1998 he became an assitant professor responsible for several research projects and teaching to graduate students. During his affilation with the university Mark Schweitzer has also used his expertise as a speaker and a consultant on real estate and financial issues. Among other engagements, he spoke at the London School of Economics, the Wharton Business School, and the University of California at Berkeley and was consultant to leading financial institutions. Mark Schweitzer published his ideas and findings in the Journal of International Money and Finance, Journal of Empirical Finance, Cambrigde University Press Proceedings, Managerial Finance, VBA Journaal, ESB, and others. In 1999 Mark Schweitzer joined Global Property Research as managing director. 